Prepared in cooperation with the National Park Service

\title{
Baseline Water-Quality Sampling to Infer Nutrient and Contaminant Sources at Kaloko-Honokōhau National Historical Park, Island of Hawai' $i, 2009$
}

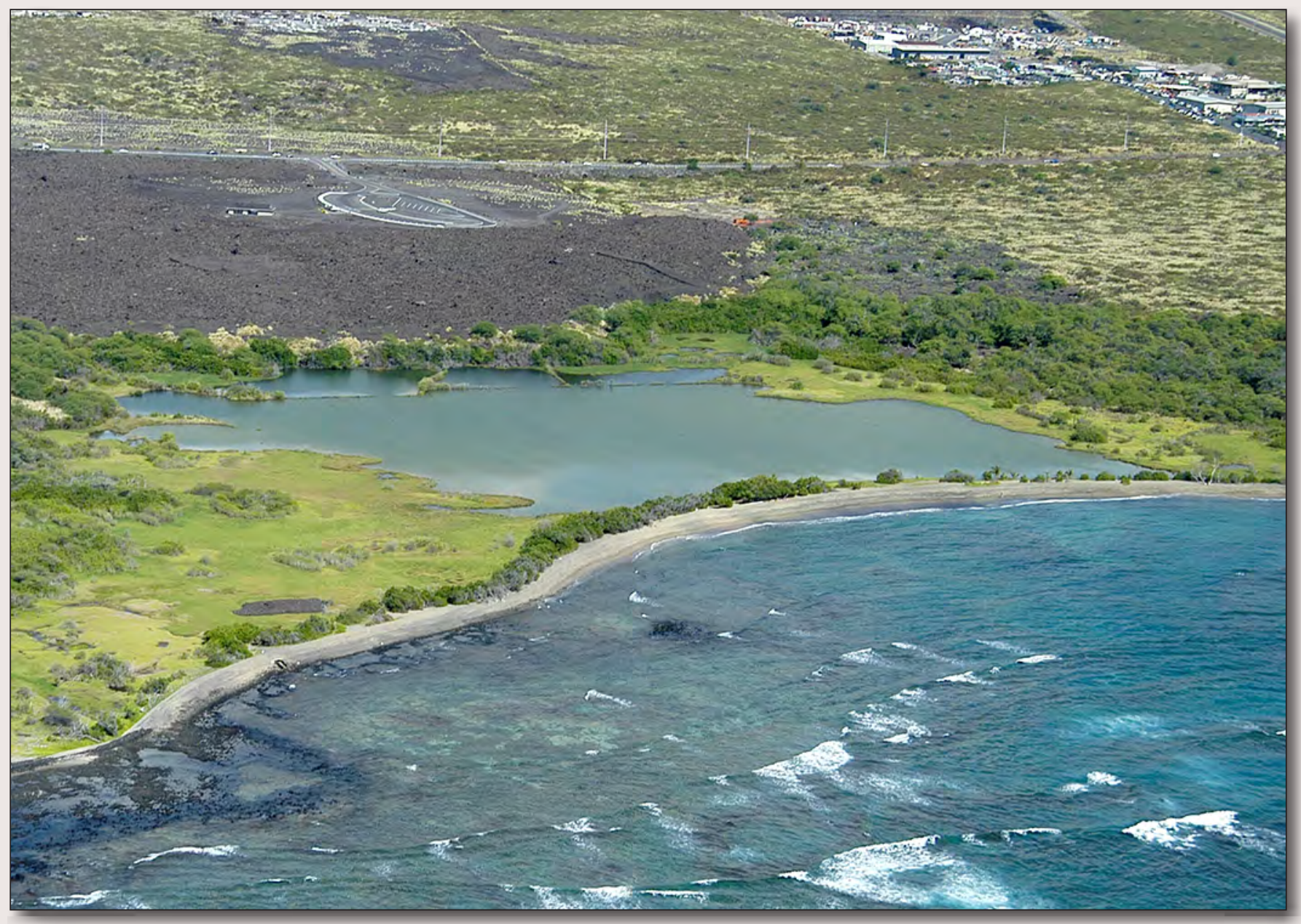

Scientific Investigations Report 2014-5158

U.S. Department of the Interior

U.S. Geological Survey 
Cover photograph. Oblique aerial photograph of 'Aimakapā Fishpond at Kaloko-Honokōhau National Historical Park, island of Hawai'i. Aerial photograph by Brian Powers, Hawaiian Images, used with permission. 


\section{Baseline Water-Quality Sampling to Infer Nutrient and Contaminant Sources at Kaloko-Honokōhau National Historical Park, Island of Hawai'i, 2009}

By Charles D. Hunt, Jr.

Prepared in cooperation with the National Park Service

Scientific Investigations Report 2014-5158 


\title{
U.S. Department of the Interior SALLY JEWELL, Secretary
}

\author{
U.S. Geological Survey \\ Suzette M. Kimball, Acting Director
}

U.S. Geological Survey, Reston, Virginia: 2014

For more information on the USGS-the Federal source for science about the Earth, its natural and living resources, natural hazards, and the environment, visit http://www.usgs.gov or call 1-888-ASK-USGS.

For an overview of USGS information products, including maps, imagery, and publications, visit http://www.usgs.gov/pubprod

To order this and other USGS information products, visit http://store.usgs.gov

Any use of trade, firm, or product names is for descriptive purposes only and does not imply endorsement by the U.S. Government.

Although this information product, for the most part, is in the public domain, it also may contain copyrighted materials as noted in the text. Permission to reproduce copyrighted items must be secured from the copyright owner.

Suggested citation:

Hunt, C.D., Jr., 2014, Baseline water-quality sampling to infer nutrient and contaminant sources at KalokoHonokōhau National Historical Park, Island of Hawai'i, 2009: U.S. Geological Survey Scientific Investigations Report 2014-5158, 52 p., http://dx.doi.org/10.3133/sir20145158.

ISSN 2328-0328 (online) 


\section{Acknowledgments}

The National Park Service at Kaloko-Honokōhau National Historical Park collaborated in study design and preparation of the project as part of the Water-Quality Partnership Program between the National Park Service (NPS) and the U.S. Geological Survey (USGS) (thanks especially to Sallie Beavers and Tahzay Jones for their contributions). NPS staff also assisted with field orientation and logistical assistance during sampling, and provided geographic information system (GIS) map layers (thanks to Lisa Marrack, Rebecca Most, Paula Cutillo, and others).

The Shores at Kohanaiki granted permission to sample monitoring wells and irrigation water on their property and assisted with site access. Thanks to Joe Root and Gregg Scheid for coordinating the sampling visits and alerting security staff to allow entry onto the property.

The County of Hawai'i Department of Water Supply granted permission to sample their Honokōhau well, provided site access, and ensured that the pump was running during the sampling visit. Thanks to Milton Pavao, Clyde Young, Bob Ravenscraft, and Owen Suzuki.

Keith Olson at the Natural Energy Laboratory of Hawai'i Authority (NELHA) provided data from their deep and shallow seawater intake pipes that help constrain saltwater-source assumptions for the samples.

Fellow USGS scientists assisted in the week-long field sampling campaigns (Ron Fay in July and Adam Johnson in December) and with site reconnaissance and preparation (Jeff Perreault, Delwyn Oki). Adam Johnson also conducted ultraviolet (UV) fluorescence tests for optical brighteners on the water samples. 


\section{Contents}

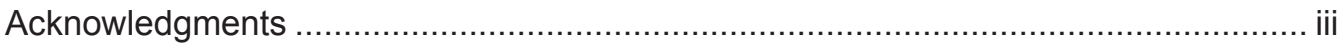

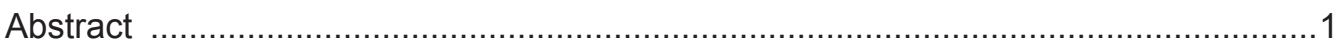

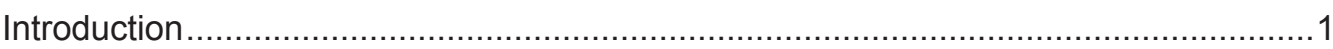

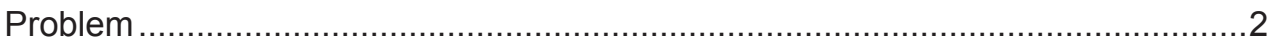

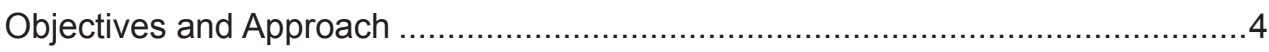

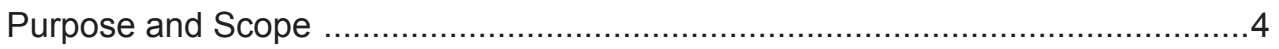

Environmental Setting and Previous Studies .......................................................

Surrounding Developments and Water-Quality Concerns for the Park .................10

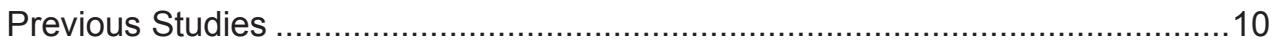

Sampling Sites, Field Methods, and Laboratory Analysis........................................ 11

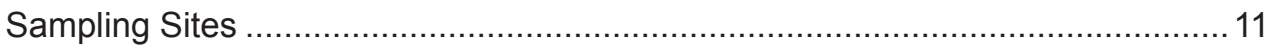

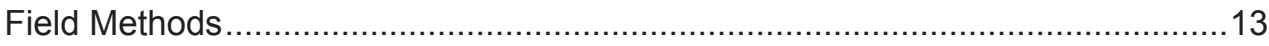

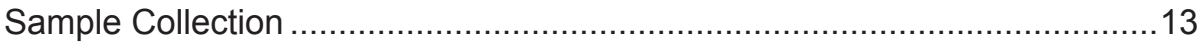

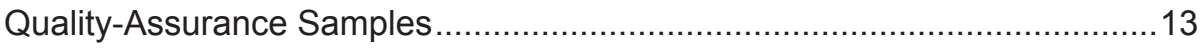

Field Measurements of Water Physical Properties ......................................13

Computation of Salinity, Saltwater Fraction, Freshwater Fraction .................13

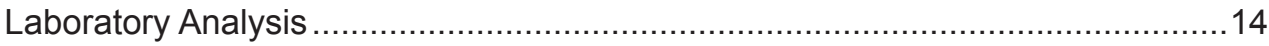

Recomputation of Reported Nutrient Concentrations ..................................14

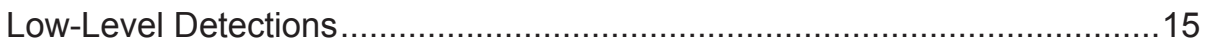

Stable Isotopes and Isotope Notation ……………………………….......15

Optical Brighteners.............................................................................. 16

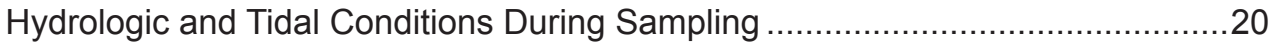

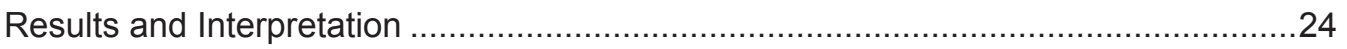

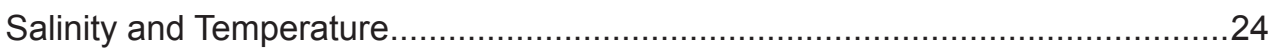

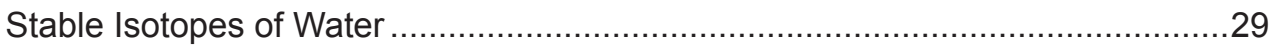

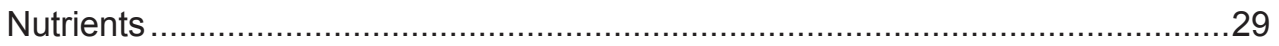

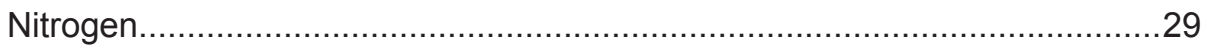

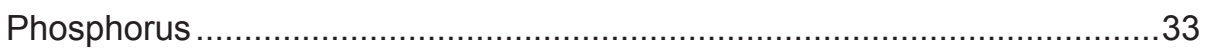

Nutrient Implications of the Cold Saline Groundwater ........................... 33

Stable Isotopes of Nitrate for Nitrate Source Identification............................ 36

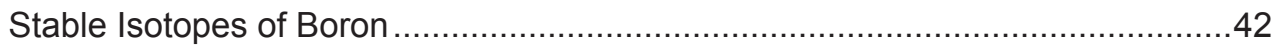

Apparent Chlorofluorocarbon Age at the Honokōhau Well.................................42

Pharmaceuticals, Wastewater Compounds, and Volatile Organic Compounds....43

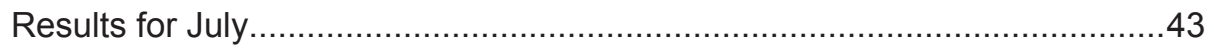

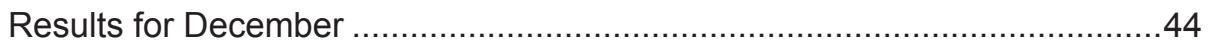

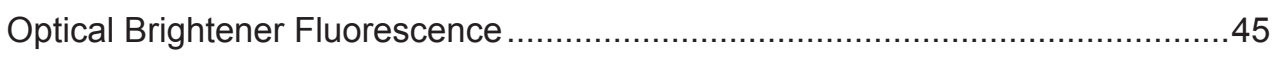

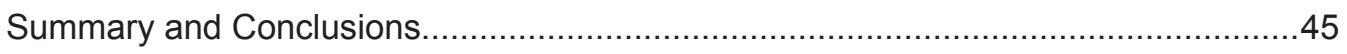

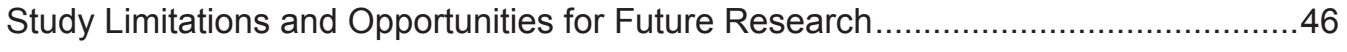

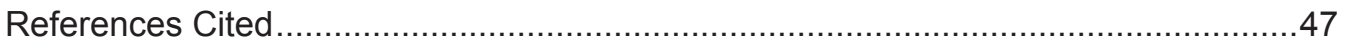




\section{Figures}

1. Map showing location of Kaloko-Honokōhau National Historical Park, Island of Hawai'i, and existing and planned urban developments and

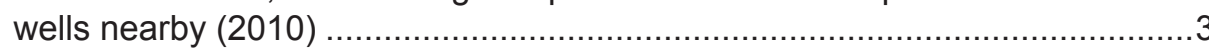

2. Photographs showing anchialine pool and endemic shrimp at KalokoHonokōhau National Historical Park, Island of Hawai'i....................................4

3. Map showing locations of water sampling sites and age of lava flows at Kaloko-Honokōhau National Historical Park, Island of Hawai'i......................5

4. Map showing mean annual precipitation near Kaloko-Honokōhau National Historical Park, Island of Hawai'i ..................................................

5. Photographs showing lava flows of different ages at Kaloko-Honokōhau National Historical Park, Island of Hawai'i ................................................. 8

6. Oblique aerial photograph of 'Aimakapā Fishpond at Kaloko-Honokōhau National Historical Park, Island of Hawai'i ...................................................... 8

7. Conceptual models of interconnection among groundwater bodies at Kaloko-Honokōhau National Historical Park, Island of Hawai'i......................... 9

8. Schematic cross section showing how fishponds and anchialine pools intersect the water table at Kaloko-Honokōhau National Historical Park, Island of Hawai'i.

9. Graph showing nitrate source classification based on nitrogen and oxygen stable-isotope compositions of dissolved nitrate

10. Graph showing daily precipitation at Kaloko-Honokōhau Park, Island of Hawai'i, 2007-09

11. Graph showing monthly precipitation at Honokōhau Harbor, Island of Hawai'i, 2000-09

12. Graph showing daily mean water levels at Kawaihae tide gage and in monitoring wells KAHO 2 and KAHO 3 at Kaloko-Honokōhau National Historical Park, Island of Hawai' $i$

13. Graph showing July 2009 sample collection times at Kaloko-Honokōhau National Historical Park in relation to daily tides at Kawaihae tide gage, Island of Hawai'i.

14. Graph showing December 2009 sample collection times at KalokoHonokōhau National Historical Park in relation to daily tides at Kawaihae tide gage, Island of Hawai' $i$.

15. Graph showing temperature versus salinity for July 2009 water samples at Kaloko-Honokōhau National Historical Park, Island of Hawai'i.

16. Graph showing temperature versus salinity for December 2009 water samples at Kaloko-Honokōhau National Historical Park, Island of Hawai'i ....26

17. Graph showing change in salinity from July to December 2009 at KalokoHonokōhau National Historical Park, Island of Hawai'i

18. Graph showing depth profiles of temperature and specific conductance in Kohanaiki monitoring well MW401, Island of Hawai'i, December 7, 2009, and USGS water samples one week earlier on November 30

19. Graph showing $\delta^{2} \mathrm{H}$ versus $\delta^{18} \mathrm{O}$ for July 2009 water samples at KalokoHonokōhau National Historical Park, Island of Hawai'i

20. Graph showing $\delta^{2} \mathrm{H}$ versus $\delta^{18} \mathrm{O}$ for December 2009 water samples at Kaloko-Honokōhau National Historical Park, Island of Hawai' i...... 
21. Graph showing dissolved inorganic nitrogen versus salinity for July 2009 water samples at Kaloko-Honokōhau National Historical Park, Island of Hawai'i

22. Graph showing dissolved inorganic nitrogen versus salinity for December 2009 water samples at Kaloko-Honokōhau National Historical Park, Island of Hawai'i

23. Graph showing change in dissolved inorganic nitrogen from July to December 2009 at Kaloko-Honokōhau National Historical Park, Island of Hawai'i 34

24. Graph showing orthophosphate versus salinity for July 2009 water samples at Kaloko-Honokōhau National Historical Park, Island of Hawai'i ....34

25. Graph showing orthophosphate versus salinity for December 2009 water samples at Kaloko-Honokōhau National Historical Park, Island of Hawai'i

26. Graph showing change in orthophosphate from July to December 2009 at Kaloko-Honokōhau National Historical Park, Island of Hawai'i.

27. Graph showing $\delta^{18} \mathrm{O}$ versus $\delta^{15} \mathrm{~N}$ of nitrate for July 2009 water samples at Kaloko-Honokōhau National Historical Park, Island of Hawai'i

28. Graph showing nitrate versus $\delta^{15} \mathrm{~N}$ of nitrate for July 2009 water samples at Kaloko-Honokōhau National Historical Park, Island of Hawai'i.

29. Graph showing $\delta^{18} \mathrm{O}$ versus $\delta^{15} \mathrm{~N}$ of nitrate for December 2009 water samples at Kaloko-Honokōhau National Historical Park, Island of Hawai'i ....40

30. Graph showing nitrate versus $\delta^{15} \mathrm{~N}$ of nitrate for December 2009 water samples at Kaloko-Honokōhau National Historical Park, Island of Hawai'i ....40

31. Graph showing change in $\delta^{15} \mathrm{~N}$ of nitrate from July to December 2009 at Kaloko-Honokōhau National Historical Park, Island of Hawai'i.

32. Graph showing change in $\delta^{18} \mathrm{O}$ of nitrate from July to December 2009 at Kaloko-Honokōhau National Historical Park, Island of Hawai'i......

\section{Tables}

[Tables 3 and 4 available online at $h t t p: / / d x . d o i . o r g / 10.3133 / s i r 20145158]$

1. Water sampling sites in and around Kaloko-Honokōhau National Historical Park, Island of Hawai'i, July and December 2009

2. Laboratory methods and field measurements for water samples collected at Kaloko-Honokōhau National Historical Park, Island of Hawai'i, July and December 2009

5. Tests for optical brighteners in water samples collected at KalokoHonokōhau National Historical Park, Island of Hawai'i, July and December 2009

6. Nitrate stable-isotope compositions of wastewater sources for comparison to results of this study 


\section{Conversion Factors}

Inch/Pound to SI

\begin{tabular}{lcl}
\hline \multicolumn{1}{c}{ Multiply } & By & \multicolumn{1}{c}{ To obtain } \\
\hline inch (in.) & Length & \\
inch (in.) & $25.4 \times 10^{6}$ & nanometer $(\mathrm{nm})$ \\
foot (ft) & 25.4 & millimeter $(\mathrm{mm})$ \\
mile (mi) & 0.3048 & meter $(\mathrm{m})$ \\
\hline & 1.609 & kilometer $(\mathrm{km})$ \\
\hline acre & Area & \\
acre & 4,047 & square meter $\left(\mathrm{m}^{2}\right)$ \\
\hline & 0.4047 & hectare $(\mathrm{ha})$ \\
\hline gallon (gal) & Volume & \\
gallon (gal) & 3.785 & liter $(\mathrm{L})$ \\
million gallons (Mgal) & 0.003785 & cubic meter $\left(\mathrm{m}^{3}\right)$ \\
\hline & 3,785 & cubic meter $\left(\mathrm{m}^{3}\right)$ \\
\hline gallon per day (gal/d) & Flow rate & \\
million gallons per day (Mgal/d) & 0.003785 & cubic meter per day $\left(\mathrm{m}^{3} / \mathrm{d}\right)$ \\
\hline
\end{tabular}

Temperature in degrees Celsius $\left({ }^{\circ} \mathrm{C}\right)$ may be converted to degrees Fahrenheit $\left({ }^{\circ} \mathrm{F}\right)$ as follows: ${ }^{\circ} \mathrm{F}=\left(1.8 \times{ }^{\circ} \mathrm{C}\right)+32$

Temperature in degrees Fahrenheit $\left({ }^{\circ} \mathrm{F}\right)$ may be converted to degrees Celsius $\left({ }^{\circ} \mathrm{C}\right)$ as follows:

${ }^{\circ} \mathrm{C}=\left({ }^{\circ} \mathrm{F}-32\right) / 1.8$

Vertical coordinate information is referenced to local mean sea level.

Horizontal coordinate information is referenced to the North American Datum of 1983 (NAD 83).

Specific conductance is given in microsiemens per centimeter at 25 degrees Celsius $(\mu \mathrm{S} / \mathrm{cm}$ at $\left.25^{\circ} \mathrm{C}\right)$.

Concentrations of chemical constituents in water are reported either in milligrams per liter $(\mathrm{mg} / \mathrm{L})$ or micrograms per liter $(\mu \mathrm{g} / \mathrm{L})$, or micromoles per liter $(\mu \mathrm{M} / \mathrm{L})$.

Isotopic compositions are reported in delta notation, in units of per mil (parts per thousand, symbol \%o). 
This page left intentionally blank. 


\title{
Baseline Water-Quality Sampling to Infer Nutrient and Contaminant Sources at Kaloko-Honokōhau National Historical Park, Island of Hawai'i, 2009
}

\author{
By Charles D. Hunt, Jr.
}

\section{Abstract}

Baseline water-quality sampling was conducted for dissolved nutrients and for chemical and isotopic tracers at Kaloko-Honokōhau National Historical Park on the Island of Hawai'i. Existing and future urbanization in the surrounding areas have the potential to affect water quality in the Park, and so the National Park Service and the U.S. Geological Survey designed a water-sampling strategy to document baseline conditions against which future changes can be compared. Sites in and near the Park were sampled twice, in July and December 2009, and included four anchialine pools, two large fishponds, five monitoring wells, an upland production well, tap water, and a holding pond for golf-course irrigation water. Water samples within the coastal park were brackish, ranging in salinity from 15 to 67 percent seawater. Samples were analyzed for dissolved inorganic nutrients (nitrogen and phosphorus), stable isotopes (nitrogen and oxygen in dissolved nitrate; hydrogen and oxygen in the water molecule), pharmaceuticals, wastewater compounds, and volatile organic compounds. A case of acute, but temporary, fertilizer contamination was evident along the Park's north boundary during the turf grow-in period of a newly constructed golf course. A maximum nitrogen concentration 280 percent above background level was measured in monitoring well MW401 in July, later falling to 109 percent above background by December. Two nearby sites (MW400 and AP 144) had nitrogen concentrations that were elevated compared to remaining sites but less severely than at MW401. Aside from this localized fertilizer influence, other water samples had lower nutrient enrichments: 40 percent or less above background for nitrogen and 57 percent or less above background for phosphorus. Background was defined in this study by a graphical mixing line between saltwater from a deep well in the Park and freshwater at a reference well in the mountainous uplands (Honokōhau production well, at 1,675 ft altitude). Potential nutrient sources between the uplands and coastal lowlands that could contribute to enrichment include rock weathering, natural vegetation, fertilizers, septic leachate, and atmospheric deposition - including motor-vehicle exhaust.
Some fraction of septic leachate is expected in groundwater because there are unsewered suburban and commercial developments upslope from the Park that rely on cesspools and septic systems. However, stable isotopes of nitrate did not implicate septic-waste nitrogen (heavy $\delta^{15} \mathrm{~N}$ values on the order of +10 per mil or greater). Instead, the heaviest $\delta^{15} \mathrm{~N}$ values of +6 to +8 per mil were associated with the large fishponds, likely as a result of biotic cycling. Water samples with $\delta^{15} \mathrm{~N}$ values of +3 to +5 per mil were still isotopically heavier than the upland groundwater value of +2 per mil and likely reflect addition of heavier nitrogen, possibly from septic sources, nitrogen-fixing vegetation, or vehicular exhaust. Pharmaceuticals, wastewater compounds, and volatile organic compounds indicated that if contamination is present, it appears to be at low, barely detectable, levels - at least as reflected by the results of this study. The most diagnostic indication of septic contamination was at monitoring well KAHO 2, closest to Kaloko Light Industrial Park, where three pharmaceuticals (carbamazepine, sulfamethoxazole, and thiobendazole) were detected at trace-level parts-per-trillion concentrations. A screening-level test for laundry fabric brighteners indicated positive detection at most sites; however, readings were quite low and if laundry graywater is present, it appears to be a small, dilute fraction. Because the weather was persistently dry throughout the study period, the USGS team was unable to conduct a wet-weather "storm" sampling. Wet-weather results are expected to differ from those reported here, though by how much remains unknown.

\section{Introduction}

Kaloko-Honokōhau National Historical Park (KAHO, or "the Park" as used in this report) is located on the west coast of the Island of Hawai'i near the urban center of Kailua-Kona (fig. 1), a popular resort, residential, and commercial center in West Hawai' $i$. Hotels and condominiums line much of the shore in Kailua-Kona, intermixed with suburban bedroom communities of year-round residents. Upland slopes are occupied by suburban residential subdivisions and farm homesteads, 
large tracts of low-intensity farmland and ranchland, and forest preserves at higher elevations. The area is supported by tourism, agriculture, and a service-based economy, with visitors and residents enjoying the warm climate, scenic views, and outdoor recreation. The area contains a State harbor that hosts an active deep-sea game fishing fleet and several golf courses at larger resorts, the closest being at the newly developed Shores at Kohanaiki resort that abuts the Park along its northern border.

The 1,160-acre Kaloko-Honokōhau Historical Park was established in 1978 "for the preservation, protection and interpretation of traditional (N)ative Hawaiian activities and culture" (National Park Service, 2014a). The Park supports nationally significant natural resources that include more than 150 known anchialine pools, two large (11- and 15-acre) Hawaiian fishponds with large associated wetlands, and 596 acres of nearshore marine waters (DeVerse, 2006).

Water quality and water quantity are vital to the Park's mission. As an example, one of the Park's goals is to restore the Kaloko Fishpond to operate in the ancient, traditional fashion of aquaculture, producing fish for human consumption. Park water resources are mainly supplied by groundwater; and the anchialine pools and 'Aimakapā Fishpond are solely dependent on groundwater and direct precipitation. In contrast, the Kaloko Fishpond has an opening in its constructed rock wall that allows direct tidal exchange of water with the ocean.

The anchialine pools are rare ecosystems of brackish water where low-lying depressions in the terrain intersect the water table (fig. 2), which lies just above sea level. Water levels fluctuate tidally, but the pools have no direct surface connection to the ocean - instead they are hydrologically connected through a permeable aquifer (Holthuis, 1973) by way of fractures, voids, and open conduits such as lava tubes.

The anchialine pools support three known candidate endangered species - two shrimp (Metabetaeus lohena, Palaemonella burnsi) and a damselfly (Megalagrion xanthomelas) (National Park Service, 2014b). 'Aimakapā Fishpond (fig. 1) and adjacent wetland is a significant foraging and nesting habitat for the two endangered waterbirds, the Hawaiian coot (Fulica alai) and the Hawaiian stilt (Himantopus mexicanus knudseni), and Kaloko Fishpond (fig. 1) is a foraging site and potential nesting site for the Hawaiian stilt. Marine waters of the Park provide habitat for the endangered hawksbill turtle (Eretmochelys imbricata), the threatened green sea turtle (Chelonia mydas), the endangered Hawaiian monk seal (Monachus schauinslandi), and the humpback whale (Megaptera novaeangliae).
Groundwater near the coast is brackish and not suitable for drinking water or household use. Public supplies of drinking water are obtained from deep wells drilled upslope, most of these wells are a mile or more inland (fig. 1) above $500 \mathrm{ft}$ elevation. Wells nearer the coast provide brackish water that is still usable for landscape irrigation, and some resorts have begun to desalinate brackish and saline groundwater to meet their irrigation needs.

\section{Problem}

When Kaloko-Honokōhau Historical Park was established in 1978, lands surrounding the Park were undeveloped and zoned for conservation purposes. In the intervening decades, land-use planning has allowed northward expansion of the Kailua-Kona urban area to lands surrounding and upslope of the Park so that, at present, most of these lands are either developed or zoned for industrial, commercial, or residential use (fig. 1). Surrounding developments include a golf course, multiple light industrial parks, and residential subdivisions (figs. 1, 3).

The National Park Service is concerned that neighboring land uses may have deleterious effects on water quality and water availability within the Park. The leading water-quality concerns for the Park are the possible migration of nutrients and other contaminants into the Park from surrounding areas, and potential long-term changes in the salinity of pools and ponds that may occur for a number of reasons.

Contaminants or constituents of concern include (1) pesticides and fertilizer nutrients from landscaping and agriculture; (2) nutrients and wastewater contaminants from cesspools and septic systems in industrial and residential areas; and (3) urban chemicals in roadway runoff, from spills, or from improper disposal. Long-term salinity changes may result from (1) relative sea-level rise, the combined effect of local island subsidence paired with a global rise in ocean levels; (2) long-term climate change that may bring drier climate and less groundwater recharge in the Park's watershed; (3) groundwater withdrawal from wells upslope, which would capture part of the fresh groundwater flowing shoreward and possibly result in altered salinity in the Park; and (4) injection of saline water resulting from the desalination process or injection of other effluents. 


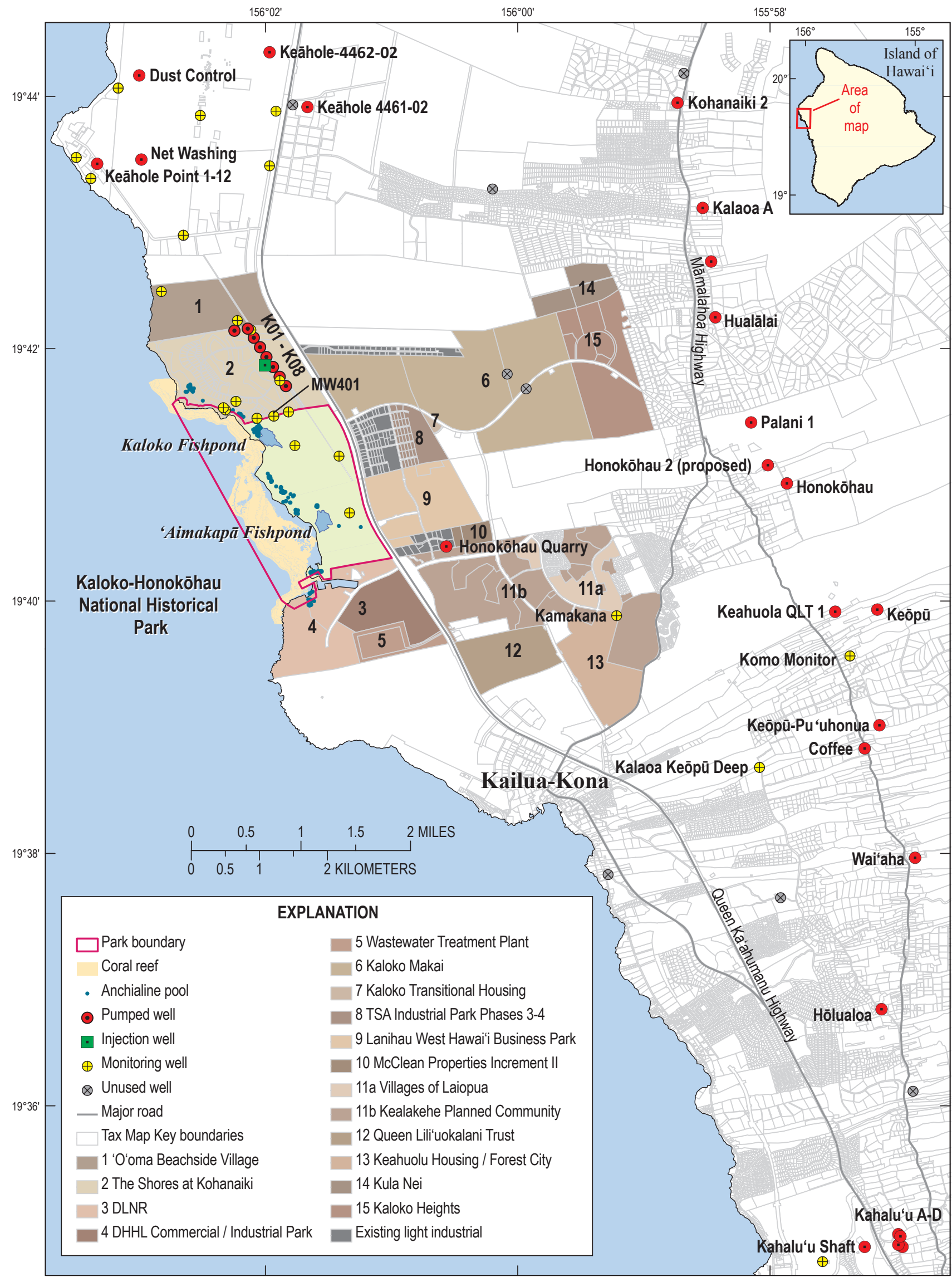

Base from U.S. Geological Survey digital data (2004), 1:24,000, UTM Zone 5, NAD83 datum.

Figure 1. Map showing location of Kaloko-Honokōhau National Historical Park, Island of Hawai' $i$, and existing and planned urban developments and wells nearby (National Park Service [NPS], written commun., 2010). 


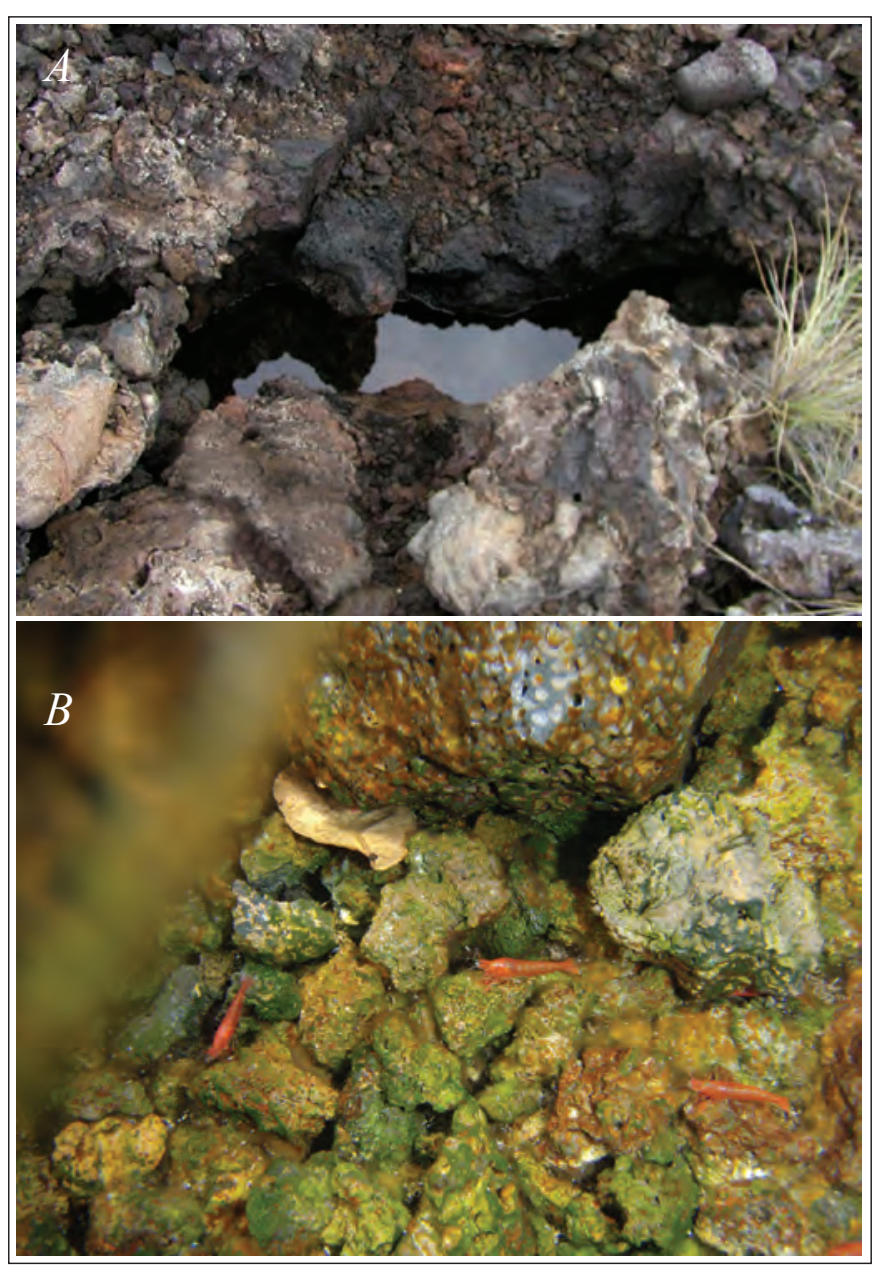

Figure 2. Photographs showing anchialine pool and endemic shrimp at Kaloko-Honokōhau National Historical Park, Island of Hawai'i. A, Anchialine pool AP 53H. $B$, Endemic shrimp Halocaridina rubra. Shrimp are about 0.5 inch long. Photographs by Delwyn Oki, U.S. Geological Survey.

\section{Objectives and Approach}

Objectives of this study were to (1) establish a baseline of current water-quality conditions while contaminant sources to groundwater in the Park are still relatively low; (2) identify sources of nutrients, particularly where nutrient concentrations are elevated; and (3) use study results to devise a chemical and isotopic monitoring strategy for the Park to consider in its management plan.

The study approach entailed sampling selected wells, ponds, and anchialine pools in and near the Park (fig. 3) in July and December 2009. One intended goal of the approach was to characterize fair-weather and storm conditions, but owing to a lack of rainstorms in the available field period, the goal of obtaining a storm sampling was not met (both sampling rounds were essentially fair-weather samplings that fell within extended periods of hot, dry weather).

A key element of the study approach was to apply nutrient and wastewater "tracers" that have been used elsewhere in Hawai' $i$ and nationally, but had not been used at the Park. In addition to nutrient concentrations (which have been analyzed in prior water-quality surveys of the Park), water samples were analyzed for nitrogen stable isotopes, organic wastewater compounds, pharmaceuticals (also present in wastewater), and volatile organic compounds (these include gasoline compounds, household and industrial cleaners and solvents, and many more chemicals). Concentrations of some of these constituents in groundwater may provide insight into possible sources that have known characteristic concentrations. For example, isotopically heavy nitrogen can indicate a human- or animal-waste source of nitrogen. Likely contaminant sources can also be inferred indirectly for simpler constituents, for example if high nitrogen concentrations in the Park are linked by a spatial pattern of even higher concentrations from an obvious source outside and adjacent to the Park.

A fundamental goal of the study was to establish a baseline of these tracer constituents now-before urban development intensifies further and water-quality effects of current development are allowed more time to manifest. Because several urban developments adjacent to and upslope from the Park have been in place for a decade or longer, current conditions are not equivalent to a "natural" or "predevelopment" baseline. However, results obtained now will provide a reference condition for future comparisons aimed at detecting water-quality changes that accompany future development and further effects of developments already in place.

\section{Purpose and Scope}

The purpose of this report is to convey results of baseline water-quality sampling within Kaloko-Honokōhau National Historical Park and its nearby environs. The report tabulates various chemical constituents and water properties that were measured, and it includes graphical presentations and cursory interpretations of the data. The degree of interpretation is limited by the study design, which was a reconnaissancelevel sampling effort and not a process-level study aimed at understanding geochemical cycling in the Park ecosystem nor effects of chemicals on park biota. Nevertheless, some process-related implications are apparent in the data and are discussed where warranted. This study did not determine effects on ecosystems of any of the chemicals or physical properties measured. 


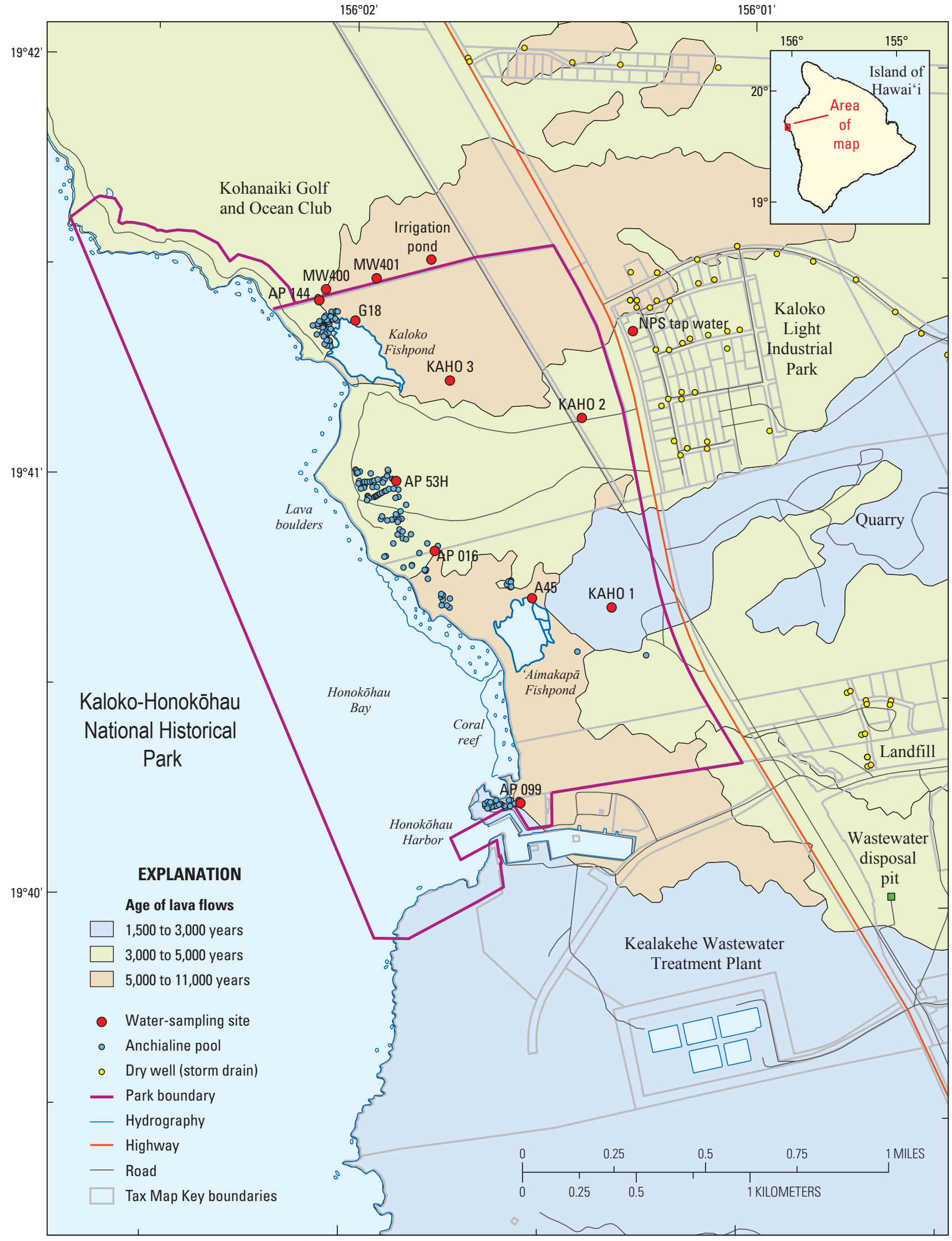

Base from U.S. Geological Survey digital data (2004), 1:24,000, UTM Zone 5, NAD83 datum. Geology from Stearns and Macdonald (1946), Wolfe and Morris (1996), Sherrod and others (2007).

Figure 3. Map showing locations of water sampling sites and age of lava flows at Kaloko-Honokōhau National Historical Park, Island of Hawai'i. Also sampled was Honokōhau well, $4.5 \mathrm{mi}$ inland (to the east) at $1,675 \mathrm{ft}$ above sea level (fig.1). Refer to table 1 for site names, abbreviations, and other related information. 
The study was designed and proposed jointly by the National Park Service (NPS) and the U.S. Geological Survey (USGS), and was selected and funded under the NPS/USGS Water-Quality Partnership Program, that provides hydrologic information and understanding needed to preserve natural and cultural resources and values of the National Park System.

\section{Environmental Setting and Previous Studies}

Kaloko-Honokōhau National Historical Park occupies coastal lowlands on the flank of Hualālai Volcano, one of several major shield volcanoes that have coalesced to form the Island of Hawai' $i$. The west flank of Hualālai intercepts moist oceanic air and causes orographic lifting and condensation, forming a persistent cloudbank part way up the mountain. Mean annual precipitation ranges from about $20 \mathrm{in}$. at the coast to more than $79 \mathrm{in}$. about 2,000 ft above sea level, before diminishing to 20 in. or less near the volcano summit above $7,000 \mathrm{ft}$ (fig. 4). Areas near the coast are generally hot and dry in the daytime, with clear to partly cloudy skies. Midslope areas beneath the orographic cloudbank are wetter and cooler, and extensive suburban bedroom communities have been built there to take advantage of the pleasant climate. Groundwater recharge is greater in the midslope area as a result of more frequent rain showers (Engott, 2011), although there is some recharge even in the driest coastal areas during infrequent torrential rains. These torrential rains are brought by seasonal winter low-pressure and frontal systems, and less frequently by hurricanes. Torrential rains tend to blanket the entire area, including the normally dry coastal lowlands.

Hualālai is a young and still-active volcano, although eruptions are infrequent. Lava flows at the land surface range from as old as 30,000 years to the youngest flow in 1800-01 that spread along the coast where Kona International Airport was later built (Wolfe and Morris, 1996). The volcanic rocks form a highly permeable aquifer, although with some lowpermeability elements (ash beds, buried soils, intrusive dikes, and other structures) that impede groundwater flow. Soils and vegetation cover older surfaces of Hualālai Volcano but are poorly developed or absent on its youngest surfaces.

Within the Park, three groups of lava flows of varying age have been mapped: $1,500-3,000 \mathrm{yr}, 3,000-5,000 \mathrm{yr}$, and $5,000-11,000 \mathrm{yr}$ (fig. 3). The youngest lavas have a surface of blocky or ropy rock on which only a few tufts of grass or other plants have taken root (fig. $5 A$ ). Intermediate-age lavas have somewhat more vegetation, but areas with particularly hummocky, irregular terrain (fig. $5 B$ ) have almost as little vegetation as the youngest lavas. The oldest terrain is extensively vegetated, although very little soil has developed and vegetation consists mostly of grasses and shrub brush (fig. $5 C$ ) with some tree groves at low elevations where the water table is shallow and coastal sediments are more favorable for root development.

Because younger lavas overran and covered older terrain, the older lavas occupy low ground locally. Near the coast, this low ground is being drowned by island subsidence (Apple and Macdonald, 1966), resulting in the two large fishponds within the Park. "Aimakapā Fishpond (fig. 6) would likely be a coastal embayment if not for the baymouth barrier berm of beach sand built up by waves, separating it from the ocean. Lacking a similar sand barrier, Kaloko Fishpond is an embayment that has been closed in by a rock wall built by Native Hawaiians.

Groundwater in the area exists as a coastal freshwaterlens system and as inland impounded-groundwater. Previous studies and interpretations have assumed that the inland impounded-groundwater and coastal freshwater-lens systems are hydrologically connected (Oki and others, 1999). However, recent information from 2012-14 suggest a low-permeability feature confines groundwater beneath the coastal lens and forms a coastal confined-groundwater system (Tillman and others, 2014). Water in the coastal confined-groundwater system is from the inland impoundedgroundwater system. The extent of the hydrologic connection between the inland impounded groundwater and freshwaterlens systems is uncertain (fig. 7).

Groundwater in the freshwater-lens system flows from inland to the shore with the water table increasing from about 1 to $5 \mathrm{ft}$ above sea level inland (fig. 7). The lens is actually brackish as a result of freshwater mixing with underlying saltwater. Several miles inland, the water table rises tens to hundreds of feet above sea level in an area of "high-level water" that is thought to be impounded by intrusive dikes or other structures within the volcano (Kauahikaua, 1993; Kauahikaua and others, 1998; Oki, 1999). This water is fresh, and numerous wells have been drilled there (fig. 1) to withdraw the highlevel water for public drinking-water supplies.

Within about a mile of the coast no freshwater remains within the freshwater-lens system; mixing by tides and other forces is complete so that all groundwater is brackish or saline, and unsuitable for drinking. Within the Park, the water table of the brackish-water lens ranges from $<1$ to about $2 \mathrm{ft}$ above sea level, and the two large fishponds are large expanses of low ground that intersect the water table (fig. 8). Similarly, the anchialine pools are simply much smaller low points in the terrain that also intersect the water table, rather than extensive areas such as the fishponds. Water levels in the ponds and pools fluctuate with the ocean tides, as water flows in and out of the coastal aquifer over the tidal cycle. 


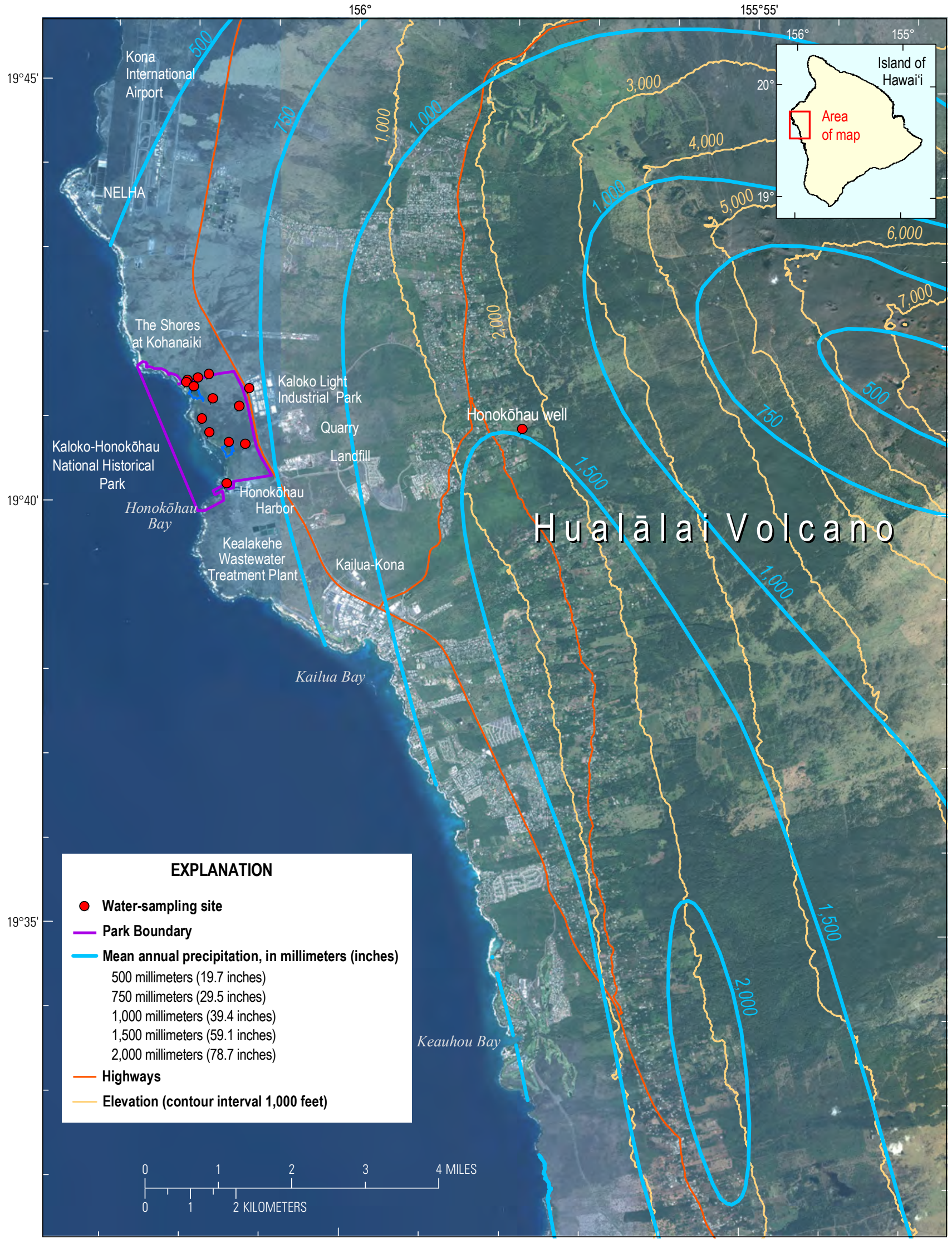

Base from U.S. Geological Survey digital data (2004), 1:24,000, UTM Zone 5, NAD83 datum.

Aerial imagery circa 2003-2007, (c) DigitalGlobe, Inc. All Rights Reserved.

Figure 4. Map showing mean annual precipitation (Giambelluca and others, 1986) near Kaloko-Honokōhau National Historical Park, Island of Hawai'i. Precipitation is greatest midslope beneath a persistent orographic cloudbank. 


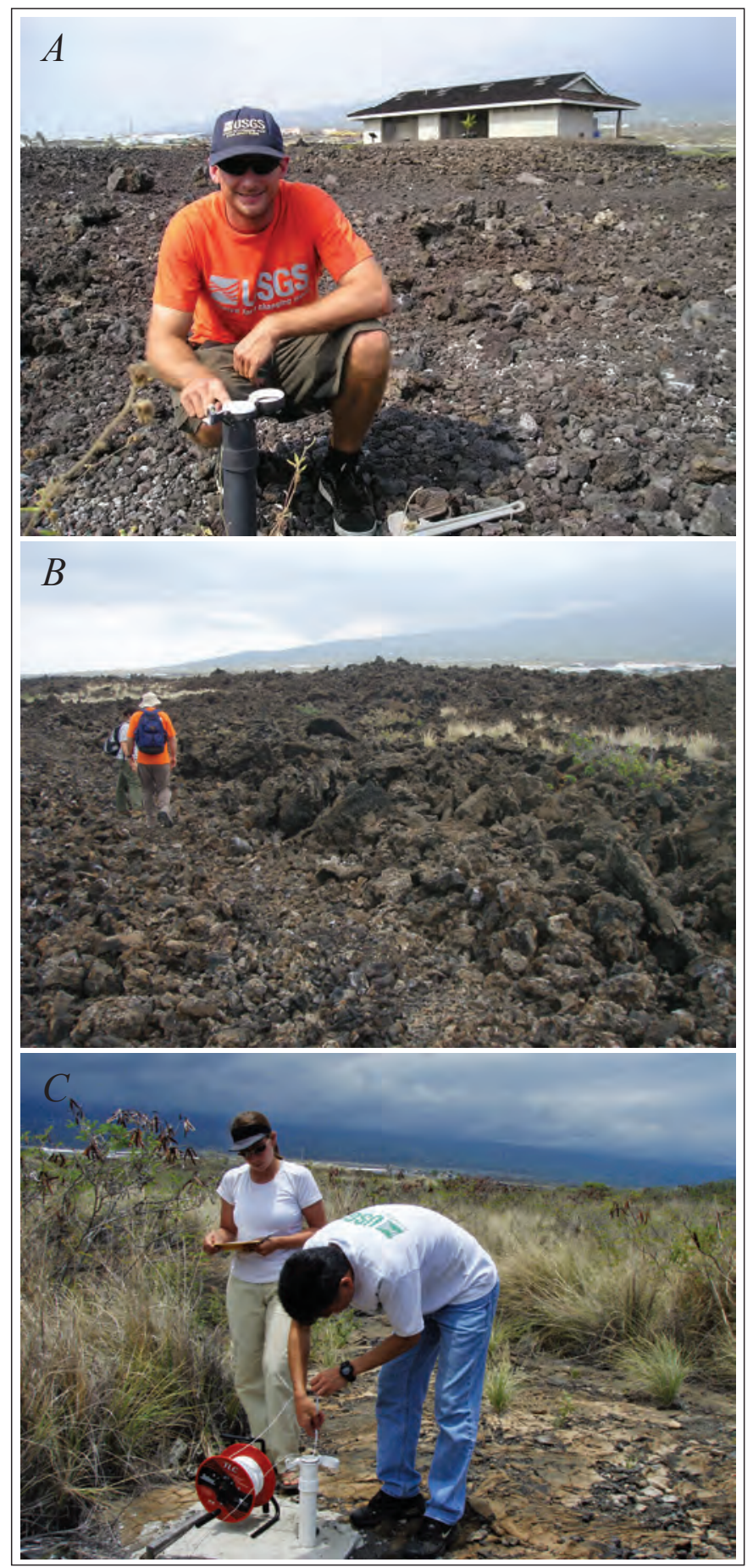

Figure 5 (left). Photographs showing lava flows of different ages at Kaloko-Honokōhau National Historical Park, Island of Hawai'i. $A$, the youngest flow $(1,500$ $3,000 \mathrm{yr})$; view is to the northeast from monitoring well KAHO 1, with the KAHO Visitor Center at right and Kaloko Industrial Park visible as light-colored buildings in the distance at left. $B$, rough, blocky lava of intermediate age $(3,000-5,000 \mathrm{yr})$ near anchialine pool AP $53 \mathrm{H}$; view is to the northeast, with Kaloko Industrial Park on the right. $C$, the oldest flow $(5,000-11,000 \mathrm{yr})$, with little soil but fairly dense grass and brush cover; view is to the east from KAHO 3 monitoring well, with Kaloko Industrial Park visible in the middle distance. Photographs $A$ and $B$ are by Jeff Perreault and Delwyn Oki, USGS; photograph $C$ is by Sallie Beavers, NPS.

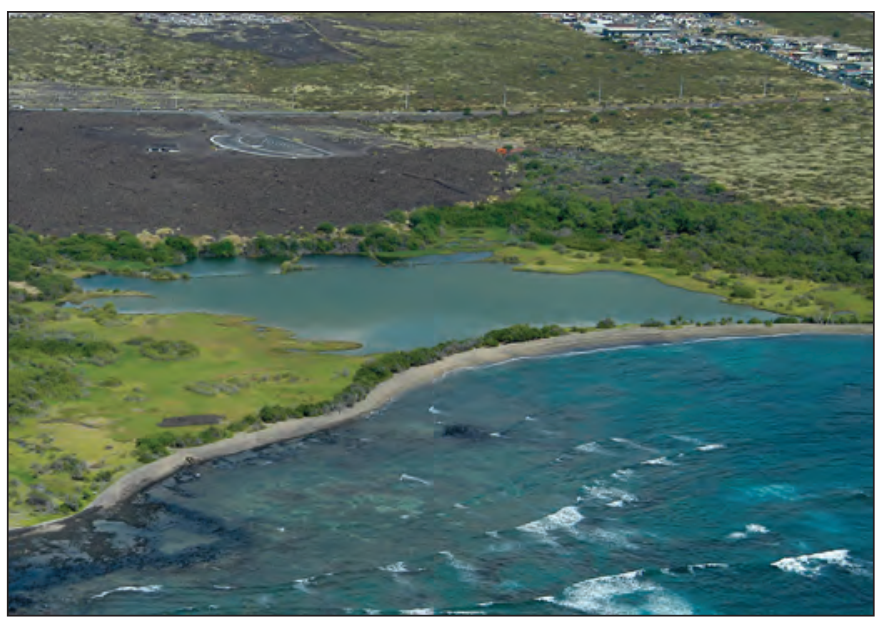

Figure 6. Oblique aerial photograph of 'Aimakapā Fishpond at Kaloko-Honokōhau National Historical Park, Island of Hawai'i. Looking southeast, the pond lies within the oldest and lowest terrain that is being drowned by island subsidence. Beyond the pond are younger, unvegetated lava flows where the Visitor Center and its semi-circular parking lot have been constructed. Aerial photograph by Brian Powers, Hawaiian Images, used with permission. 

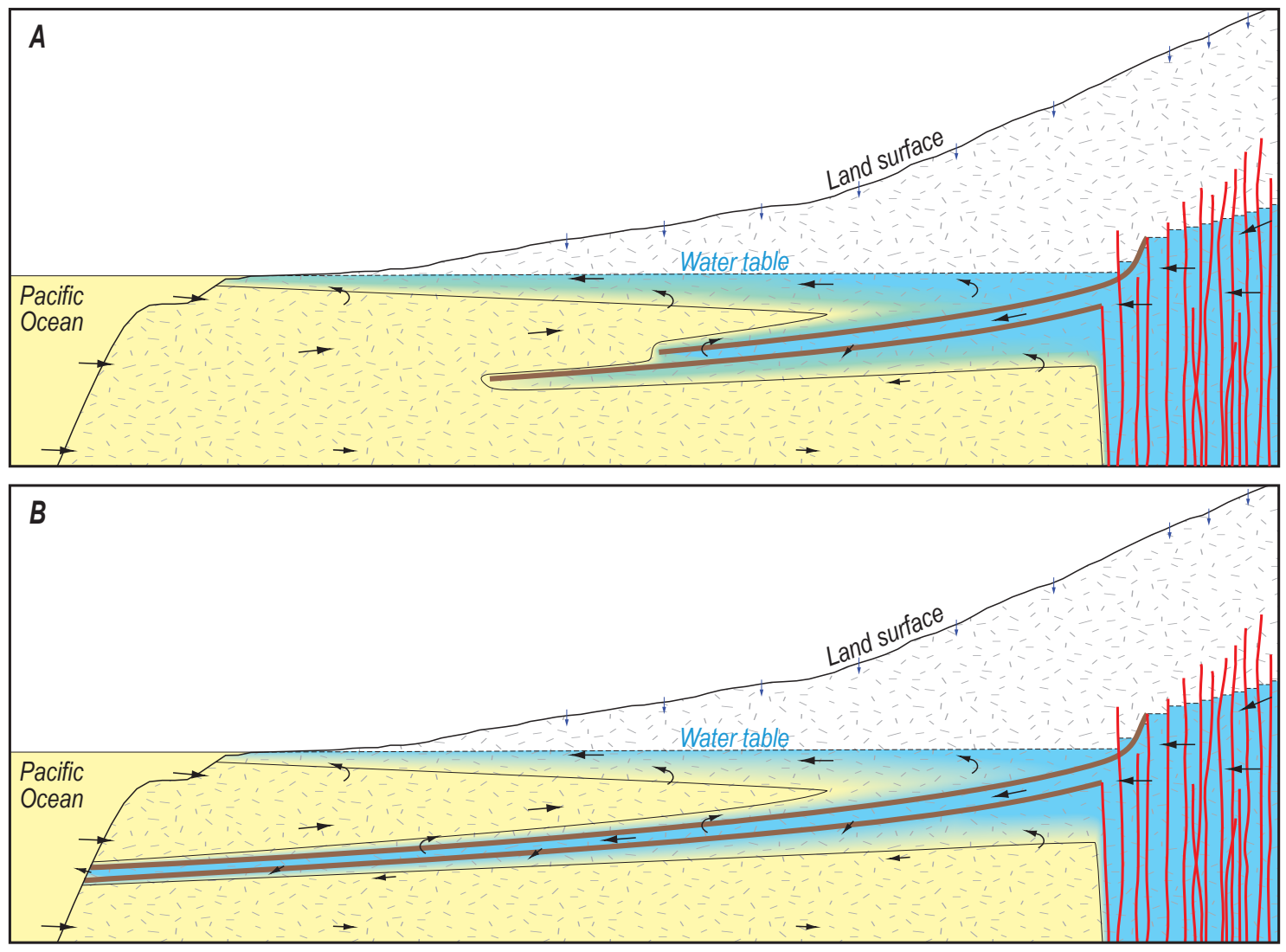

Figure 7. Conceptual models of interconnection among groundwater bodies at Kaloko-Honokōhau National Historical Park, Island of Hawai'i (from Tillman and others, 2014).

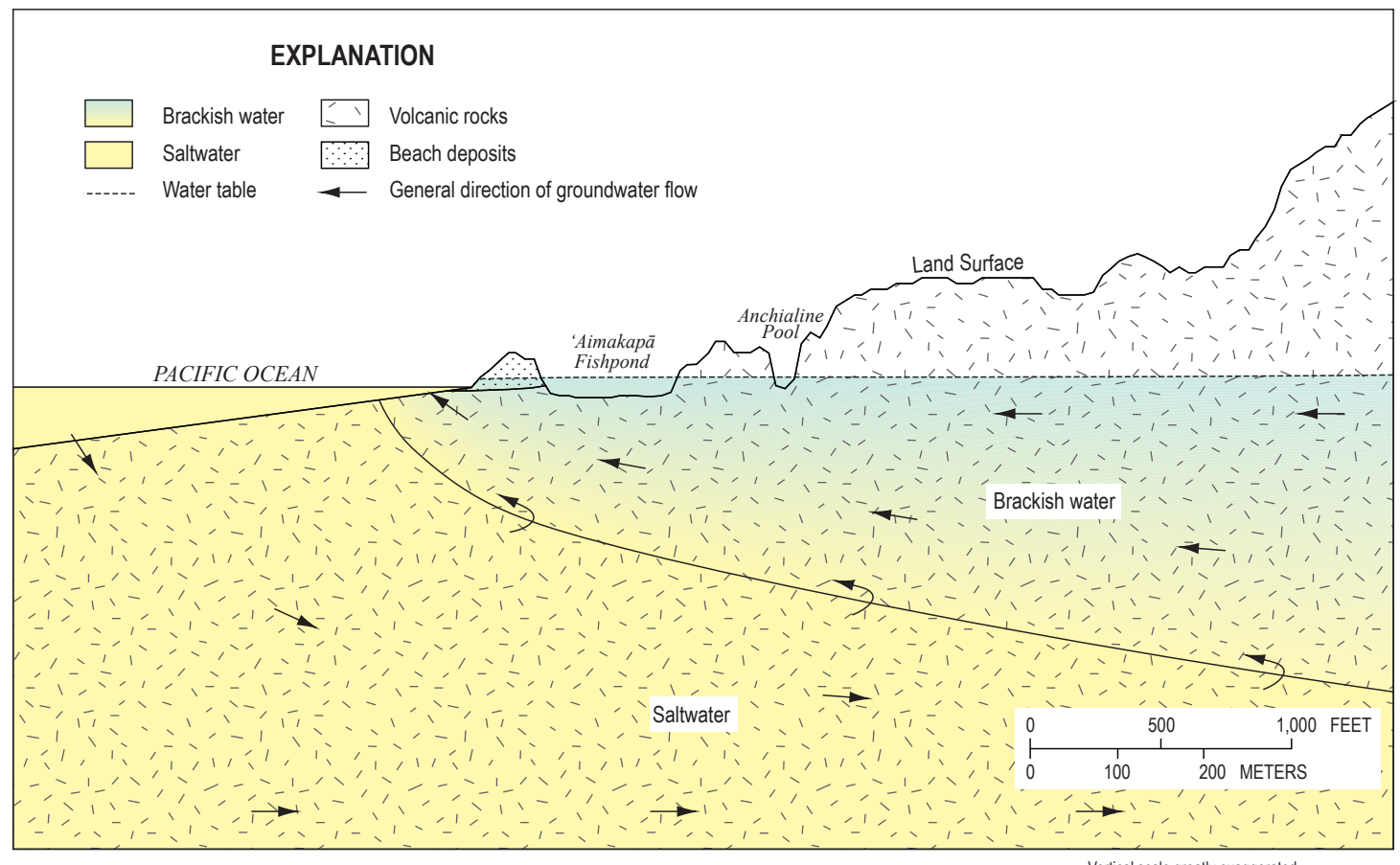

Vertical scale greatly exaggerated

Figure 8. Schematic cross section showing how fishponds and anchialine pools intersect the water table at Kaloko-Honokōhau National Historical Park, Island of Hawai'i (from Oki and others, 1999). 


\section{Surrounding Developments and Water- Quality Concerns for the Park}

A combination of old, new, and proposed urban developments have the potential to influence water quality in the Park. Developments adjacent and just upslope from KAHO that have been in place for a decade or longer, include Kaloko Light Industrial Park, a rock quarry, and a landfill (figs. 1, 3). Much farther upslope and several miles inland to the east are agricultural parcels and residential subdivisions along the Māmalahoa Highway, concentrated at elevations between 1,000-2,000 ft (figs. 1, 4). All developments upslope from $\mathrm{KAHO}$, including the industrial park and residential subdivisions, are currently (2009) using cesspools or septic systems, and are not served by the area's regional sewer system. Immediately south of KAHO is Honokōhau Harbor, and slightly farther south and southeast is Kealakehe Wastewater Treatment Plant (WWTP), a regional collection and treatment system serving the urban center of Kailua-Kona and other developments along the coast.

Adjacent to $\mathrm{KAHO}$ on its northern boundary is a resort development, The Shores at Kohanaiki, for which grading began in 2007, and golf-course greens and fairways had just grown in at the time of sampling in 2009. The resort produces its own irrigation water by reverse-osmosis desalination of brackish groundwater and has an assortment of wells of several types including (1) groundwater withdrawal wells to supply brackish feed water for desalination; (2) injection wells to dispose saline water resulting from the desalination process back into the aquifer; and (3) monitoring wells to measure changes in the hydrologic environment. The resort is sewered and connected to the wastewater treatment plant at Kealakehe. In addition to the existing developments just described, additional developments have been proposed or are under construction in the area surrounding the Park (fig. 1), including residential subdivisions, business and light industrial parks, and resorts.

Leading water-quality concerns for the Park include (1) possible migration of nutrients and contaminants into the Park from surrounding areas; (2) changes in salinity that may result from climate change or from withdrawal of fresh groundwater that would otherwise flow through the Park; and (3) changes in salinity or other water qualities that may result from injection of saline water resulting from the desalination process or injection of other effluents. Besides development immediately adjacent to the Park, water quality in KAHO is also expected to be influenced by regional groundwater flow from the volcanic uplands that extend miles inland to the east, and by overlying suburban and agricultural activities in those uplands. Park water quality could also conceivably be influenced by land use north and south of the Park along the coast, with contaminants potentially being conveyed to the Park by longshore ocean currents.

Constituents potentially migrating into the Park include (1) nutrients and other dissolved substances from natural watershed sources (atmospheric deposition, soil fixation, decomposition of forest litter, rock weathering); (2) fertilizer nutrients from landscaping and agriculture; (3) urban chemicals from spills, improper disposal, or in-roadway runoff; (4) nutrients and chemicals from wastewater sources (cesspools, leaking sewer lines, and discharge from the regional wastewater treatment plant at
Kealakehe); and (5) atmospheric deposition of automotive emissions from vehicular traffic.

Suburban and commercial developments upslope from the Park to the east utilize cesspools or septic systems. Wastewater leachate from these sources can be expected to infiltrate to the water table and join laterally flowing groundwater that has recharged farther upslope. The leachate will contain elevated concentrations of nitrogen and phosphorus, laundry detergents, and various personal care products and household cleaning products, some of which may contain solvents. Whether these contaminants can be detected in groundwater will depend on the sensitivity of laboratory methods, the degree of dilution by cleaner groundwater, and the degree of degradation or attenuation of nutrients and other constituents in the aquifer. The cesspool and septic seepage in the uplands is widespread enough that it can be considered a nonpoint source or, alternately, a widespread assortment of many small point sources.

At Kealakehe WWTP, municipal wastewater receives secondary treatment in aerated lagoons, is disinfected with chlorine, and is disposed to a seepage pit in a permeable lava field inland from the treatment plant and across the main highway (Van Dyke, 2001). From there, the treated effluent joins and displaces ambient groundwater flowing to the coast. Honokōhau Harbor, having been excavated into the coast, is thought to preferentially intercept much of the local groundwater discharge from the surrounding land area (Bienfang, 1980; Bowles and others, 2006; Johnson and others, 2008). Disposal of treated effluent at Kealakehe has averaged about $1.5 \mathrm{Mgal} / \mathrm{d}$ (million gallons per day) in recent years (Jensen, 2013). This effluent flow is imposed over an ambient groundwater flow that has been estimated at $3 \mathrm{Mgal} / \mathrm{d}$ per coastline mile (Oki and others, 1999). The effluent therefore represents a large point source of sufficient volumetric rate that it can be expected to largely divert ambient groundwater flow around it for some distance, forming a horseshoe-shaped plume extending to the coast and embedded in the ambient groundwater flow from uplands to the sea (figs. 8-30 of Bear, 1979). Treated wastewater effluent discharging to Honokōhau Harbor or along the Kealakehe shoreline could conceivably be conveyed northward to marine areas of the Park at times by longshore ocean currents; these marine areas include Kaloko Fishpond, which has an opening in its seaward rock wall.

Concern has been raised about roadside storm drains called "dry wells" (fig. 3) that direct roadway runoff to underlying deep aquifers. This stormwater may carry contaminants to groundwater and ultimately to receiving waters such as the ponds, anchialine pools, and marine waters of the Park. Contaminants could include oil and grease, fuel hydrocarbons and products of incomplete combustion, nitrogen compounds, and solvents, detergents, and other chemicals that might be used or spilled on paved areas and later flushed into the roadside drains. Potential contamination from dry wells was studied by Izuka and others (2009).

\section{Previous Studies}

There have been many notable studies of water and biological resources in and near Kaloko-Honokōhau National Historical Park. Brock and others (1987) measured water quality in the Park's anchialine pools and concluded that groundwater was a principal source of nutrients for the pools. Brock 
and Kam (1997) reviewed the biological functioning of the Park's anchialine pools and measured water quality in groundwater, anchialine pools, fishponds, and nearshore marine waters at the Park. Brock also conducted a water-quality monitoring program for Kohanaiki Golf Club and Resort at The Shores at Kohanaiki, the resort development adjoining the Park to the north (Brock, 2010). Dollar and Atkinson (1992) had earlier studied nutrient fluxes from similar resort golf courses and landscaping at resorts far north and south of the Park. Bienfang $(2007 ; 2008)$ conducted a two-year study of nutrient sources, nutrient fluxes, and water quality of 'Aimakapā and Kaloko Fishponds, and also reported data for anchialine pools and wells in the Park and surrounding region.

The National Park Service has actively accumulated data on aquatic and marine resources to establish baseline conditions prior to construction or expansion of various large-scale developments. The NPS assessed baseline water-quality data (2000) and coastal and watershed conditions at KAHO (Hoover and Gold, 2005). The NPS monitors water quality at KAHO and other national parks in the Pacific under its NPS Inventory and Monitoring Program (HaySmith and others, 2005).

Migration of nutrients and contaminants is not uniquely a park concern. Statewide, sections of Hawaiian coastal waters have been designated as impaired water bodies or "Water Quality Limited Segments" for exceeding one or more water-quality criteria such as nutrients and suspended sediment. Nutrient-related concentrations (total nitrogen, nitrite plus nitrate, total phosphorus, chlorophyll-a, and ammonium) in coastal water in the Honokōhau area have exceeded water-quality criteria (Hawai'i State Department of Health, 2006; 2013).

Bienfang (1980) measured water quality in the adjacent Honokōhau Harbor and documented cold, nutrient-rich, brackish groundwater discharging from springs and floating as a thin layer on warmer seawater within the harbor. Bienfang and Johnson (1980) studied phytoplankton production within the harbor and found evidence of sewage contamination from a local comfort station. Cold, nutrient-rich, brackish groundwater discharging to the harbor and adjacent coastal margin was identified by thermal-infrared imagery and extensive waterquality sampling of ocean waters and wells by Johnson and others (2008).

Bowles and others (2006) described geology and groundwater flow directions in the vicinity of the Park, and Bowles (2007) offered evidence that the brackish groundwater lens in the Kona area is underlain by cold, nutrient-rich saline groundwater very different from the warm, nutrient-poor surface seawater just offshore. Bowles hypothesized that the cold saline groundwater originates as subthermocline seawater that enters the island aquifer at depth offshore, below the warm surface-mixed layer.

The USGS has conducted or participated in studies of various elements of the Park's resources. These include an inventory of anchialine pools and their fauna (Foote, 2005), a benthic marine habitat map of park waters (Gibbs and others, 2007), geologic resources of the Park (Richmond and others, 2008), and coastal circulation and submarine groundwater discharge along the coast at KAHO (Storlazzi and Presto, 2005; Presto and others, 2007; Knee and others, 2008; 2010; Street and others, 2008; Grossman and others, 2010). USGS reports on groundwater resources, including groundwater modeling, include Oki (1999) for the general Kona area, and Oki and others (1999) for the KAHO park specifically.

In 2002, the USGS analyzed semivolatile organic compounds in KAHO groundwater, fishpond sediments, fish tissue, and nearshore waters, detecting only a few compounds at low, trace-level concentrations below laboratory reporting levels. Pentachloroanisole, a degradation product of pentachlorophenol, was detected in the KAHO 2 well (U.S. Geological Survey, 2003, written commun.).

South of the Park, Hunt (2008) analyzed nutrients, pharmaceuticals, and wastewater compounds in treated wastewater at Kealakehe WWTP and found that two pharmaceuticals in the treated effluent were detectable at two coastal springs in Honokōhau Harbor and in water from two monitoring wells between the Kealakehe wastewater disposal pit and the harbor. Similar testing on Maui detected the same pharmaceuticals (carbamazepine and sulfamethoxazole) in nearshore coastal waters where groundwater effluent plumes of treated, injected wastewater emerged at the shore near Kinhei and Lahaina (Hunt and Rosa, 2009). Mapping of nitrogen and other constituents defined a mile-wide effluent plume at Kīhei, in good agreement with model estimates of plume width by Hunt (2007). The wastewater injection rate at Kinhei was twice that at Kealakehe (3 Mgal $/ \mathrm{d}$ versus $1.5 \mathrm{Mgal} / \mathrm{d}$ ), but the ambient regional groundwater flow rate was the same in both locales ( $3 \mathrm{Mgal} / \mathrm{d}$ per coastline mile).

\section{Sampling Sites, Field Methods, and Laboratory Analysis}

Two rounds of water sampling were conducted in 2009 to establish baseline water-quality conditions at the Park for measured constituents. The first sampling round was conducted from July 23-29 (hereafter referred to as the "July" sampling) and the second round was from November 30- December 2 (the "December" sampling).

\section{Sampling Sites}

Sampling site descriptions are listed in table 1. With one exception, locations of all sampling sites are shown on figure 3 ; the location of the Honokōhau well is shown on figures 1 and 4. Two drinking-water sources were sampled. The first was the Honokōhau well, a production well off Māmalahoa Highway part way up the mountain flank at an elevation of $1,675 \mathrm{ft}$ above sea level (fig. 1). This well was sampled at the wellhead, before tank storage and water treatment, and the sample should provide a good representation of upland "background" freshwater quality because land farther upslope from 
Table 1. Water sampling sites in and around Kaloko-Honokōhau National Historical Park, Island of Hawai'i, July and December 2009.

[USGS, U.S. Geological Survey; NPS, National Park Service; KAHO, Kaloko-Honokōhau; MW, monitoring well; AP, anchialine pool; dip samples were collected 10 centimeters below water surface; database limitations preclude the use of Hawaiian diacritical marks in USGS station names]

\begin{tabular}{|c|c|c|c|c|c|}
\hline Type of site & USGS station name & $\begin{array}{l}\text { Name used in this } \\
\text { report }\end{array}$ & $\begin{array}{c}\text { Alternate or } \\
\text { supplemental NPS } \\
\text { designation }\end{array}$ & USGS station ID & $\begin{array}{l}\text { Sampling } \\
\text { method }\end{array}$ \\
\hline Production well & $\begin{array}{l}\text { 8-4158-02 Honokohau, } \\
\text { HI }\end{array}$ & Honokōhau well & Honokōhau well & 194056155575201 & $\begin{array}{l}\text { Hose bib at well- } \\
\text { head }\end{array}$ \\
\hline Tap water & $\begin{array}{l}\text { Kaloko National Park } \\
\text { Office, HI }\end{array}$ & NPS tap water & KAHO office & 194122156011801 & $\begin{array}{l}\text { Hose bib at NPS } \\
\text { office }\end{array}$ \\
\hline Irrigation water & $\begin{array}{l}\text { Kohanaiki irrigation } \\
\text { pond, HI }\end{array}$ & Irrigation pond & Kohanaiki irrigation $\mathrm{RO}$ & 194131156014801 & Dip sample \\
\hline Monitoring well & $\begin{array}{l}\text { 8-4061-01 KAHO } \\
\text { Well } 1\end{array}$ & KAHO 1 & Visitor Center well & 194053156013001 & Sampling pump \\
\hline Monitoring well & $\begin{array}{l}\text { 8-4161-02 KAHO } \\
\quad \text { Well } 2\end{array}$ & KAHO 2 & Upper Kaloko well & 194120156013501 & Sampling pump \\
\hline Monitoring well & $\begin{array}{l}\text { 8-4161-01 KAHO } \\
\text { Well } 3\end{array}$ & KAHO 3 & Lower Kaloko well & 194125156015501 & Sampling pump \\
\hline Monitoring well & Kohanaiki MW400, HI & MW400 & Kohanaiki makai well & 194127156020401 & Sampling pump \\
\hline Monitoring well & $\begin{array}{l}\text { 8-4161-11 Kohanaiki } \\
\text { MW401, HI }\end{array}$ & MW401 & Kohanaiki mid well deep & 194128156015601 & Sampling pump \\
\hline Anchialine pool & $\begin{array}{l}\text { Kaloko Anchialine } \\
\text { Pool 144, HI }\end{array}$ & AP 144 & 144 & 194125156020501 & Dip sample \\
\hline Anchialine pool & $\begin{array}{l}\text { Kaloko Anchialine } \\
\text { Pool 53H, HI }\end{array}$ & AP $53 \mathrm{H}$ & $053 \mathrm{H}$ & 194100156015301 & Dip sample \\
\hline Anchialine pool & $\begin{array}{l}\text { Kaloko Anchilaine } \\
\text { Pool 016, HI }\end{array}$ & AP 016 & 016 & 194050156014701 & Dip sample \\
\hline Anchialine pool & $\begin{array}{l}\text { Kaloko Anchialine } \\
\text { Pool 099, HI }\end{array}$ & AP 099 & 099 & 194014156013301 & Dip sample \\
\hline Fishpond & $\begin{array}{l}\text { North Kaloko Fishpond } \\
\text { G18, HI }\end{array}$ & $\begin{array}{l}\text { Kaloko Fishpond } \\
\text { G18 }\end{array}$ & G18 & 194122156015901 & Dip sample \\
\hline Fishpond & $\begin{array}{l}\text { Aimakapa Fishpond } \\
\text { A45, HI }\end{array}$ & $\begin{array}{l}\text { 'Aimakapā Fishpond } \\
\text { A45 }\end{array}$ & A45 'Aimakapā & 194043156013201 & Dip sample \\
\hline
\end{tabular}

the site is mainly forest preserve and low-intensity pasture. Average pumpage for the period January through September 2008 was $1.7 \mathrm{Mgal} / \mathrm{d}$. The second drinking-water source was tap water at the NPS office at Kaloko Light Industrial Park. This water is supplied mainly by the Honokōhau well but may contain some water blended in from other wells, most commonly from the Keahuola QLT 1 well (fig. 1). Water from the NPS office tap is chlorinated by the distribution system.

Kohanaiki irrigation water was sampled from a lined, open-water pond where it is stored before being used to irrigate landscaping at the resort. This water is produced by reverse-osmosis (RO) desalination of brackish groundwater. The pond is exposed to the environment and supports some aquatic plant and animal biota, algae being the most obvious visually.

Five monitoring wells were sampled, including three NPS wells within the Park and two wells at Kohanaiki, along the north boundary of the Park. All of the wells except Kohanaiki
MW401 are short-screened wells with open intervals extending less than $11 \mathrm{ft}$ below sea level. Kohanaiki MW401 is one of several deep salinity monitoring wells in the area, extending $131 \mathrm{ft}$ below land surface to $115 \mathrm{ft}$ below sea level. NPS measures depth profiles of salinity and temperature in the well using a downhole sensor, profiling the brackish groundwater lens and saltwater beneath.

Four of the anchialine pools in the Park were sampled. AP 016 and AP 53H are only a couple of feet in their largest dimension (AP 53H is shown in fig. 2); however, AP 099 and AP 144 are somewhat larger, with a width of about $10 \mathrm{ft}$.

Finally, samples were collected from the two large fishponds within the Park. Kaloko Fishpond was sampled at site G18, and 'Aimakapā Fishpond was sampled at site A45. The numbered sites are at discernible springs contributing groundwater inflow to the ponds and were located by their latitude and longitude coordinates while sampling from a kayak, so as to not stir pond-bottom mud into the water samples. 


\section{Field Methods}

\section{Sample Collection}

The method of water sample collection varied depending on the type of site (table 1). Pressurized sources (Honokōhau well and NPS tap water) were sampled by connecting Teflon sample tubing to a hose bib. Monitoring wells were sampled with a Fultz stainless steel portable sampling pump with Teflon riser tubing, pumping at a low rate of $0.5 \mathrm{~L} / \mathrm{min}$ (liter per minute) and allowing a half-hour purging period in which water physical properties (temperature, $\mathrm{pH}$, dissolved oxygen, turbidity, and specific conductance) were monitored and stabilized in a flow-through chamber. At ponds and pools, a dip sample was taken from $10 \mathrm{~cm}$ below water surface, bottles were uncapped and capped underwater to minimize the effect of any surface film that might be present. Samples were collected and processed according to USGS protocols (U.S. Geological Survey, variously dated), filtered and placed on ice in the field, refrigerated overnight at the end of the workday, and air-shipped in iced coolers to USGS laboratories.

Laboratory analyses and field measurements made on the water samples are listed in table 2. Nutrient samples (nitrite + nitrate, ammonia nitrogen, and orthophosphate) were filtered into polyethylene bottles pre-rinsed with deionized water and field rinsed three times with the filtered sample water $(0.45 \mu \mathrm{m}$ [micrometer] filters were used). Unfiltered water samples were collected in pre-baked glass bottles to test for pharmaceuticals and wastewater compounds; the pharmaceuticals sample was later filtered at the USGS National Water Quality Laboratory (NWQL) in Denver. Volatile organic compounds (VOCs) were collected as unfiltered water in pre-baked glass VOC vials, three vials per site. Samples for water isotopes of hydrogen and oxygen were collected unfiltered in glass bottles. Samples for nitrogen and oxygen isotopes in dissolved nitrate were collected in the same manner as nutrient samples, but with an added $0.2 \mu \mathrm{M}$ filter inline after the $0.45 \mu \mathrm{M}$ filter, and were frozen until shipped. Boron and strontium isotopes were sampled in the same manner as nutrient samples (filtered water collected in polyethylene bottles). A chlorofluorocarbon (CFC) water-dating sample was collected at the Honokōhau well by routing the sample tubing into an overflowing container, and filling and capping glass sample bottles underwater to prevent exposure to the atmosphere. Samples were also collected to test for optical brighteners (laundry fabric whiteners); these were unfiltered water samples collected in $125-\mathrm{mL}$ opaque brown polyethylene bottles and chilled in the field.

\section{Quality-Assurance Samples}

In addition to the environmental samples, field qualityassurance (QA) samples included one blank for each sampling round and one replicate for the December sampling round. The blanks and replicate samples were applied selectively across analytical methods as a cost-saving consideration. The field blanks were prepared by running inorganic blank water and nitrogen-purged VOC-free organic blank water through the portable sampling pump and tubing after a standard decontamination cycle (detergent rinse, tap water rinse, methanol rinse, organic blank water rinse). The blank results allow one to judge the effectiveness of the decontamination in preventing carryover contamination from well to well, and to identify possible laboratory artifacts such as detections in both environmental samples and field blanks. The portable pump was the sampling method most susceptible to carryover contamination, therefore the blanks were applied there rather than on the dip-sampling procedure. The July blank was collected after sampling KAHO 2 (the first site sampled in July) and its subsequent decontamination cycle. The December blank was collected after sampling KAHO 3 and its subsequent decontamination cycle, which was performed at KAHO 2 before it was sampled. A thorough decontamination cycle also was performed on the sampling pump and tubing at the office before equipment was taken into the field in July.

In addition to these field QA samples, USGS laboratories conducting their analyses also collect extensive laboratory QA samples, including blanks, replicates, and spikes to verify the validity of their results and to set method detection and reporting levels.

\section{Field Measurements of Water Physical Properties}

Field measurements of water physical properties were made with a multiparameter water-quality sonde (Hydrolab DS-5) and included temperature, $\mathrm{pH}$, dissolved oxygen, turbidity, and specific conductance, from which salinity was computed. All properties were measured in July, but in December the multiparameter sonde malfunctioned after the first day of use and only specific conductance was measured on the remaining days using a handheld conductance meter (Yellow Springs Instruments EC-300). Instruments were calibrated with standard solutions for specific conductance, $\mathrm{pH}$, dissolved oxygen, and turbidity according to manufacturer instructions and USGS protocols. Barometric pressure was set to the sea-level-adjusted observation from the nearest National Weather Service station each morning. Dissolved-oxygen saturation was computed using the DOTABLES online calculator (U.S. Geological Survey, 2008) that employs the methodology of Weiss (1970).

\section{Computation of Salinity, Saltwater Fraction, Freshwater Fraction}

Salinity was computed from specific conductance (Wagner and others, 2006, equation 9) and saltwater and freshwater fractions in each sample were further computed from salinity using values of 35 for seawater and 0 for pure freshwater. Expression of salinity as percent seawater or freshwater allows easier understanding for non-specialists who are not as conversant with the salinity scale used by oceanographers and environmental scientists. Although pure freshwater and standard seawater are used as end members rather than actual groundwater and seawater in the vicinity, this is an acceptable 
Table 2. Laboratory methods and field measurements for water samples collected at Kaloko-Honokōhau National Historical Park, Island of Hawai'i, July and December 2009.

[USGS, U.S. Geological Survey; N, nitrogen; P, phosphorus; H, hydrogen; O, oxygen; B, boron; Sr, strontium; nm, nanometers; -, not applicable]

\begin{tabular}{|c|c|c|c|}
\hline $\begin{array}{l}\text { Type of analysis or } \\
\text { measurement }\end{array}$ & USGS method & Laboratory or measurement & Reference \\
\hline Nitrogen, nitrite + nitrate, as $\mathrm{N}$ & Lab code 1979 & National Water Quality Lab ${ }^{1}$ & Fishman (1993) \\
\hline Nitrogen, ammonia, as $\mathrm{N}$ & Lab code 3116 & National Water Quality Lab ${ }^{1}$ & Fishman (1993) \\
\hline Orthophosphate, as $\mathrm{P}$ & Lab code 3118 & National Water Quality Lab ${ }^{1}$ & Fishman (1993) \\
\hline $\begin{array}{l}\text { Pharmaceuticals (filtered at the } \\
\text { laboratory) }\end{array}$ & Schedule 2080 & National Water Quality Lab ${ }^{1}$ & Furlong and others (2008) \\
\hline Wastewater compounds, unfiltered & Schedule 4433 & National Water Quality Lab ${ }^{1}$ & Zaugg and others (2006) \\
\hline Volatile organic compounds (VOCs) & Schedule 2020 & National Water Quality Lab ${ }^{1}$ & Connor and others (1998) \\
\hline Stable isotopes of $\mathrm{H}, \mathrm{O}$ in water & Schedule 1142 & Reston Stable Isotope $\mathrm{Lab}^{2}$ & Révész and Coplen (2008a, 2008b) \\
\hline $\begin{array}{l}\text { Stable isotopes of } \mathrm{N}, \mathrm{O} \text { in dissolved } \\
\text { nitrate }\end{array}$ & Schedule 2900 & Reston Stable Isotope $\mathrm{Lab}^{2}$ & Révész and Casciotti (2007a, 2007b) \\
\hline Stable isotopes of $\mathrm{B}, \mathrm{Sr}$ in water & - & Menlo Park Stable Isotope $\mathrm{Lab}^{3}$ & - \\
\hline $\begin{array}{l}\text { Chlorofluorocarbon (CFC) recharge } \\
\text { date }\end{array}$ & - & Reston Chlorofluorocarbon $\mathrm{Lab}^{4}$ & - \\
\hline $\begin{array}{l}\text { Specific conductance, temperature, } \\
\text { pH, dissolved oxygen, turbidity }\end{array}$ & - & Multiparameter sonde & $\begin{array}{l}\text { U.S. Geological Survey (variously } \\
\text { dated) }\end{array}$ \\
\hline Specific conductance & - & Handheld meter & $\begin{array}{l}\text { U.S. Geological Survey (variously } \\
\text { dated) }\end{array}$ \\
\hline $\begin{array}{l}\text { UV fluorescence at } 445 \mathrm{~nm} \text { emission } \\
\text { wavelength (optical brighteners) }\end{array}$ & - & Handheld meter & Turner Designs (2004) \\
\hline
\end{tabular}

simplification for comparative purposes in this study, and it avoids the inconsistency that arises when actual end members differ over time and space.

\section{Laboratory Analysis}

Laboratory analyses were conducted by each of the USGS laboratories using their standard methods and qualityassurance procedures. Results from the July sampling are tabulated in table 3 and those from the December sampling are in table 4 (tables 3 and 4 available online at $h t t p: / / d x$.doi. org/10.3133/sir20145158). Concentrations are reported as detections (at the numeric value shown), or as non-detections ("less-than" values with the " $<$ " sign followed by the laboratory reporting level).

The Honokōhau well and NPS office tap water were sampled in July only because (1) a one-time characterization was expected to capture most of the explanatory value and (2) the costs and effort of repeat sampling were considered better spent on other environmental samples. At Kohanaiki deep monitoring well MW401, two samples were collected in "December" (more precisely November 30): one from $5 \mathrm{ft}$ below the water surface in the well, and a second sample to obtain saltier water by lowering the pump as far as it would go ( $45 \mathrm{ft}$ below the water surface in the well; much less than the full well depth of $115 \mathrm{ft}$ below water).

\section{Recomputation of Reported Nutrient Concentrations}

Dissolved nutrients (tables 3, 4) were reported by the laboratory in milligrams per liter for ammonia $\left(\mathrm{NH}_{3}\right)$, nitrite+nitrate $\left(\mathrm{NO}_{2}+\mathrm{NO}_{3}\right)$, and orthophosphate $\left(\mathrm{PO}_{4}\right)$. Results are stated "as N" and "as P" regardless of the form of speciation. Nitrogen species were summed to compute dissolved inorganic nitrogen $\left(\mathrm{DIN}=\mathrm{NH}_{3}+\mathrm{NO}_{2}+\mathrm{NO}_{3}\right)$. Results are shown as reported from the laboratory in milligrams per liter $(\mathrm{mg} / \mathrm{L}$; also known as parts per million) and recomputed to micrograms per liter ( $\mu \mathrm{g} / \mathrm{L}$; also known as parts per billion) and micromoles per liter $(\mu \mathrm{M} / \mathrm{L}$, or simply $\mu \mathrm{M}$, for micromolar) because different units are used within different segments of the water-quality discipline (terrestrial, marine, and so forth). 
Hawai' $i$ water-quality standards are expressed primarily in micrograms per liter (Hawai'i State Department of Health, 2006; 2013). The dominant fraction of DIN in all samples was nitrite-plus-nitrate, within which nitrate is generally the dominant dissolved species in natural waters (Hem, 1985).

\section{Low-Level Detections}

For the organic compounds (pharmaceuticals, wastewater compounds, volatile organic compounds), most results were non-detections. Bold and shaded values in the tables are highconfidence detections having 99 percent or greater confidence that they are not false positives. Other reported detections in plain text are lower in confidence and may not represent true environmental detections. Some are very low "trace-level" concentrations with greater than a 1 percent chance of being false positives (see footnote 1). Others correspond to detections in field or laboratory blanks at similar concentrations, raising the prospect that they are artifacts of sampling or laboratory contamination (see footnote 2). Results are reported in micrograms per liter $(\mu \mathrm{g} / \mathrm{L})$, also known as parts per billion. Values in decimal fractions less than one are "sub-parts-perbillion" concentrations, also known as parts-per-trillion.

Detections designated with the prefix "E" for estimated are mostly very low concentrations below laboratory reporting levels - commonly referred to as "trace" by other laboratories. Methods in use by the USGS National Water Quality Laboratory (NWQL) for these compounds use a combination of chromatography and mass-spectrometry for compound identification and quantitation (referred to as information-rich methods that are discussed more in the following paragraph). E-coded values are lower than the laboratory reporting level (LRL) and lowest calibration standard used in the method. The concentration is flagged as estimated because its numeric value is subject to more uncertainty than concentrations within the calibration range, as bracketed by prepared calibration standards. However, the compound is judged to be present by agreement between the chromatograph peak and mass spectrometer ionic fragments matching the same compound. Concentrations below the LRL also run an increased chance of resulting in false negatives (constituent is present but not reported) and detection and reporting might vary from sample to sample or from day to day in the laboratory (Childress and others, 1999). Finally, results that exceed the highest calibration standard also are flagged with the $\mathrm{E}$ code.

Of similar relevance is the Long-Term Method Detection Level (LT-MDL), which is one-half the LRL and is set so that there is a greater than 99 percent probability that the reported concentration is not a false positive (constituent reported but not actually present). Quoting from Childress and others (1999):

At the LT-MDL concentration, the chance of a false positive detection is statistically limited to $<1$ percent. At concentrations less than the $L T-M D L$, the risk of false positive detections can increase rapidly. Mass spectrometric or photodiode array ultraviolet/visible spectroscopic detectors used for organic methods are classified by the NWQL as "information-rich" methods because they have enhanced analyte identification capabilities. For these methods, the NWQL will report values below the $L T-M D L$, along with an estimated " $E$ " remark code, because the criteria for identification must be met before quantitative results are reported ... Although information-rich methods provide enhanced analyte identification capabilities, concentrations reported below the LT-MDL still have an increased risk (>1 percent) of being a false positive.

The LRL and LT-MDL are set by statistical analysis of large numbers of laboratory blanks and spikes. To summarize, the LRL is set high enough to give 99 percent assurance against false negatives (constituent present but not reported) and the LT-MDL is set low enough to give 99 percent assurance against false positives (constituent reported but not actually present). For a more thorough discussion see Childress and others (1999).

M-flagged entries indicate that a constituent is present but that no estimate of concentration is made. For this study, the M code is only used for the "sniff test" for hydrogen sulfide. Very low concentrations of hydrogen sulfide can be detected by smell, but in this case no chemical analysis was performed to determine the concentration. Hydrogen sulfide was smelled in only one sample, the July sample from KAHO 1, the monitoring well at the NPS Visitor Center (table 3).

\section{Stable Isotopes and Isotope Notation}

Under favorable conditions, stable isotopes can be used to infer the origin and modification of water and nutrients. Isotopes are variant atomic forms of an element in which the atomic nucleus has the same number of protons but differing numbers of neutrons. Isotopic compositions measured in this study include $\delta^{15} \mathrm{~N}$ and $\delta^{18} \mathrm{O}$ of dissolved nitrate $\left(\mathrm{NO}_{3}\right)$, $\delta^{2} \mathrm{H}$ and $\delta^{18} \mathrm{O}$ of water $\left(\mathrm{H}_{2} \mathrm{O}\right), \delta^{11} \mathrm{~B}$ of dissolved boron, and the ${ }^{87} \mathrm{Sr} /{ }^{86} \mathrm{Sr}$ ratio of dissolved strontium. The various isotopic measures are ratios of a heavier isotope to a lighter isotope for a given element $\left({ }^{15} \mathrm{~N}\right.$ to ${ }^{14} \mathrm{~N},{ }^{18} \mathrm{O}$ to ${ }^{16} \mathrm{O},{ }^{2} \mathrm{H}$ to ${ }^{1} \mathrm{H},{ }^{11} \mathrm{~B}$ to ${ }^{10} \mathrm{~B},{ }^{87} \mathrm{Sr}$ to ${ }^{86} \mathrm{Sr}$ ). The $\delta$ symbol signifies "delta notation" and is read as "delta-N-15," "delta-O-18," "delta-H-2," and "delta-B-11." Units are parts per thousand (per mil, denoted by the \%o symbol) and normalized to reference standards: atmospheric air (AIR) for N, Vienna Standard Mean Ocean Water (VSMOW) for $\mathrm{O}$ and $\mathrm{H}$, and National Bureau of Standards (NBS) 951 for B. Isotopic compositions can be positive or negative, with larger or more positive values referred to as "heavier" and smaller or more negative values as "lighter." Positive and negative values arise from a sample being isotopically heavier or lighter than the reference standard to which it is being compared. Further explanation can be found in texts on isotope chemistry, for example Kendall and McDonnell (1998). 
Hydrogen and oxygen isotopes in water $\left(\delta^{2} \mathrm{H}\right.$ and $\left.\delta^{18} \mathrm{O}\right)$ characterize the water molecule, $\mathrm{H}_{2} \mathrm{O}$. Isotopic fractionation in water is a partitioning process whereby isotopic composition is changed mainly during phase changes: during condensation from water vapor or evaporation from liquid water back to vapor. These processes occur in clouds where water precipitates, on the landscape where some fraction of precipitation evaporates, and by evaporation from standing water (lakes, streams, marshes, and oceans). A useful property of water isotopes is that once water infiltrates to the water table, $\delta^{2} \mathrm{H}$ and $\delta^{18} \mathrm{O}$ tend to remain fixed and behave conservatively (not changing, other than by simple mixing) during groundwater transport to destinations farther along the flow system. This makes them good tracers for some waters, although mixing calculations may be needed to correctly interpret the data. Groundwater recharged at different elevations in Hawai ${ }^{i} i$, obtains distinctive isotopic compositions (Scholl and others, $1995 ; 2002)$ that contrast strongly with isotopic compositions of seawater.

Nitrogen and oxygen isotopes in dissolved nitrate $\left(\delta^{15} \mathrm{~N}\right.$ and $\delta^{18} \mathrm{O}$ ) may allow the predominant source of the nitrate to be inferred under favorable conditions. One such source classification, shown in figure 9, was compiled by Kendall and McDonnell (1998) from various studies and represents results of hundreds of samples. This classification scheme has been used to differentiate human and animal waste nitrate from nitrate originating throughout the watershed from other sources such as plant-fixed soil nitrate or mineral nitrate fertilizers. The range for soil nitrogen (fixed from the atmosphere by plants) is centered at roughly $\delta^{15} \mathrm{~N}=+5$ per mil and $\delta^{18} \mathrm{O}=$ +5 per mil and spans a $\delta^{15} \mathrm{~N}$ range from about +2 to +8 per mil. Graphed values for ammonium in fertilizer and rain plot to the left: lighter in $\delta^{15} \mathrm{~N}$ but not much different in $\delta^{18} \mathrm{O}$. Graphed values for nitrate from fertilizer plot up and to the left of those for soil nitrate, the fertilizer being heavier in $\delta^{18} \mathrm{O}$ and lighter in $\delta^{15} \mathrm{~N}$. Manure and septic waste have a broad range spanning $\delta^{15} \mathrm{~N}=0$ to +25 and centered at $\delta^{18} \mathrm{O}=+5$. Finally, graphed values for nitrate in precipitation plot at upper left, being generally light in $\delta^{15} \mathrm{~N}$ and very heavy in $\delta^{18} \mathrm{O}$. The actual amount of nitrate in precipitation is small, however, so the isotopic composition of most groundwater will be dominated by the terrestrial sources of nitrate plotted along the bottom of the graph.

Compositions anywhere on the plot can be modified by fractionation processes in which a physical, chemical, or biologic process selectively incorporates the lighter or heavier isotope and leaves behind a residual pool of material enriched in the other isotope. The large arrow shows a denitrification trend at a slope of $1: 2$, or 1 unit change in $\delta^{18} \mathrm{O}$ for every 2 units in $\delta^{15} \mathrm{~N}$. Denitrification of nitrate to $\mathrm{N}_{2}$ gas is one of a number of microbial nitrogen-cycling processes carried out by bacteria that cause isotopic fractionation, in this case driving isotopic values heavier while reducing nitrate concentration. The processes include volatilization of ammonia, nitrification of ammonium to nitrate, denitrification, and anammox (anaerobic oxidation of ammonium to $\mathrm{N}_{2}$ gas). Biologic uptake or assimilation of nitrate by phytoplankton also drives isotopic values heavier, but at a steeper slope of 1:1 (Granger and others, 2004). This trend was not shown on Kendall and McDonnell's classification (fig. 9) but is shown on figures later in the report because biologic uptake is likely an active process affecting the fishponds and anchialine pools at KAHO.

\section{Optical Brighteners}

Samples were screened by ultraviolet (UV) fluorescence as a test for fabric whiteners or "optical brighteners" (table 5). These are additives in laundry detergents that act as whitening agents, and they impart high fluorescence levels to laundry graywater and household wastewater. Fluorescence measurements on environmental water samples can, therefore, be an effective screening test for the presence of wastewater and (or) graywater (Hagedorn and others, 2005; Hartel and others, 2007; Cao and others, 2009).

UV fluorescence was measured at the USGS Honolulu office using a handheld Aquaflor fluorometer sensing an emission wavelength of 445 nanometers in response to excitation at 350 nanometers (Turner Designs, 2004; 2007a). All readings were made with the instrument at factory calibration setting and not re-calibrated to secondary standards. As a result, meter readings are in arbitrary fluorescence units and are strictly comparable only within the dataset and relative to control samples of deionized and tap water. Some environmental readings were negative, but not as negative as the control samples, indicating "more fluorescence" than the controls.

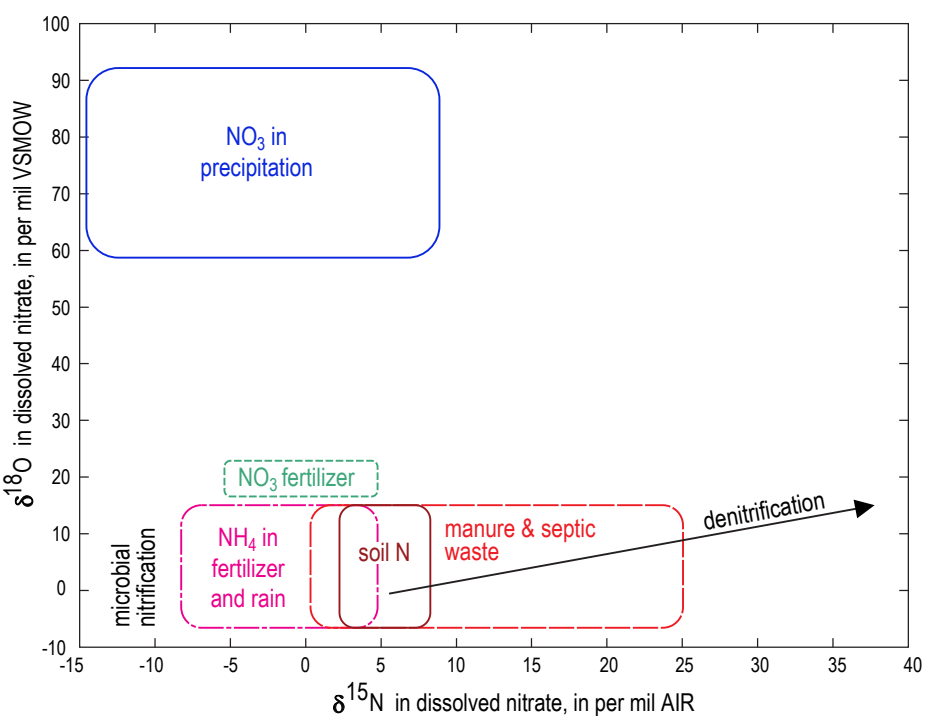

Figure 9. Graph showing nitrate source classification based on nitrogen and oxygen stable-isotope compositions of dissolved nitrate (Carol Kendall, USGS, written commun., 2006, her modification from Kendall and McDonnell, 1998). Although useful as a general guide, compositions can be shifted by fractionation processes such as denitrification. $\mathrm{NO}_{3}$, nitrate; $\mathrm{NH}_{4}$, ammonium ion; VSMOW, Vienna Standard Mean Ocean Water; AIR, atmospheric air. 


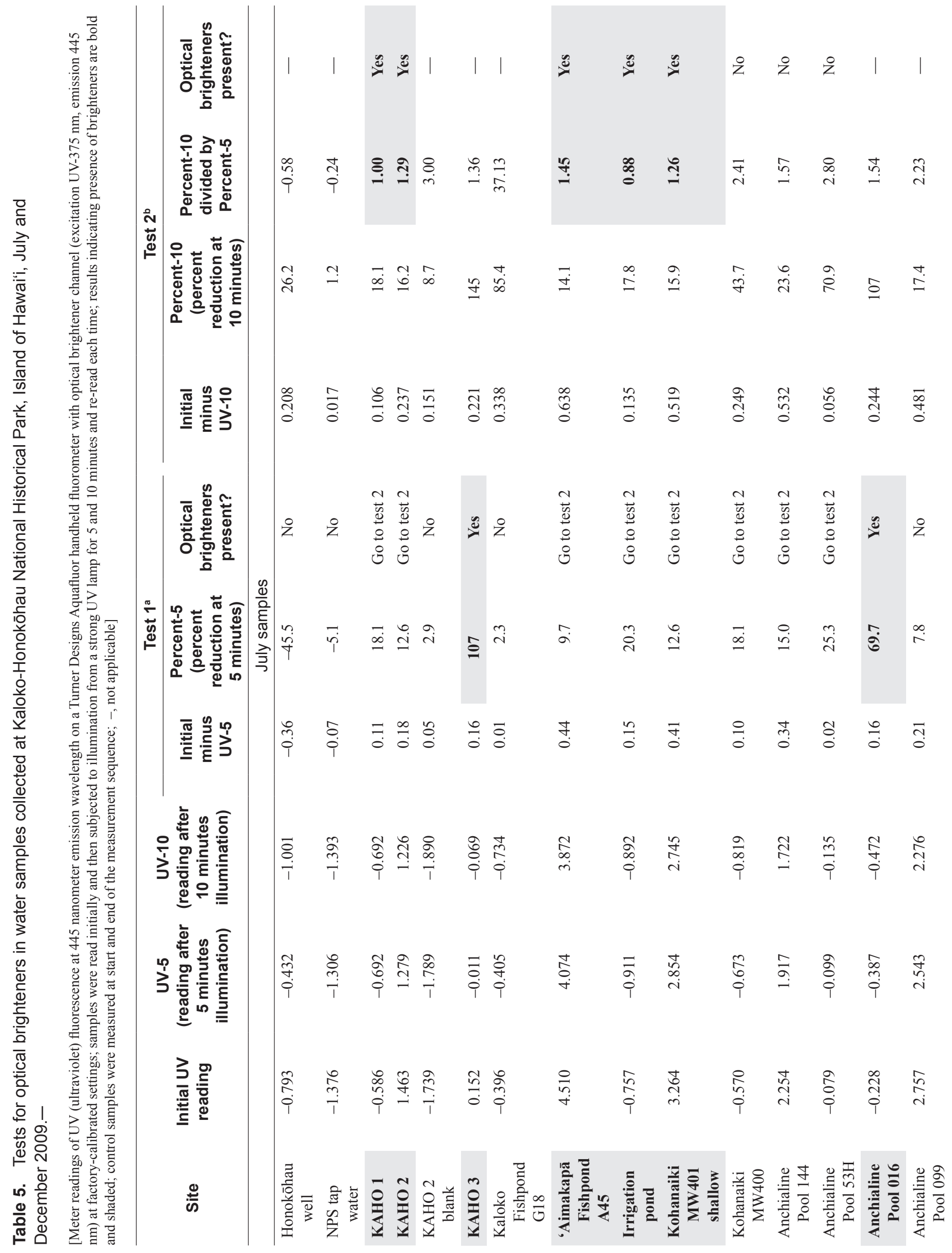




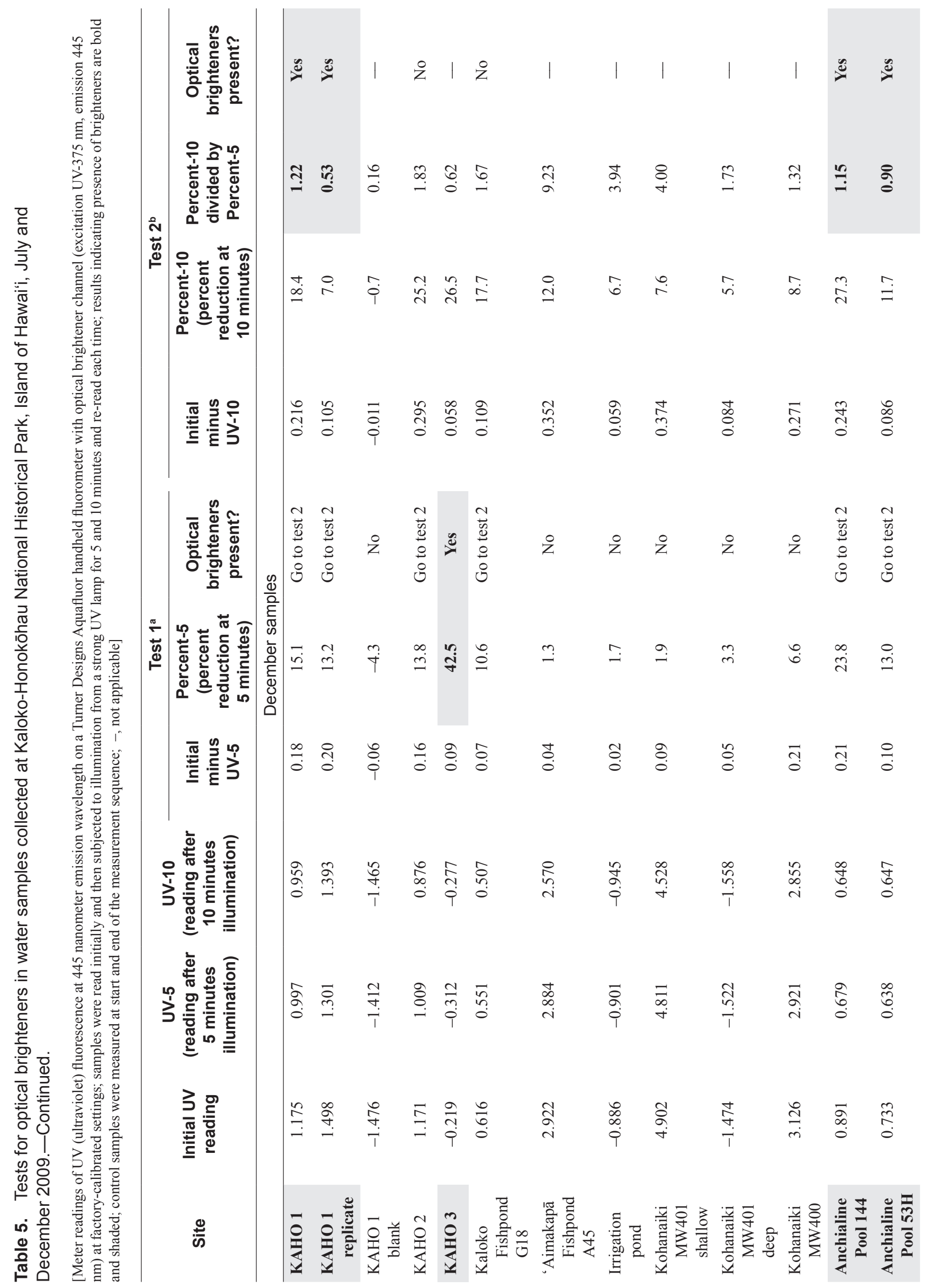




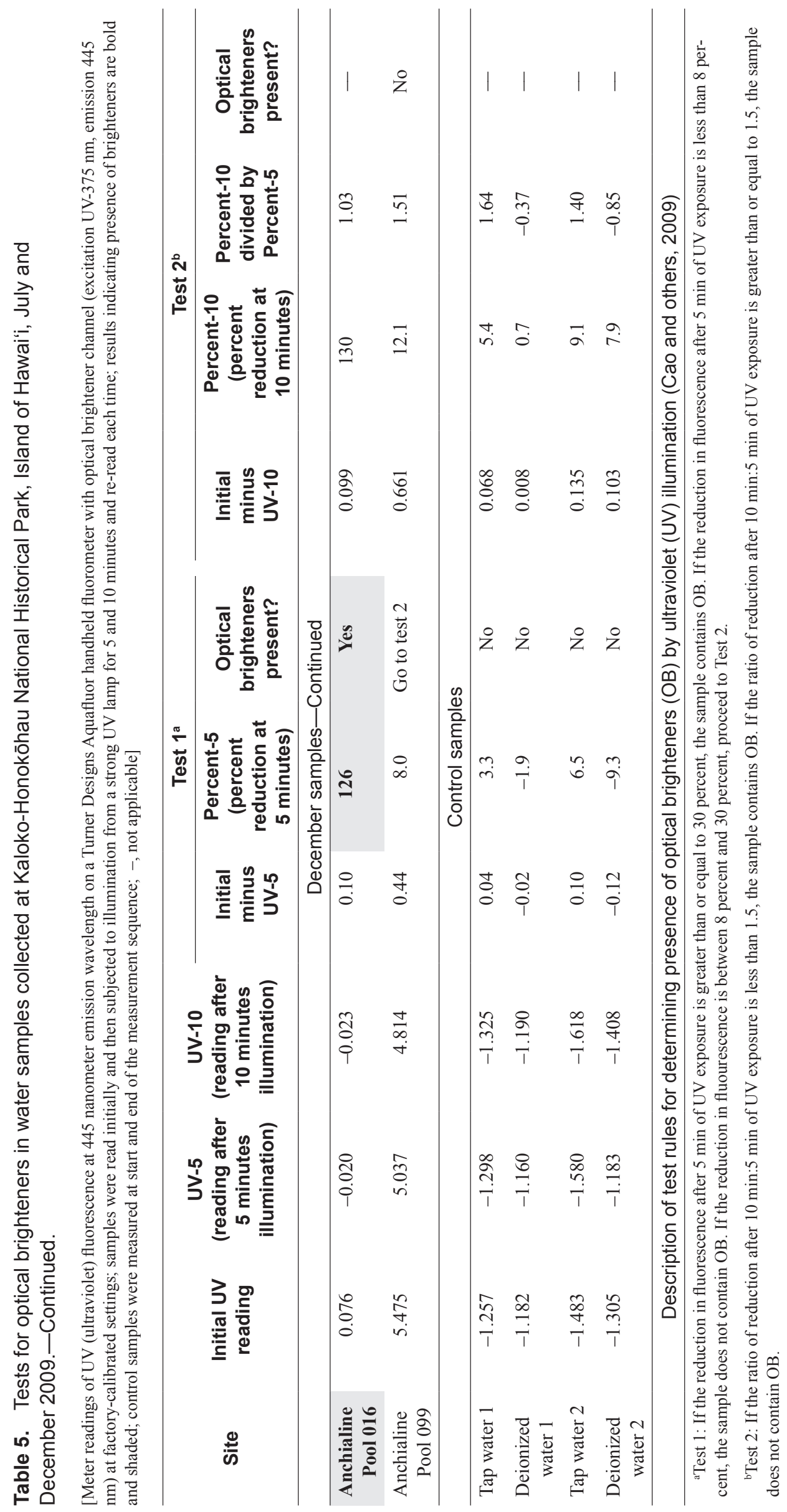


Fluorescence readings were taken initially, then again after 5 and 10 min of illumination by a strong UV lamp, following the testing procedure of Cao and others (2009). This procedure takes advantage of the fact that the fluorescence response of optical brighteners is more stable than that of dissolved organic matter (DOM), which breaks down preferentially under intense UV exposure. The initial, 5- and 10-min readings are subjected to empirical formulas to determine if optical brighteners are present (Cao and others, 2009).

\section{Hydrologic and Tidal Conditions During Sampling}

One goal of the study was to sample during both fairand wet-weather to see if groundwater quality differed under varied hydrologic conditions. The project proposal stated, "The wet-weather sampling will occur within 48 hours of heavy coastal rainfall defined as 1.5 inches over 24 hours based on data from the park's Remote Automated Weather Station (RAWS)" (Beavers and Hunt, 2008). However there were no rains of this magnitude in the year available for field work (2009) and both sampling rounds were essentially fairweather samplings conducted during extended periods of hot, dry weather.

Daily precipitation records at the KAHO RAWS station (fig. 10) indicate that the year 2009 was quite dry compared to 2007 and 2008, which had several large daily rainstorms respectively. Large precipitation events in 2007 included 4.37 in. on February 1, 2.23 in. on December 3, 5.02 in. on December 5, and 0.85 in. on December 10. In 2008, large daily events included 1.93 in. on June 12 and 2.39 in. on December 11. In 2009 the site received 0.85 in. on January 11, but the gage apparently malfunctioned from around March to the end of the year (it could have been partly malfunctioning earlier, it is difficult to know).

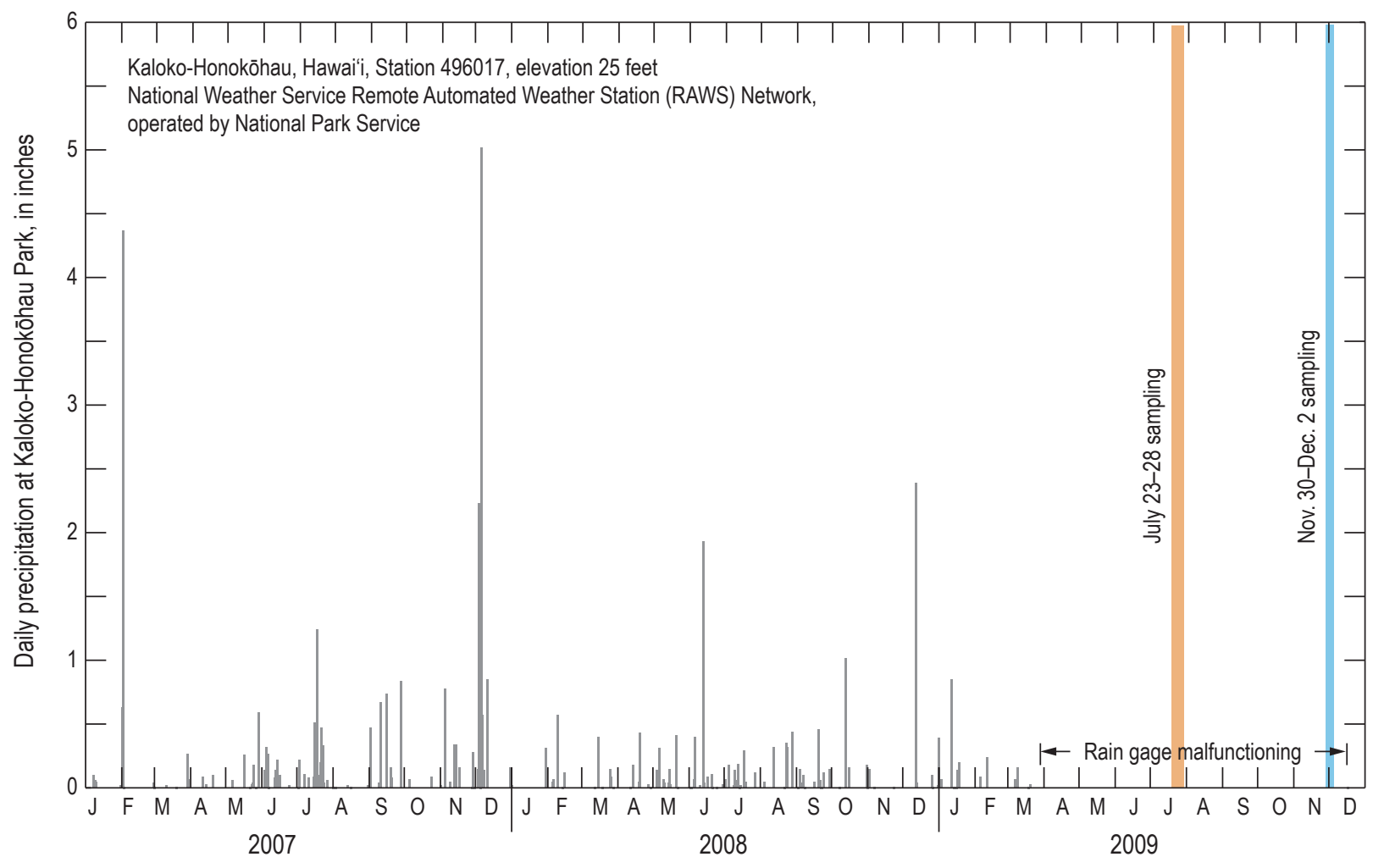

Figure 10. Graph showing daily precipitation at Kaloko-Honokōhau Park, Island of Hawai'i, 2007-09 (Western Regional Climate Center, 2010a). Following heavy December 2007 rains that caused groundwater recharge in the Park, 2009 was a dry year, although instrument malfunction for much of the year requires that conclusion to be drawn from the nearby Honokōhau Harbor weather station observations (fig. 11). 
The December 2007 rains caused substantial flooding in the Kona watershed and runoff plumes of muddy water extended offshore in the ocean, witnessed by the author when flying in for another sampling project. The December 5, 2007, rain of $5.02 \mathrm{in}$. at the $\mathrm{KAHO}$ rain gage was large enough to cause groundwater recharge at the Park, discernible as a small peak in recorded groundwater levels at KAHO 3 after filtering out tidal fluctuations (Delwyn Oki, USGS, written commun., 2010). The recharge pulse was detected within hours of the heaviest hourly precipitation on December 5. This is not entirely surprising because the land surface at KAHO 3 is only $23 \mathrm{ft}$ above mean sea level and the terrain is rough, permeable lava with discontinuous soil and only sparse, grassy vegetation. Daily rains less than one or two inches may not generate much recharge in the coastal lowlands, although locally focused recharge is possible where runoff is channeled to roadside swales, drains, and dry wells.

Given the malfunction at the KAHO RAWS station for much of 2009, it is fortunate that precipitation records also were available from the nearby Honokōhau Harbor rain gage. Monthly precipitation for the years 2000-09, including the 2009 period of missing data at the KAHO station are shown in figure 11. The Honokōhau Harbor records reemphasize the magnitude of the December 2007 rains and show 2009 to have been a dry year; 2008 was wetter mid-year than is apparent on the daily graph for KAHO (fig. 10). December 2007 precipitation at the Honokōhau Harbor station was 10.33 in., quite similar to the December 2007 total of 9.00 in. at the KAHO station.

In summary, heavy rains in December 2007 recharged the brackish groundwater lens in the Park and surrounding coastal

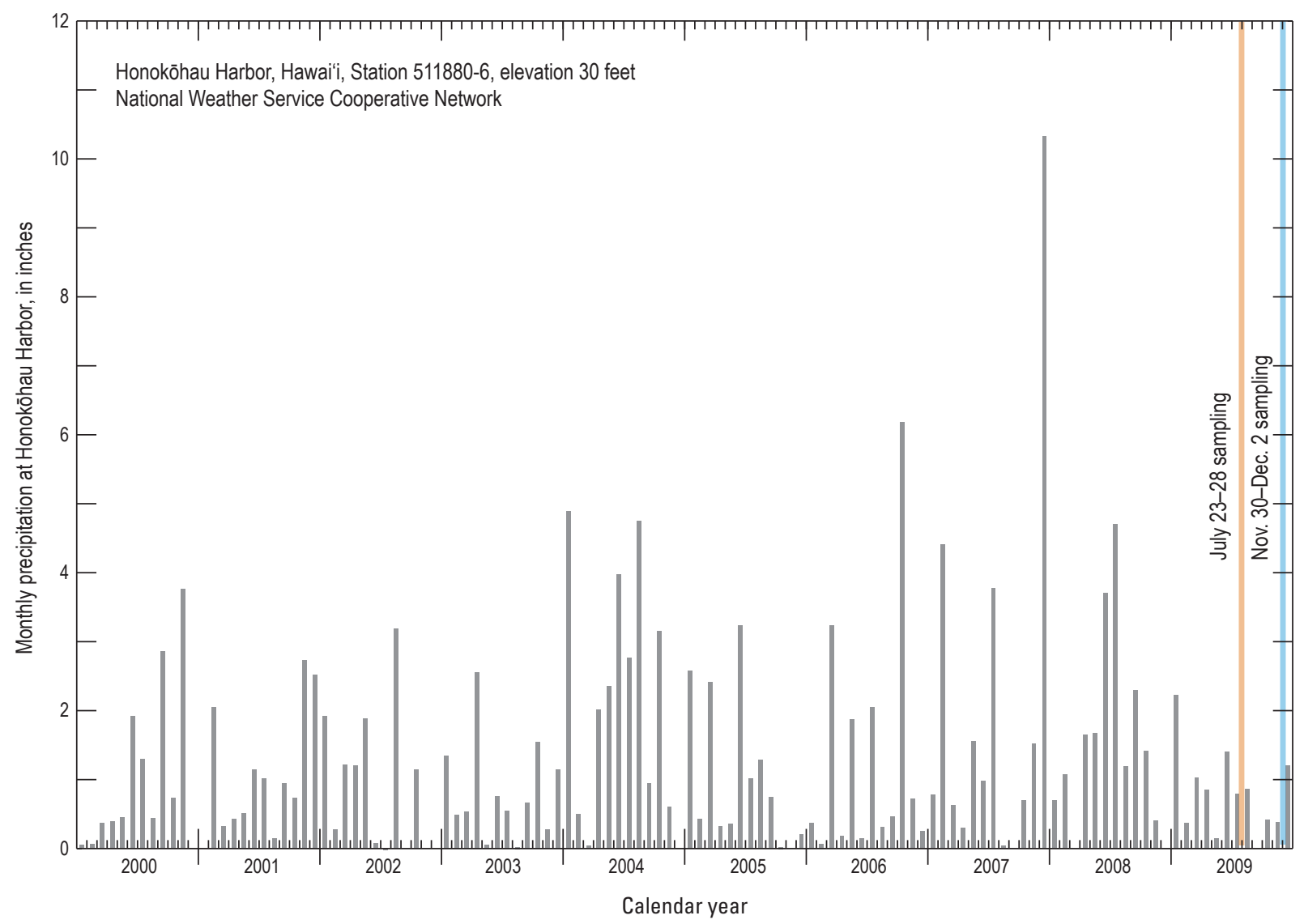

Figure 11. Graph showing monthly precipitation at Honokōhau Harbor, Island of Hawai' i, 2000-09 (Western Regional Climate Center, 2010b). These data show 2009 was a dry year and December 2007 had the largest monthly precipitation total of the decade. 
lowlands, temporarily raising groundwater levels and increasing coastal discharge of groundwater. There may have been some lowland recharge in 2008 as well; however, there probably was little to no recharge locally in 2009 in the lowlands where KAHO is situated and where most of the sampling was conducted. Viewed in this light, both the July and December 2009 samplings reflect dry-season groundwater conditions if the groundwater system had fully recessed from the late 2007 recharge (that is, if groundwater levels and coastal discharge had diminished to baseline levels). Alternately, if the groundwater system was still in recession from late 2007 recharge, the July 2009 samples may reflect slightly more of a "wetseason signature" and the December 2009 samples more of a "dry-season signature" - being that December would have been farther out on the recession than July. If this is true, the July 2009 samples may have better captured contaminants leached into groundwater through the land surface or by way of roadside dry wells during the late 2007 recharge. By December 2009, more time had elapsed, possibly allowing greater degradation and sorption of contaminants within the aquifer.
Tides and longer-term fluctuations in ocean level have the potential to influence sampling results because the brackish coastal groundwater lens rises and falls with changes in ocean level. Locally, irregular flushing or forcing of water through preferential voids and permeable layers in the aquifer likely is also occurring. Long-term fluctuations of daily mean ocean level for 2009 at the Kawaihae tide gage (National Oceanic and Atmospheric Administration, 2010) and groundwater levels in two monitoring wells at the Park, KAHO 2 and KAHO 3 (U.S. Geological Survey water-level records) are shown in figure 12. The Kawaihae tide gage is $26.5 \mathrm{mi}$ north-northeast of KAHO. The well water levels closely mimic ocean fluctuations as the groundwater lens rises and falls with changes in ocean level. Well water levels were about $0.3-0.35 \mathrm{ft}$ higher at the start of July sampling than at the start of December sampling. Any effect this slight difference in groundwater levels may have had on water quality cannot readily be determined. Although this slight difference may have caused some corresponding salinity change in wells and anchialine pools, daily tides cause more extreme groundwater fluctuations, and some hydrologic evolution in the brackish lens would also be expected over the several months between sampling.

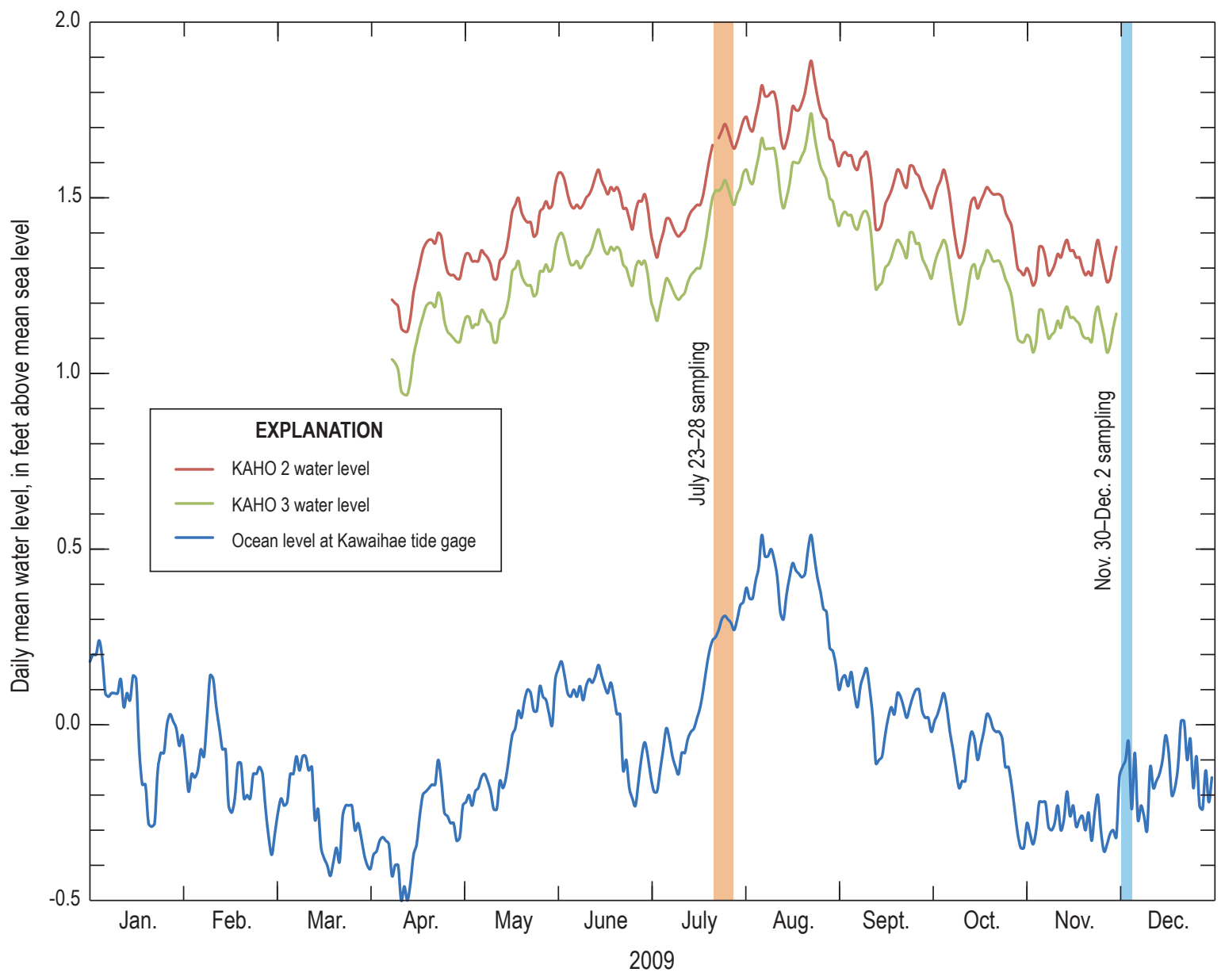

Figure 12. Graph showing daily mean water levels at Kawaihae tide gage and in monitoring wells KAHO 2 and KAHO 3 at Kaloko-Honokōhau National Historical Park, Island of Hawai'i (National Oceanic and Atmospheric Administration, 2010; U.S. Geological Survey water-level records). Wellwater levels closely mimic ocean fluctuations and were about $0.3-0.35 \mathrm{ft}$ higher at the start of July sampling than at the start of December sampling. 
Water samples could not be collected at a consistent stage in the daily tidal cycle because of limitations of completing sampling during daylight hours. Tidal variations during sampling are shown in figures 13 and 14, with sample collection times superposed. In these graphs, the sample symbols don't correspond to the measured water levels at the sites; they are simply plotted directly on the tidal trend line by sample time alone. Tidal time differences between predicted tides at Kawaihae and Kailua-Kona (National Oceanic and Atmospheric Administration, [2014]) range from several minutes to about a half-hour and can be disregarded to a first approximation.

Tidal range was more extreme during July sample collection than during December sample collection. In July (fig. 13), water samples were collected over a maximum tidal range of $2.65 \mathrm{ft}$ early in the sampling period when daytime sampling hours coincided with the extreme hydrographic limb of the daily tide. That range lessened to about $0.6 \mathrm{ft}$ by the end of the sampling period as the tides progressed and daytime hours fell on lesser hydrographic limbs of the tide. The timing of the July sampling, unfortunately, was governed by logistical arrangements and could not be shifted to a more favorable week in the monthly tidal cycle. The December sampling (fig. 14) did take place under a more favorable tidal stage: daytime hours coincided with the lesser limbs of the tidal cycle, and all samples were collected within a tidal range of about $0.8 \mathrm{ft}$ and at fairly low tidal stage overall.

Water-quality results for any site could be somewhat dependent on the stage of tide on which the sample was collected. However, there is no way to determine the possible effect of this without round-the-clock subsampling at close time intervals (for example, hourly or every other hour) at each site. This would be an interesting approach for a detailed process-level study but is not possible in a reconnaissancelevel study such as this one.

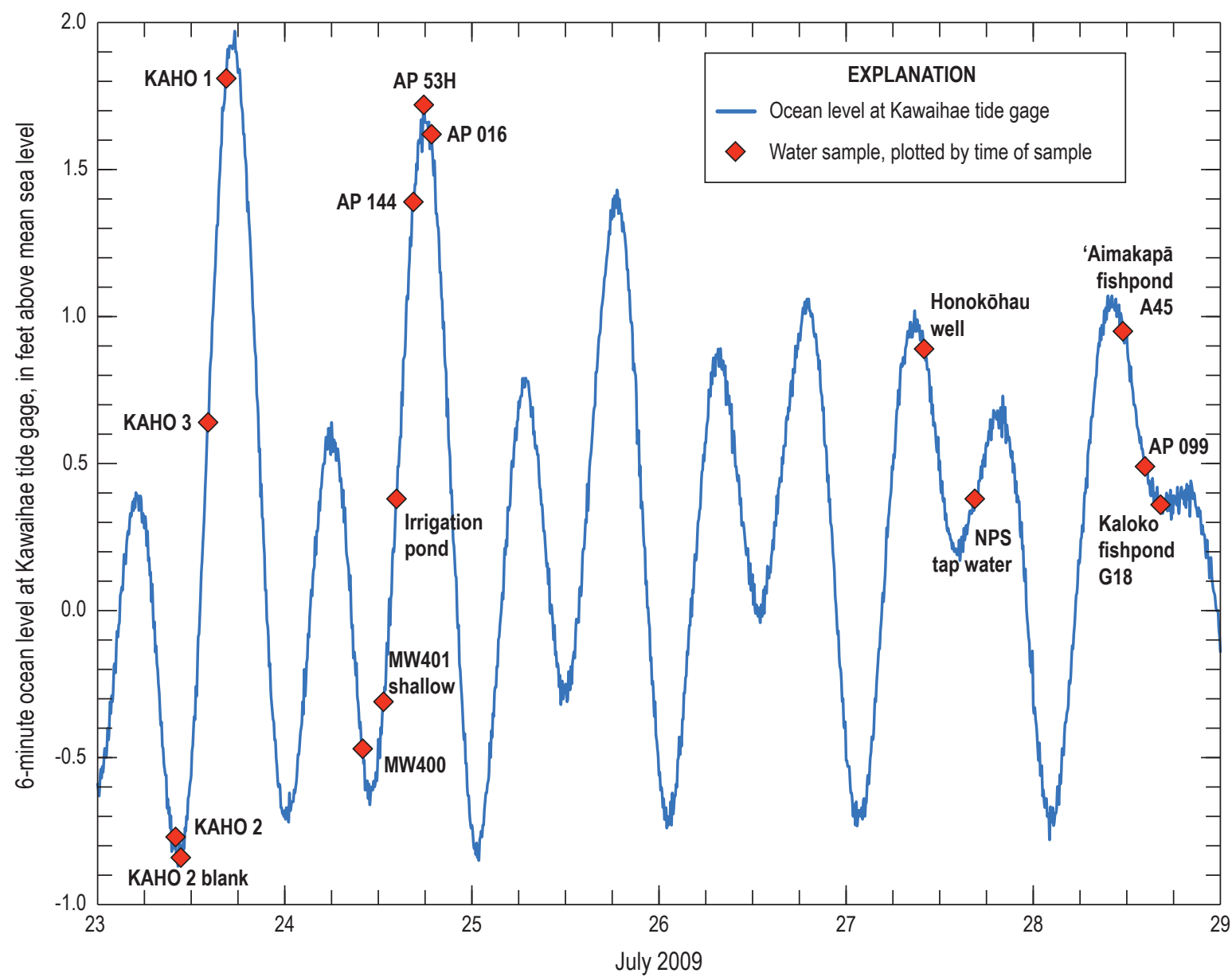

Figure 13. Graph showing July 2009 sample collection times at Kaloko-Honokōhau National Historical Park in relation to daily tides at Kawaihae tide gage (National Oceanic and Atmospheric Administration, 2010), Island of Hawai'i. Tidal range was extreme during daytime sampling hours early in the sampling period but lessened by the end of sampling. 


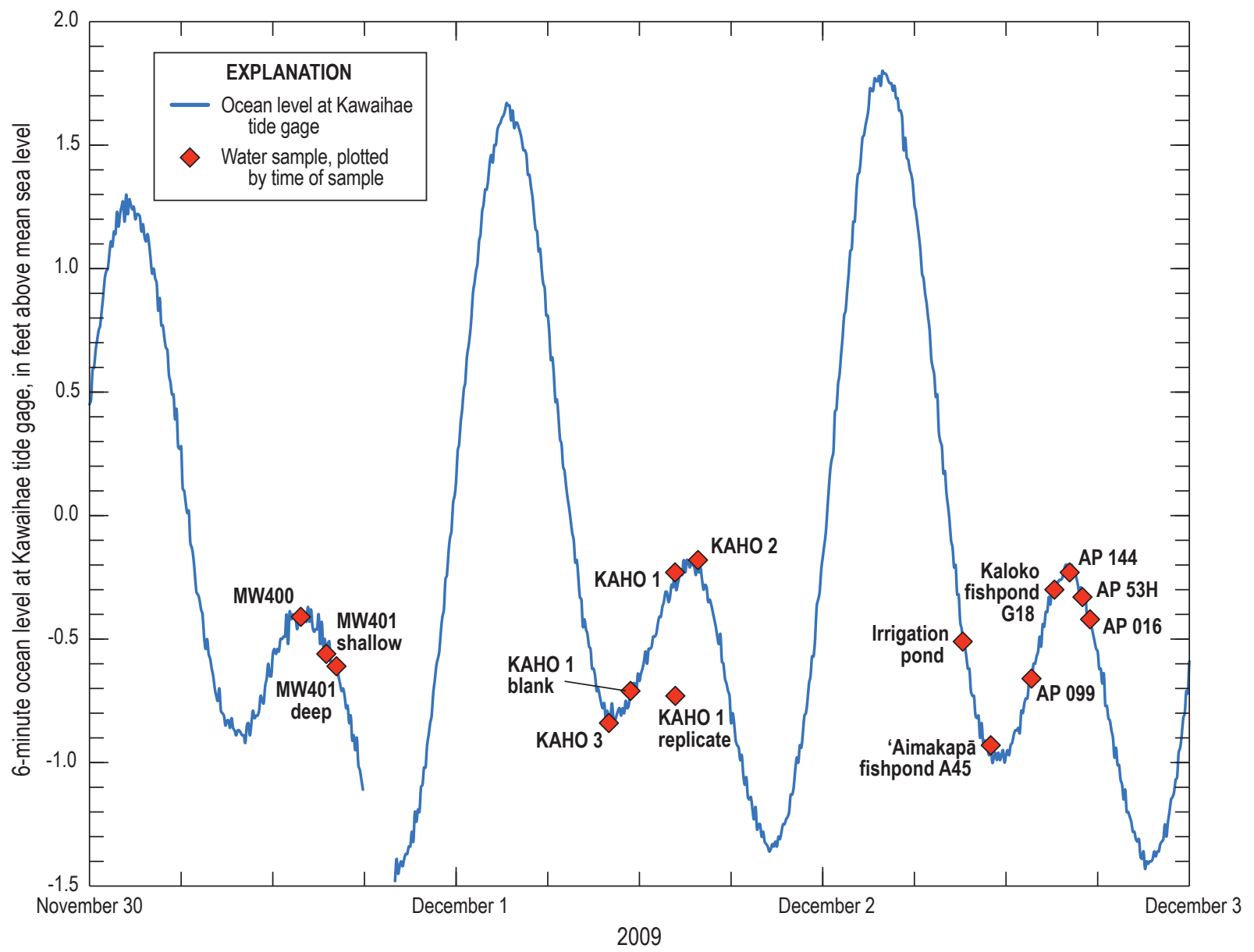

Figure 14. Graph showing December 2009 sample collection times at Kaloko-Honokōhau National Historical Park in relation to daily tides at Kawaihae tide gage (National Oceanic and Atmospheric Administration, 2010), Island of Hawai'i. A favorable relation of tides to daytime sampling hours allowed all samples to be collected over a small tidal range and at low tidal stage.

\section{Results and Interpretation}

The collected water-quality data are interpreted here with several questions in mind: (1) Were notable contaminants found, such as pesticides or solvents? (2) Were naturally occurring constituents such as nitrate or phosphorus abnormally high at some sites, high enough to implicate human enrichment by fertilizer or septic waste? (3) How similar or different were results from the two sampling rounds?

Nutrients, stable isotopes, and selected field measurements are interpreted mainly through the use of $\mathrm{X}$-Y graphs. A principal reason for this is that the samples encompass a wide range in salinity resulting from mixing of fresh and saline source waters. Because the degree of mixing or dilution varies from sample to sample along with sample salinity, constituent concentrations are not strictly comparable by their raw numeric values alone but are better interpreted in relation to a hypothetical freshwater-saltwater mixing line on various plots.

Organic compounds (pharmaceuticals, wastewater compounds, and volatile organic compounds) and optical brighteners are interpreted mainly by examining their numeric values in the respective data tables (tables 3, 4). Although these concentrations (or values) may vary somewhat with the degree of freshwater-saltwater mixing, a simple mixing relationship is not expected and one is limited mainly to discerning whether compounds are detected at all and one is only secondarily able to compare concentrations.

\section{Salinity and Temperature}

The salinity and temperature of water samples indicate that most samples were plausible mixtures of fresh groundwater originating farther inland and colder saline groundwater that underlies the coastal brackish groundwater lens. Some samples were warmer than would be expected by simple mixing, most likely as a result of solar warming of exposed ponds and water transmitted in pipelines under hot roadways.

The relation of temperature versus salinity for July and December is shown in figures 15 and 16, respectively. All July samples are represented on the plots but the multiparameter 
instrument malfunctioned in December and prevented field temperature measurement on all but the first day's samples at the two Kohanaiki monitoring wells (although specific conductance was later measured and salinities computed for all of the December samples). Most samples had salinities that were $<50$ percent seawater, but a sample from deep monitoring well MW401 was 67 percent seawater and had the lowest temperature, reinforcing an earlier finding by Bowles (2007) that the brackish-water lens in the Kona area is underlain by cold saltwater.

A hypothetical mixing line is drawn in figures 15 and 16 to represent mixing between upland fresh groundwater and deep saline groundwater. Termed the "upland-deep saline groundwater mixing line" in this report, it is drawn through the July value for the Honokōhau well and the December value for the MW401 deep sample. These are the freshest and saltiest waters sampled and are, therefore, chosen to represent end members in the hypothetical mixing relation. The Honokōhau well is the farthest inland sample and represents upland "background" freshwater before additional salts are added farther downgradient by tidal mixing and evaporative concentration in low-elevation recharge. Anthropogenic constituents also are presumed to be lesser in concentration in upland groundwater and to increase downslope with additions from agricultural, suburban, and commercial/industrial land activities. The MW401 December sample from $45 \mathrm{ft}$ below the water table was the saltiest water collected, having a salinity two-thirds that of seawater (a salinity of 23.6, equal to 67 percent seawater). If upland groundwater resembling that from the Honokōhau well flows toward shore and mixes with saline groundwater from which the MW401 deep sample originates, then varying mixtures of the waters would fall along the hypothetical mixing line.

Also shown for context are values for surface and deep seawater at the Natural Energy Laboratory of Hawai' $i$ Authority (NELHA) facility at Keāhole, north of Honokōhau. These waters are used for ocean thermal energy conversion (OTEC) and aquaculture, and they are pumped from 55-in diameter pipelines offshore. NELHA surface seawater (SSW55) is from the solar-warmed, mixed surface layer of the ocean and is pumped from an intake depth of $79 \mathrm{ft}$. NELHA deep seawater (DSW55) is cold, subthermocline water pumped from an intake depth of 3,000 ft. Average temperatures for these NELHA seawaters are $26.2 \pm 0.20^{\circ} \mathrm{C}$ for surface seawater and $5.64 \pm 0.35^{\circ} \mathrm{C}$ for deep, subthermocline seawater. These temperatures are means and standard deviations of 57 measurements from August 2005 to June 2010 (Olson, 2010). Oceanographic soundings offshore of NELHA have shown the warm, upper mixed layer to be about $260 \mathrm{ft}$ thick above the top of the thermocline (Campbell and Erlandson, 1979).

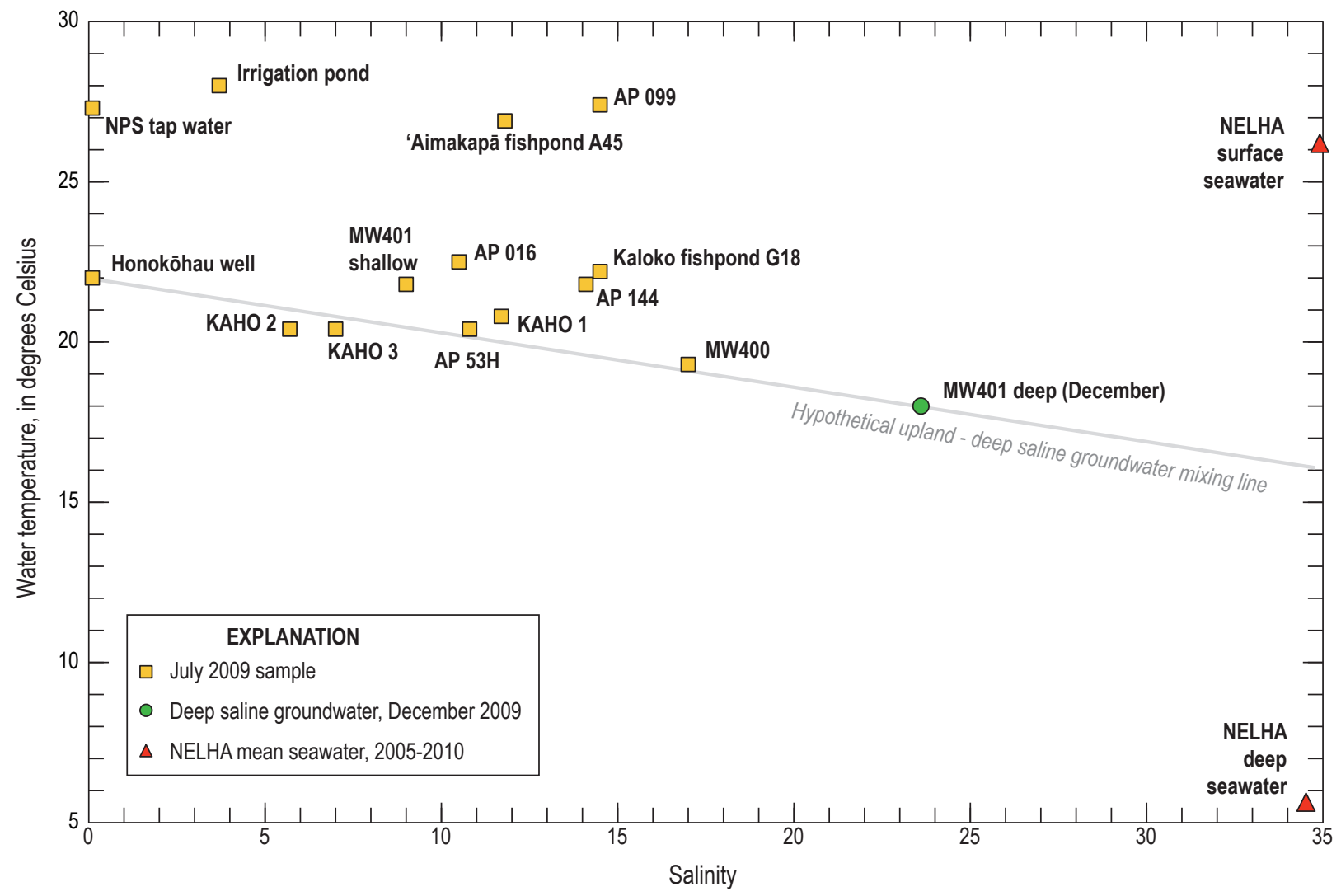

Figure 15. Graph showing temperature versus salinity for July 2009 water samples at KalokoHonokōhau National Historical Park, Island of Hawai'i. Some samples lie well above the mixing line as a result of solar warming of open water bodies and water-distribution piping below hot pavement (in the case of the NPS tap water sample). NELHA, Natural Energy Laboratory of Hawai'i Authority. 


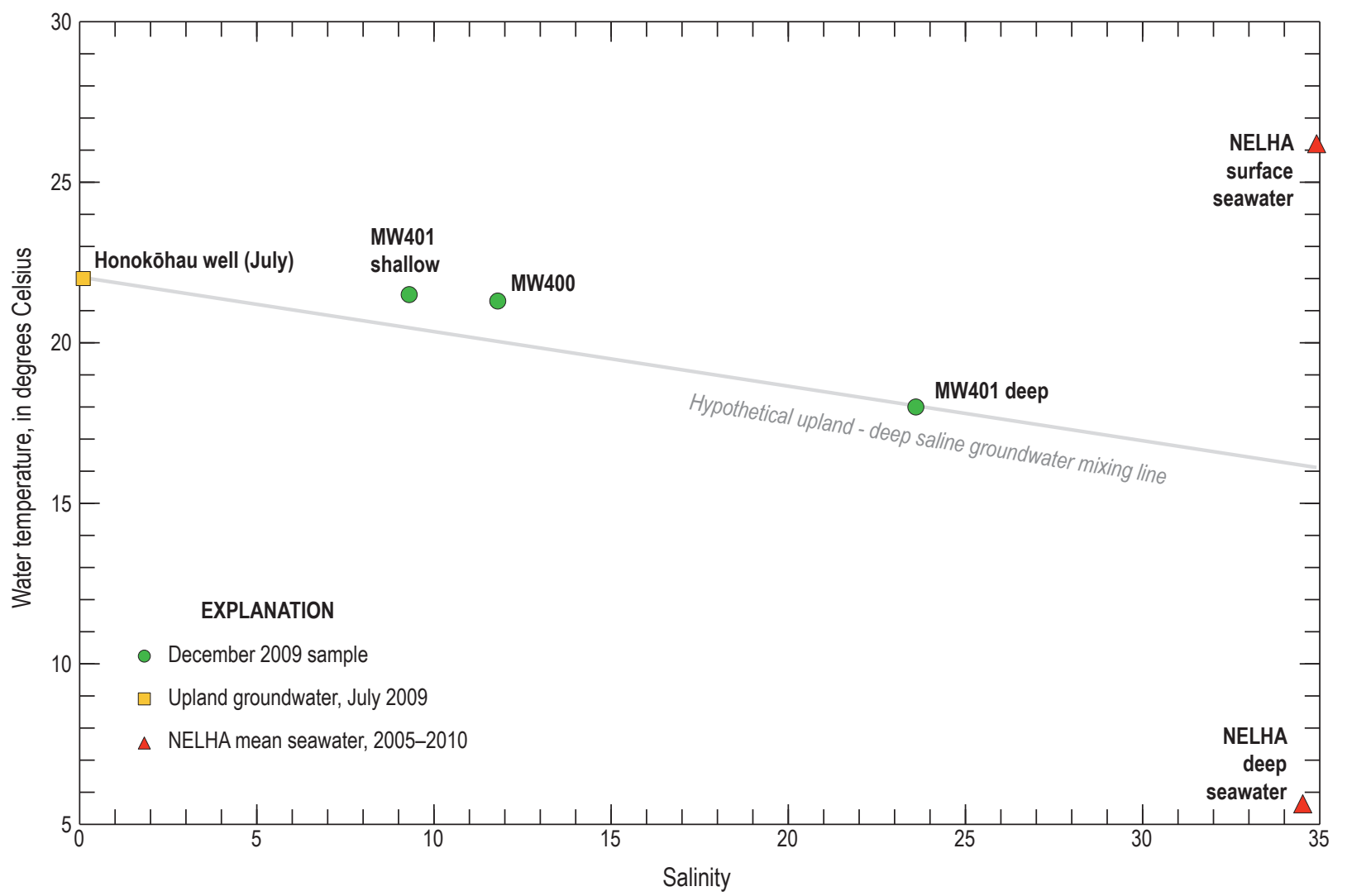

Figure 16. Graph showing temperature versus salinity for December 2009 water samples at KalokoHonokōhau National Historical Park, Island of Hawai'i. Only three samples were measured the first day before the instrument malfunctioned.

Many of the July values plot close to the mixing line shown in figure 15, including those for anchialine pool AP53H and all of the short-screened monitoring wells (KAHO 1, KAHO 2, KAHO 3, MW400, MW401 shallow). This is interpreted as supporting the basic mixing premise and the choice of end members. Samples whose values lie farther above the mixing line have a greater amount of the y-axis variable, in this case temperature, or heat. Samples with slight excess heat include anchialine pools AP 016 and AP 144, and Kaloko Fishpond G18. The anchialine pools are surrounded by black lava that warms in the sun and likely conducts heat to the shallow groundwater. Sample G18 at Kaloko Fishpond was collected at a known spring in the fishpond and presumably resembles other groundwater more than open pond water that has been subjected to solar warming or to mixing with warmer seawater that has entered through the fishpond rock wall.

Data points that lie well above the mixing line in figure 15 indicate large amounts of excess heat, and reasonable warming mechanisms can be postulated for each of these samples. NPS office tap water originates mostly from the Honokōhau well, with some fraction of its water contributed from another nearby well at times. The water at the well is cool, but by the time it reaches the NPS office it has been conveyed through miles of distribution piping beneath asphalt roadways heated by the subtropical sun. The Kohanaiki irrigation pond is an exposed pond with a black synthetic lining and is subject to direct solar warming; the warm temperature of the pond water sample suggests a long residence time and low flushing or turnover rate by new water, resulting in substantial solar warming (at least at the time of the sampling). At 'Aimakapā Fishpond A45, the warm sample may represent solar-warmed pond water rather than colder groundwater such as the Kaloko Fishpond G18 spring sample. Anchialine pool AP 099 is exposed to direct sun, having no overhead tree canopy such as at AP 144. It is also on a narrow peninsula, and it is conceivable that warm surface seawater is flushed in and out of the peninsula by the tides, mixing in with groundwater.

Extension of the mixing line in figure 15 to the right side of the graph (salinity $=35$ ) produces a y-intercept temperature of $16^{\circ} \mathrm{C}$, roughly midway between the NELHA surface- and deep-seawater reference values. Presuming that it is valid to extend the mixing line to estimate the temperature of fully saline groundwater, there are several plausible explanations for the intermediate temperature. One possibility is mixing of surface and deep seawater from offshore in the proper proportions that yield the intermediate temperature. Another possibility is a predominant influx of saltwater having that particular $16^{\circ} \mathrm{C}$ temperature, for example from a limited segment of the offshore submarine slope that intersects the oceanic thermocline at about that temperature. Finally, the saline groundwater may have originated mostly from colder subthermocline seawater and been warmed to $16^{\circ} \mathrm{C}$ by geothermal heat within 
the flank of Hualālai Volcano. Remnant volcanic heat, particularly from the rift zone of the volcano, would tend to drive a thermal-convective flow of saltwater in and upward within the aquifer, much like the salt-entrainment-driven cyclic flow just beneath the brackish lens but potentially extending much deeper, perhaps to depths of thousands of feet within the mountain flank. Regardless of the exact origin, one important implication of the cold saline groundwater is that it is much higher in nutrients than surface seawater in the upper, mixed layer of the ocean where nutrients are stripped by phytoplankton uptake (Bienfang and Szyper, 1981).

Salinity did not change much from July to December at most sites (fig. 17). Exceptions were Kaloko Fishpond G18 and Kohanaiki monitoring well MW400 (the closest to the ocean of the monitoring wells sampled), which showed opposite trends. Salinity at Kaloko Fishpond G18 was higher in December than in July, perhaps indicating a greater proportion of pond water over spring water in the sample, or a residual effect of the higher tide in December (fig. 14), even though the G18 sample was collected on the falling (hydrograph) limb near low tide. At MW400, the July sample had a higher salinity of 17 (about 50 percent seawater) and the December sample had a much lower salinity of 11.8 . Average daily ocean level was about $0.5 \mathrm{ft}$ lower during December sampling than in July (fig. 12), and the brackish coastal lens and water table will rise and fall with these ocean-level changes. MW400 is a short-screened monitoring well tapping salinity-stratified groundwater just below the water table. A 0.5 -ft lowering of ocean and lens may have resulted in a greater proportion of the freshest, uppermost groundwater at the site in the December sample. Golf-course irrigation may also have contributed to the low salinity of the December sample, as discussed in the "Nutrients" section of this report.

Salinity and temperature profiles (fig. 18) from deep monitoring well MW401 at the north park boundary further reinforce Bowles (2007) finding that colder saltwater underlies a warmer brackish-water lens in the Kona area. Depth profiles of temperature and specific conductance (an electrical measure of salinity) were measured by NPS on December 7, 2009, a week after USGS sampling at the well on November 30 (profile data from Lindsey Kramer, National Park Service, written commun., 2011). The profile data - measured by NPS at many depths using a down-hole instrument - show that temperature decreases with depth in the well as specific conductance (salinity) increases. Values from two USGS water samples (especially the specific-conductance values) at -5 and $-45 \mathrm{ft}$ below the water table agree well with the profile data. Sample temperatures were $0.6-0.8^{\circ} \mathrm{C}$ warmer than profile data at corresponding depths, perhaps reflecting an offset between NPS and USGS temperature sensors or warming of the sampled water during USGS sampling.
The minimum temperature measured in the NPS profile was $17.0^{\circ} \mathrm{C}$, and the maximum specific conductance was $45,970 \mu \mathrm{S} / \mathrm{cm}$. This equates to a salinity of 29.8 (using the conversion formula of Wagner and others, 2006), or a saltwater fraction of 85 percent seawater. The maximum conductance recorded by NPS in monthly profiles from November 2008 through February 2011 was 47,800 $\mu \mathrm{S} / \mathrm{cm}$, corresponding to a salinity 31.1 or about 89 percent seawater (Rebecca Most, National Park Service, written commun., 2009). Apparently, the well is not deep enough to have reached 100 percent seawater within its depth of $116 \mathrm{ft}$ below the water table (about $115 \mathrm{ft}$ below mean sea level). The deep USGS water sample in MW401 was about 67 percent seawater and had a temperature of $18^{\circ} \mathrm{C}$, colder than the $22^{\circ} \mathrm{C}$ of fresh groundwater from the Honokōhau well far inland and much colder than the $26^{\circ} \mathrm{C}$ of nearby NELHA surface seawater.

Similar temperature and salinity profiles have been measured in other monitoring wells near the Park. Bowles (2007) reported a minimum temperature of about $16{ }^{\circ} \mathrm{C}$ in a monitoring well southeast of Honokōhau Harbor and introduced a "cold saline groundwater" hypothesis in which saltwater below the top of the oceanic thermocline is able to flow readily into the aquifer through the steep submarine slope offshore. Cold saline water was worthy of note by Bowles because it ran counter to the general pattern at most other deep monitoring wells in Hawai $i$, where warmer saline groundwater underlies colder freshwater (for example Visher and Mink, 1964; Rotzoll, 2010). A more complex exception to the general pattern is the very deep KP-1 scientific borehole in Hilo, also on the island of Hawaili. Temperature profiles in this 3,465-ft deep borehole indicated cold, subthermocline saltwater of $5-7^{\circ} \mathrm{C}$ temperature at depths greater than about 1,600 ft (Thomas and others, 1996). The well also penetrated two separate freshwater lenses, each grading into underlying saltwater: a shallow lens within the surficial Mauna Loa Volcano and a second lens in the underlying and older Mauna Kea Volcano. A second exception is a multi-aquifer configuration in Kona that is similar in some respects to that in Hilo. The Kamakana well, located roughly mid-slope between the coast and the Honokōhau well (fig. 1), was drilled from elevation $542 \mathrm{ft}$ above sea level to $1,220 \mathrm{ft}$ below sea level. Salinity and temperature profiles in the well indicate a shallow brackish-water lens near sea level that is underlain by cold saline groundwater, much like the brackish lens at KAHO. However, the well encountered a second freshwater body at a depth of about $1,050 \mathrm{ft}$ below sea level in what appears to be an underlying aquifer confined by poorly permeable rock and distinct from the surficial coastal aquifer (Tom Nance Water Resource Engineering, 2013).

One might question the choice of MW401 as the saline end member rather than, for example, surface seawater. However, the cold temperature of the MW401 sample and the NPS temperature profiles in figure 18 imply that saline groundwater 


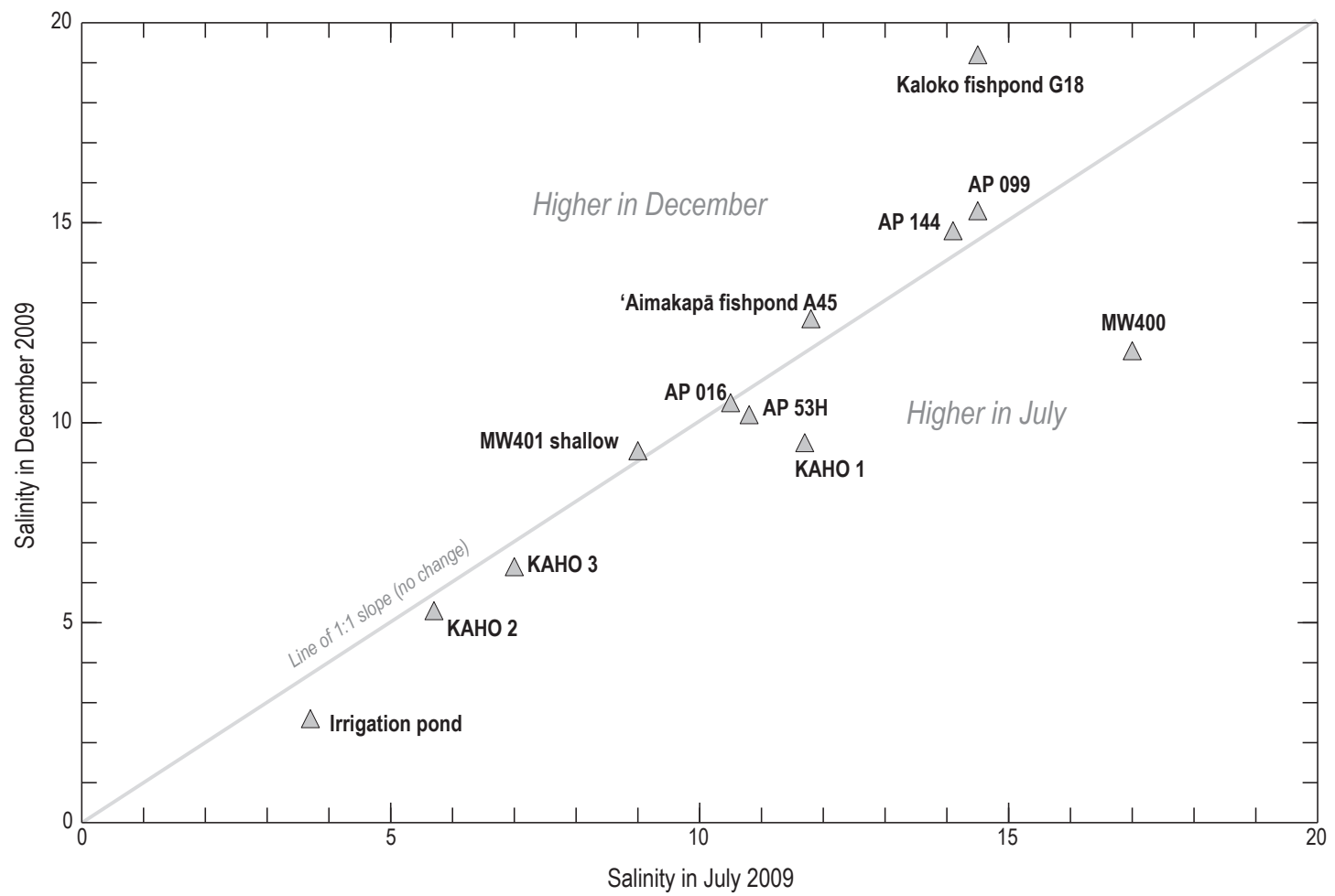

Figure 17. Graph showing change in salinity from July to December 2009 at Kaloko-Honokōhau National Historical Park, Island of Hawai'i. Salinity was substantially higher in July at monitoring well MW400 and in December at Kaloko Fishpond G18. NELHA, Natural Energy Laboratory of Hawai'i Authority.

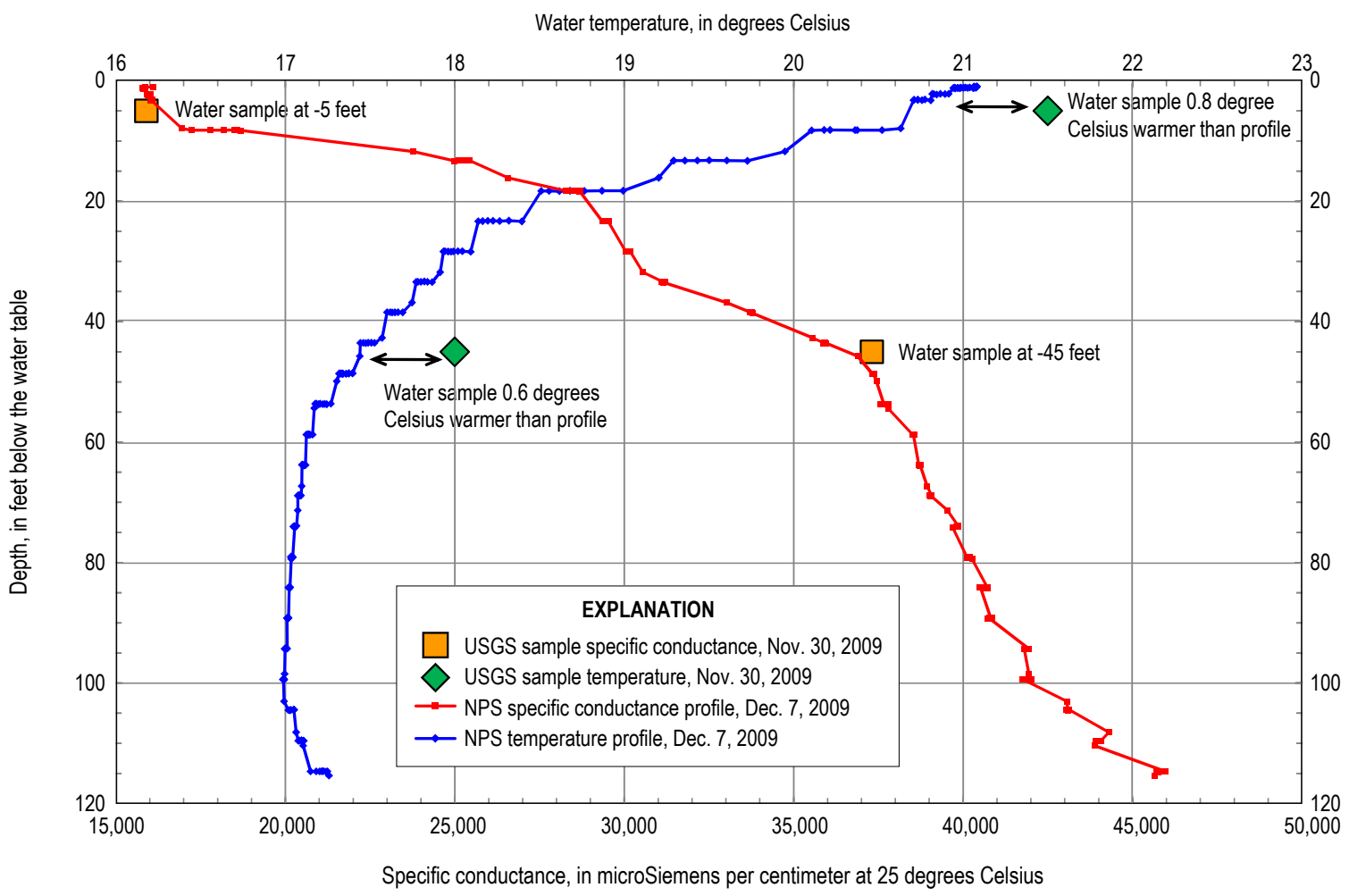

Figure 18. Graph showing depth profiles of temperature and specific conductance in Kohanaiki monitoring well MW401, Island of Hawai'i, December 7, 2009, and USGS water samples one week earlier on November 30. Sample values coincided reasonably well with the profiles, although the water samples were $0.4-0.7^{\circ} \mathrm{C}$ warmer than the temperature profile. Profile data are from Lindsey Kramer, National Park Service, written commun., 2011). 
at $\mathrm{KAHO}$ cannot originate solely from warm surface seawater, a large fraction of cold, subthermocline seawater must be present to explain the temperatures. The precise relevance of the NELHA surface and deep seawaters to environmental waters at KAHO can only be inferred, whereas the deep MW401 sample from immediately beneath the brackish-water lens in the vicinity of the other samples is unquestionably of more local relevance and so was chosen as the saline end member for the dataset.

To summarize, plotting of salinity and temperature data for the July and December 2009 water samples allows the samples to be interpreted with respect to a hypothetical conservative mixing line between fresh upland groundwater from Honokōhau well and cold saline groundwater beneath the brackish-water lens (best sampled at monitoring well MW401). Data from the monitoring wells and from most anchialine pools plot close to the hypothetical mixing line, whereas data from tap water and the larger ponds plot well above the mixing line and can be explained reasonably by direct solar warming or by mixing with nearby warm surface seawater (AP 099). A similar approach to graphical interpretation is taken (later in this report) with other constituents such as nutrients and isotopic compositions.

\section{Stable Isotopes of Water}

Stable isotopes of water further support the hypothesis that most samples are plausible mixtures of upland groundwater and saline water. A slight shift of most samples off of a hypothetical mixing line may indicate that mid-slope recharge contributing to the low-elevation samples may differ isotopically from upland recharge that determines the composition of the freshwater end member at the Honokōhau well.

Plots of $\delta^{2} \mathrm{H}$ and $\delta^{18} \mathrm{O}$ isotopic compositions are shown in figures 19 and 20 for July and December samples, respectively. Most of the data fall close to the hypothetical mixing line, having intermediate compositions between those of the Honokōhau well and MW401 deep; therefore most samples are plausible mixtures of the fresh and saline end members to a first approximation. NPS office tap water is distinctly isotopically heavier (more positive) than Honokōhau well water, suggesting that it has some fraction of water from another source blended in, perhaps from Keahuola QLT 1 well (fig. 1) as discussed earlier. The NELHA seawater values plot close to the mixing line where the line is extended to the upper right (note that the NELHA values for isotopic composition span a much shorter time than for temperature, roughly 1.5 months in late 2009). The July and December plots do not differ dramatically, with the greatest shifts in composition being the two fishpond samples, Kaloko and 'Aimakapā Fishponds. Plots of most of the samples fall slightly above the mixing line, indicating that they are slightly heavier in $\delta^{2} \mathrm{H}$ composition than would be predicted by simple mixing between Honokōhau well water and deep saline groundwater. An alternate approach would be to draw the mixing line through the NELHA seawater symbols for a true seawater end member, and in that case MW401 deep would plot slightly above that line like the other samples.

\section{Nutrients}

Nitrogen and phosphorus in most water samples in and near the Park were enriched in comparison to expected background concentrations along a freshwater-saltwater mixing line. Most nutrient enrichments were less than 60 percent, but three sites along the north boundary of the Park (anchialine pool AP 144 and monitoring wells MW400 and MW401) had nitrogen enrichments of 75,110 , and 280 percent above background that can be attributed to fertilizer application during an initial turf grow-in period when vegetation was being established at the adjacent resort golf course. Combined nitrogen and phosphorus enrichments at monitoring wells closest to Kaloko Light Industrial Park may indicate septic contamination in that vicinity.

\section{Nitrogen}

Dissolved inorganic nitrogen (DIN $=\mathrm{NH}_{3}+\mathrm{NO}_{2}+\mathrm{NO}_{3}$ ) is plotted against salinity in figures 21 and 22 for July and December water samples, respectively, in order to interpret the various brackish waters across their range in salinity. As was done for water temperature, most water samples are assumed to have originated as mixtures of fresh and saline groundwater end members, and a mixing line is drawn between the upland freshwater sample from the Honokōhau well and the deep saline water sample from $45 \mathrm{ft}$ below the water table in monitoring well MW401. With regard to nutrients, both of these waters can be thought of as representing "natural background" conditions subject to minimal anthropogenic addition of nutrients. The Honokōhau well is located high on the mountain flank above most developed lands, and fresh groundwater from the well was recharged mostly through forested and grassy uplands. DIN concentration at the Honokōhau well was $1,160 \mu \mathrm{g} / \mathrm{L}$ (table 3 ), closely comparable to the average nitrate concentration of $1,148 \mu \mathrm{g} / \mathrm{L}$ for 22 samples from the same well (Bienfang, 2008) and the 1,170 $\mu \mathrm{g} / \mathrm{L}$ background nitrate concentration for the similarly arid Kîhei uplands on Maui (Hunt, 2007). The deep saline-water sample from monitoring well MW401 had a DIN concentration of $647 \mu \mathrm{g} / \mathrm{L}$ (table 4).

Samples plotting above the mixing line in figures 21 and 22 are interpreted as being enriched in nitrogen above background concentrations; that is, nitrogen has been added from some source in comparison to simple mixing of the end-member upland and saline background waters. Similarly, samples plotting below the mixing line are interpreted as being depleted in nitrogen (nitrogen has been removed by some mechanism). The amount of enrichment or depletion can be expressed in concentration units above or below the mixing line, or as a percentage of the mixing line DIN concentration at that point along the salinity scale. 
The highest DIN concentration measured was 3,660 $\mu \mathrm{g} / \mathrm{L}$ at monitoring well MW401 in July (fig. 21), in a water sample pumped from $5 \mathrm{ft}$ below the water table. This corresponds to an apparent enrichment of $2,700 \mu \mathrm{g} / \mathrm{L}$ or 280 percent above the expected background concentration of $960 \mu \mathrm{g} / \mathrm{L}$ on the mixing line (mixing-line concentrations were estimated graphically, by scaling vertical heights above the hypothetical mixing line against the y-axis).

Brock (2010) monitored water quality for The Shores at Kohanaiki during this time period and measured increasing nitrogen concentrations from 2007 through early 2009 in anchialine pools and marine waters that he sampled. Brock attributed the elevated nitrogen to fertilization and watering of golf course landscaping during the "turf grow-in" period necessary to establish the vegetation. Brock also described later declines in nitrogen as the grow-in period waned (it concluded in October 2009) and fertilizer application and watering were reduced. Monitoring well MW401 is on the Kohanaiki property, immediately adjacent to such landscaping, and the depth to the water table is only $18 \mathrm{ft}$. It is apparent that excess nitrogen from fertilizers leached into groundwater at Kohanaiki and was reflected in the July water sample from MW401. The acute nitrogen enrichment at MW401 appears to have been temporary, however, and by December (fig. 22) DIN concentration at MW401 had fallen to 2,010 $\mu \mathrm{g} / \mathrm{L}$. This represents a 45 percent decline from July, though the December concentration was still enriched by $1,050 \mu \mathrm{g} / \mathrm{L}$ or 109 percent above the mixing-line background concentration.

The second highest DIN concentration in July was $1,480 \mu \mathrm{g} / \mathrm{L}$ at AP 144, an apparent enrichment of $630 \mu \mathrm{g} / \mathrm{L}$ or 75 percent above the background concentration of $845 \mu \mathrm{g} / \mathrm{L}$ at the mixing line. Anchialine pool AP 144 is very near the north park boundary and may have experienced the same nitrogen enrichment from fertilizers as MW401. Alternately, the apparent nitrogen enrichment at AP 144 could be a result of biotic cycling, as this pool hosts a large population of endemic shrimp that were seen on all site visits.

Monitoring well MW400 is just a short distance away from AP 144, but it did not show a similar DIN enrichment in July (fig. 21). However, by December DIN concentration at MW400 had risen to $1,900 \mu \mathrm{g} / \mathrm{L}$, an enrichment of $1,000 \mu \mathrm{g} / \mathrm{L}$ or 111 percent above the estimated background concentration of $900 \mu \mathrm{g} / \mathrm{L}$ at the mixing line (fig. 22). A small part of the DIN increase at MW400 can be attributed to the sharp decline in salinity from July to December, from 17 to 11.8 (tables 3,4). The greater fraction of freshwater in the December sample would have been accompanied by a slight increase in DIN, but only along a trend paralleling the mixing line if the only change was the degree of freshwater-saltwater mixing. Instead, the considerable vertical displacement of MW400 off of the mixing line in the December plot requires a large addition of DIN, over and above what can be attributed to freshwater-saltwater mixing. One possible source is the same fertilizer-derived nitrogen as at MW401 but delayed, perhaps, as a plume of fertilizer-enriched groundwater flowed shoreward from MW401 to MW400 over the intervening months.
The lower salinity of the December sample at MW400 could also be a marker of landscape irrigation water: infiltration of freshwater from excess irrigation would tend to dilute the ambient brackish groundwater in the vicinity, as well as carry fertilizer-derived nutrients downward and shoreward.

Remaining sites had DIN concentrations less than $1,500 \mu \mathrm{g} / \mathrm{L}$ and DIN enrichments within about $300 \mu \mathrm{g} / \mathrm{L}$ of the mixing line, or no more than 30 to 40 percent above background concentrations. DIN concentration at monitoring well KAHO 1 plotted right on the mixing line in July (fig. 21), but by December DIN had risen to 1,330 $\mu \mathrm{g} / \mathrm{L}$ (fig. 22), an enrichment of $380 \mu \mathrm{g} / \mathrm{L}$ or 40 percent above the estimated background concentration of $950 \mu \mathrm{g} / \mathrm{L}$ at the mixing line. As was true at MW400, a drop in salinity at KAHO 1 from July to December may account for a small part of the increase in DIN, but simple dilution by freshwater would have shifted its plotting position along the mixing line. Instead, movement of the data point well off the mixing line in figure 22 implies that there was a substantial addition of nitrogen.

A potentially key observation at KAHO 1 was that hydrogen sulfide gas was detected by smell in July, indicating sulfate-reducing and denitrifying conditions in the aquifer. Sulfate reduction is an intermediate step in a sequence of bacterially catalyzed redox reactions and is preceded by nitrate reduction, which itself is preceded by oxic respiration (Schwarzenbach, Gschwend, and Imboden, 2002). Active denitrification could mean that the July DIN concentration at KAHO 1 was diminished somewhat in at least part of the aquifer contributing to the well. If this is true, the higher DIN concentration in December may be more generally indicative of the site's usual nitrogen state - that is, about 40 percent enriched above the expected DIN background concentration at the mixing line.

Furthermore, these redox reactions typically proceed by bacterial consumption of organic carbon, sequentially utilizing and depleting oxygen, nitrogen, and sulfate in the process. The presence of hydrogen sulfide at KAHO 1 suggests a source of organic carbon in the aquifer that would promote the chain of redox reactions. One possible source of organic carbon is septic waste. The nearby KAHO visitor center (about $150 \mathrm{ft}$ uphill from KAHO 1) has restrooms but has never had an onsite septic system; instead, it has been connected to a stem line of the regional sewer system since the center opened in 2003 (Sallie Beavers, National Park Service, oral commun., 2014). Somewhat farther away are various septic systems at Kaloko Light Industrial Park, across the highway to the northeast (fig. 3). The Industrial Park is not directly uphill from KAHO 1, but Bowles and others (2006) show a conceptual model of regional groundwater convergence toward Honokōhau Harbor, raising the possibility that groundwater from beneath the Industrial Park may plausibly be drawn southwest toward KAHO 1 by that flow convergence. The harbor was excavated into the aquifer a lateral distance of $0.4 \mathrm{mi}$ from the pre-existing shore and is thought to act as a regional drain, preferentially focusing groundwater discharge there. 


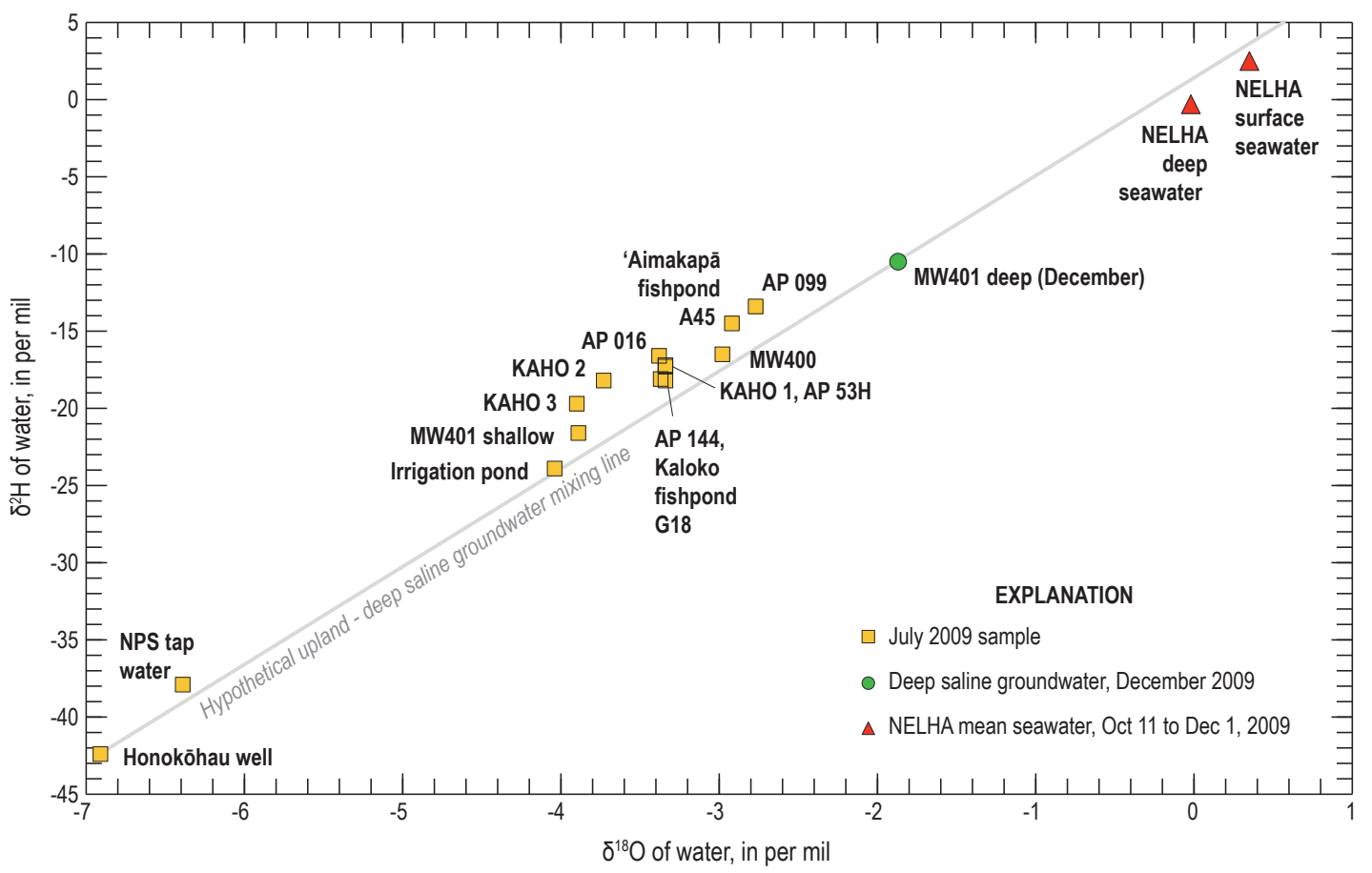

Figure 19. Graph showing $\delta^{2} \mathrm{H}$ versus $\delta^{18} \mathrm{O}$ for July 2009 water samples at KalokoHonokōhau National Historical Park, Island of Hawai'i. Most samples fall close to a hypothetical mixing line between freshwater (Honokōhau well) and seawater (NELHA). NELHA, Natural Energy Laboratory of Hawai'i Authority.

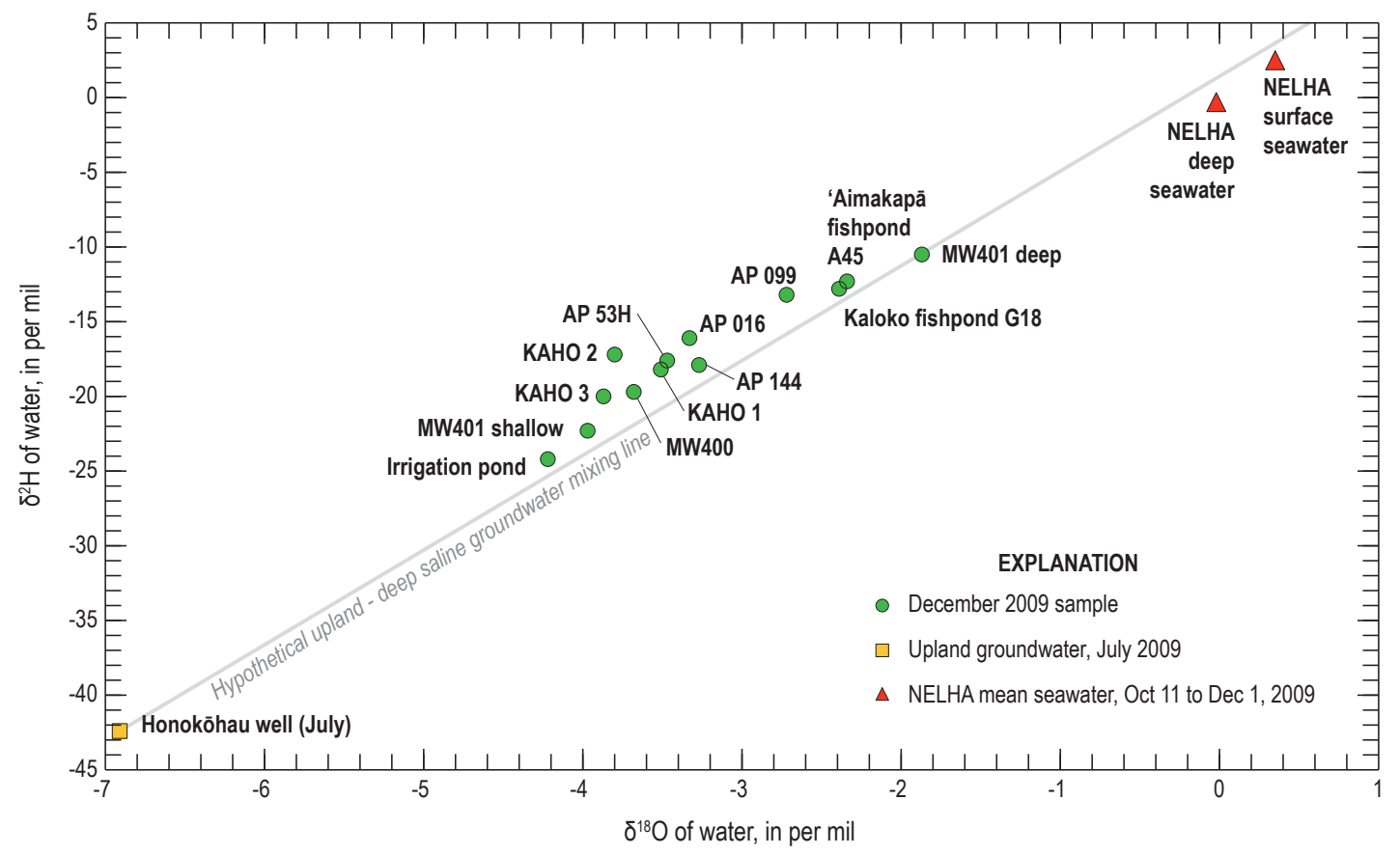

Figure 20. Graph showing $\delta^{2} \mathrm{H}$ versus $\delta^{18} \mathrm{O}$ for December 2009 water samples at Kaloko-Honokōhau National Historical Park, Island of Hawai'i. Most samples fall close to a hypothetical mixing line between freshwater (Honokōhau well) and seawater (NELHA). NELHA, Natural Energy Laboratory of Hawai'i Authority. 


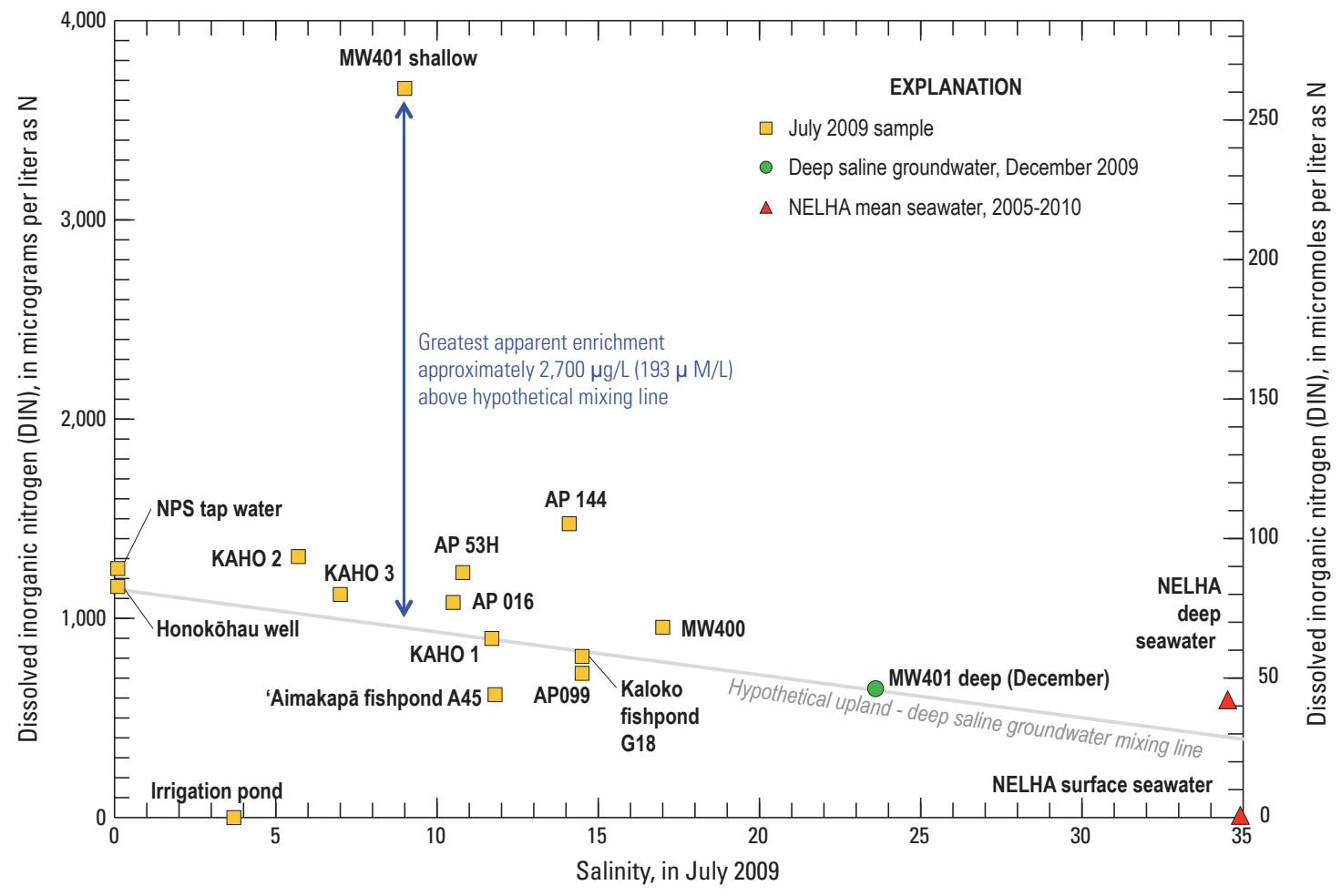

Figure 21. Graph showing dissolved inorganic nitrogen (DIN) versus salinity for July 2009 water samples at Kaloko-Honokōhau National Historical Park, Island of Hawai'i. Acute DIN enrichment at MW401 was likely caused by fertilizer applied nearby. NELHA, Natural Energy Laboratory of Hawai'i Authority.

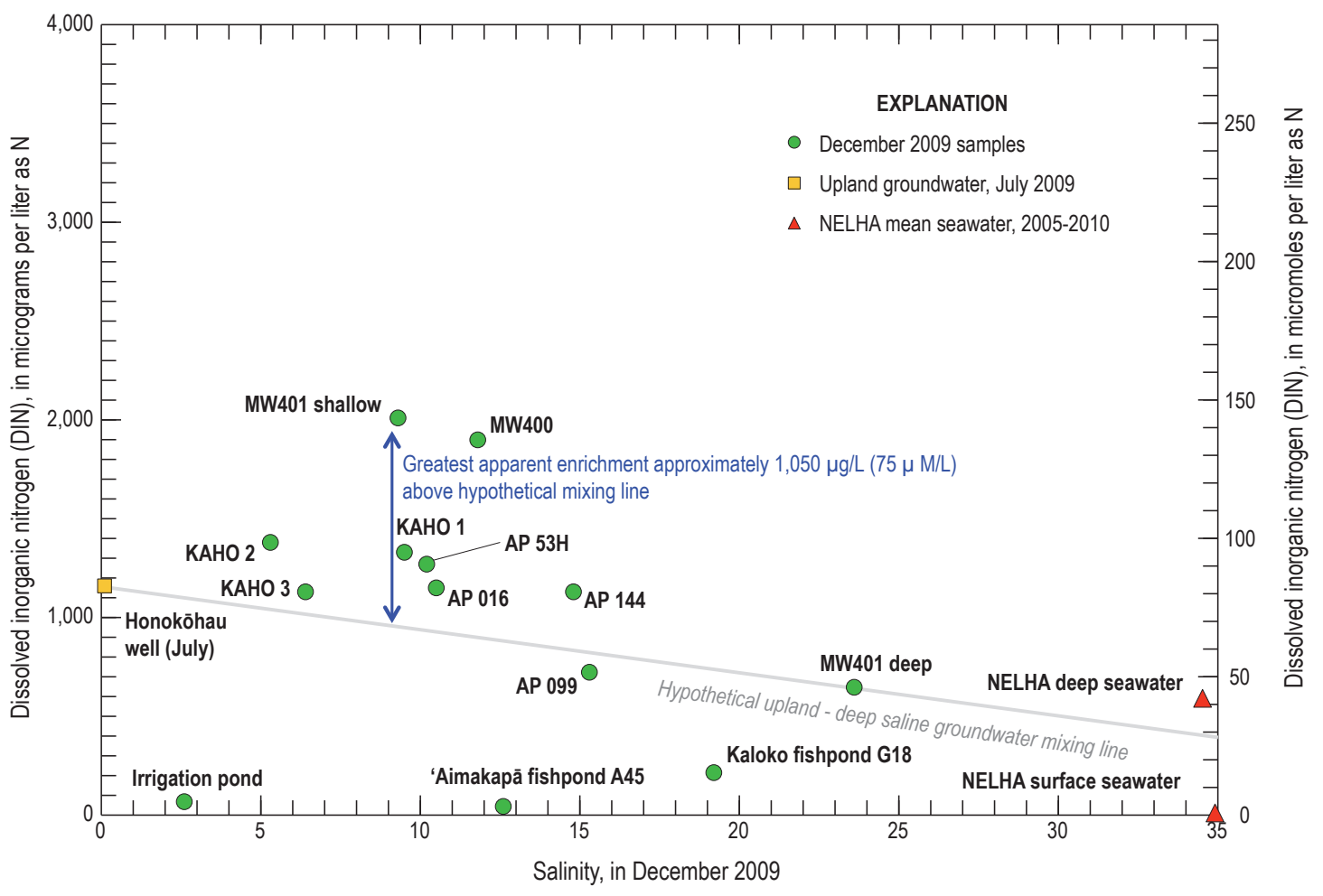

Figure 22. Graph showing dissolved inorganic nitrogen (DIN) versus salinity for December 2009 water samples at Kaloko-Honokōhau National Historical Park, Island of Hawai'i. DIN concentration at MW401 shallow dropped by nearly half (45 percent) from July. NELHA, Natural Energy Laboratory of Hawai'i Authority. 
Some water samples showed DIN depletion from the mixing line; these include 'Aimakapā Fishpond in July (fig. 21) and both 'Aimakapā and Kaloko Fishponds in December (fig. 22). Possible mechanisms for depletion of DIN in the fishponds include biotic uptake (assimilation) by phytoplankton and aquatic plants, and sequestration and denitrification in muddy bottom sediments. Simple dilution of DIN could also result from incursion of low-nutrient surface seawater, but only in Kaloko Fishpond through the opening in its seaward rock wall. Kohanaiki irrigation pond had very low DIN concentrations in both July and December. This is an expected result because this water has been produced by reverse-osmosis (RO) desalination, which removes most dissolved constituents including nitrogen and phosphorus.

Changes in DIN concentration from July to December for sites sampled both times are shown in figure 23. The greatest changes in groundwater samples were at MW401, where DIN was much higher in July and declined sharply by December; and at MW400, where DIN was much lower in July and increased sharply by December. Lesser changes were observed at anchialine pool AP 144 (DIN higher in July) and monitoring well KAHO 1 (DIN higher in December). In the 'Aimakapā and Kaloko Fishponds, respectively, DIN concentrations declined from 617 and $809 \mu \mathrm{g} / \mathrm{L}$ in July to 44 and $215 \mu \mathrm{g} / \mathrm{L}$ in December.

For comparison purposes, nitrogen concentration in the water sample from the upland Honokōhau well $(1,160 \mu \mathrm{g} / \mathrm{L})$ was essentially identical to that in a sample from an upland well $(1,170 \mu \mathrm{g} / \mathrm{L})$ in the similarly dry Kîhei area of Maui (Hunt, 2007). Nitrogen concentrations were much less in the Park than in intensively agricultural areas such as Lahaina, Maui (Soicher and Peterson, 1997) or central Oahu (Hunt, 2004), where nitrate concentrations (ranging from 2,000$5,000 \mu \mathrm{g} / \mathrm{L}$ ) have historically been 2 to 4 times greater than at $\mathrm{KAHO}$ as a result of agricultural fertilizer use.

\section{Phosphorus}

Phosphorus concentrations (orthophosphate $\mathrm{PO}_{4}$, as $\mathrm{P}$ ) are plotted against salinity in figures 24 and 25 for July and December samples, respectively. Phosphorus concentrations were less than $180 \mu \mathrm{g} / \mathrm{L}$ and were about an order of magnitude lower than nitrogen concentrations. This is typical, and is largely because phosphorus has a strong tendency to sorb to soil and mineral surfaces and is therefore less likely to leach into groundwater than nitrogen. As was done for DIN, samples are interpreted by their distance above or below the mixing line (enriched or depleted in comparison to the upland-deep saline groundwater mixing line), and enrichments are expressed in concentration units or as a percentage of the mixing-line concentration, which is considered the background concentration in mixtures of the fresh and saline end-member waters.

The greatest apparent phosphorus enrichments were at monitoring wells KAHO 2 in July and KAHO 1 in December. The July $\mathrm{PO}_{4}$ concentration at KAHO 2 was $177 \mu \mathrm{g} / \mathrm{L}$, an enrichment of $55 \mu \mathrm{g} / \mathrm{L}$ or 45 percent above the mixing-line concentration of $122 \mu \mathrm{g} / \mathrm{L}$. The December $\mathrm{PO}_{4}$ concentration at KAHO 1 was $171 \mu \mathrm{g} / \mathrm{L}$, an enrichment of $62 \mu \mathrm{g} / \mathrm{L}$ or 57 percent above the mixing-line concentration of $109 \mu \mathrm{g} / \mathrm{L}$. Other notable but slightly lesser enrichments were at monitoring well KAHO 3 and anchialine pools AP 53H and AP 016. All of these sites are downslope from or near Kaloko Light Industrial Park (fig. 3), particularly KAHO 2, and their elevated phosphorus concentrations may reflect some fraction of septic leachate in the water samples.

Also notable in figures 24 and 25 is that plots of $\mathrm{PO}_{4}$ concentrations for MW400, MW401, and AP 144 lie near the mixing line and show no more than slight enrichment in contrast to the high DIN enrichments from fertilizer at those sites (figs. 21, 22). Nitrogen in fertilizer is readily leached to groundwater, but phosphorus is not because it tends to sorb to soil where the fertilizer is applied. Although true, this may not be the entire reason that phosphorus was not elevated to nearly the same degree as nitrogen at these sites. Another factor is that many fertilizers are richer in nitrogen than phosphorus, and landscaping specialists may have tailored fertilizer proportions to be much more heavily weighted toward nitrogen over phosphorus for the purpose of establishing the golf-course vegetation.

Changes in $\mathrm{PO}_{4}$ from July to December at sites sampled both times are shown in figure 26. Sites with substantially higher $\mathrm{PO}_{4}$ concentrations in December were KAHO 1 and MW400. December salinity was lower in these samples than in July, and by accounting for translation along the mixing trend in figures 24 and 25 , it is estimated that the lower salinity can account for the entire $20 \mu \mathrm{g} / \mathrm{L}$ increase in $\mathrm{PO}_{4}$ at MW400 from July to December, but only about $10 \mu \mathrm{g} / \mathrm{L}$ of the $34 \mu \mathrm{g} / \mathrm{L}$ increase in $\mathrm{PO}_{4}$ at KAHO 1, with the remainder presumably representing a real addition of phosphorus over July.

Kaloko and 'Aimakapā Fishponds had substantially higher $\mathrm{PO}_{4}$ concentrations in July than in December (fig. 26), but this is more a function of their December concentrations apparently being depleted: their $\mathrm{PO}_{4}$ concentrations plot on or near the mixing line in figure 24 but well below the mixing line in figure 25. The low December $\mathrm{PO}_{4}$ concentrations corresponded with similarly low DIN concentrations in December (fig. 23), suggesting depletion mechanisms at work for both nutrients, the most likely being biotic uptake of $\mathrm{N}$ and $\mathrm{P}$ by phytoplankton and denitrification of nitrate in pond-bottom muds.

\section{Nutrient Implications of the Cold Saline Groundwater}

Saline groundwater beneath the brackish groundwater lens at KAHO is both colder and much higher in nutrients than surface seawater in the upper mixed layer of the ocean around Hawai'i. The single deep groundwater sample from monitoring well MW401 had a temperature of $18^{\circ} \mathrm{C}$, and projection of the mixing line plotted on figure 15 to the right axis (salinity $=35$ ) 


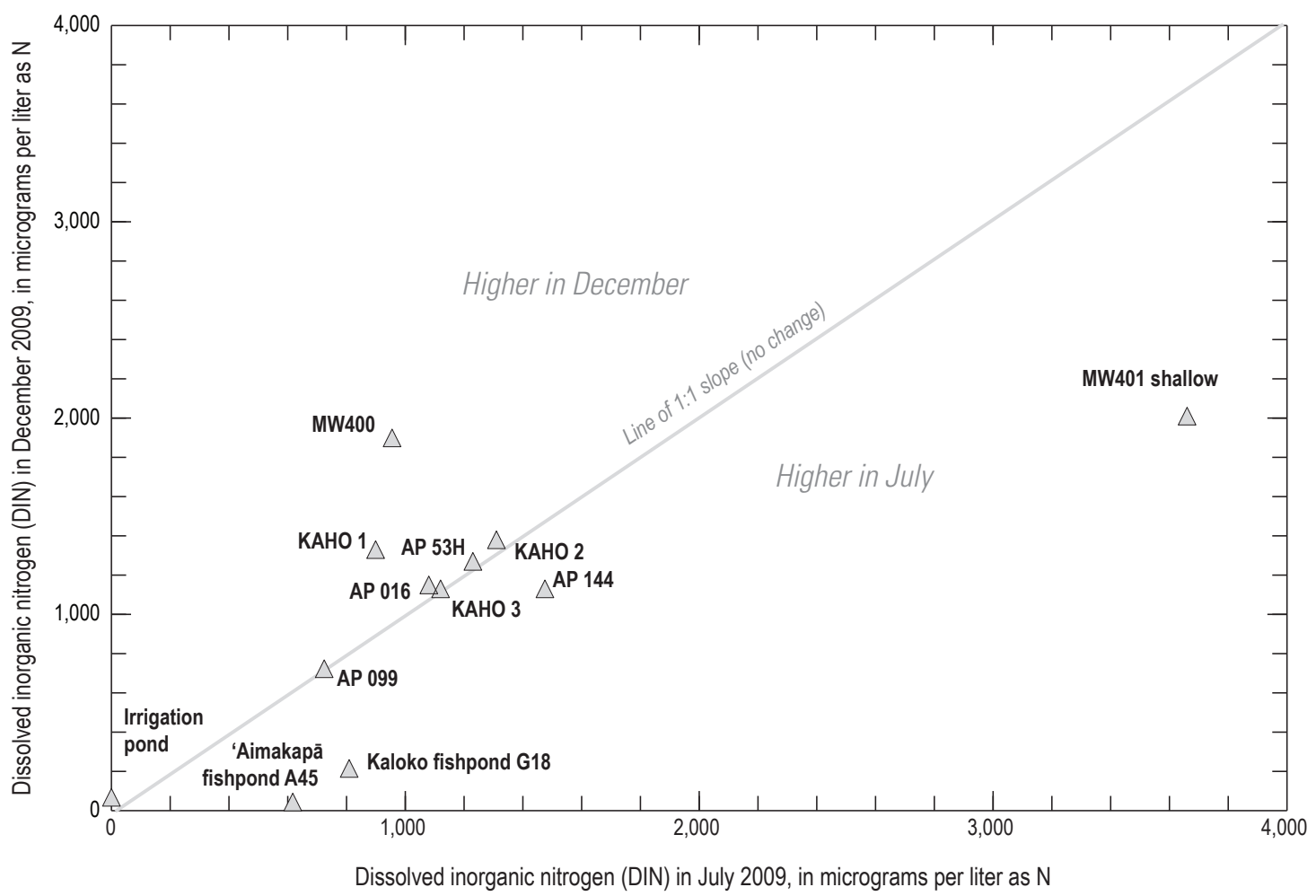

Figure 23. Graph showing change in dissolved inorganic nitrogen (DIN) from July to December 2009 at Kaloko-Honokōhau National Historical Park, Island of Hawai'i. Changes at MW401 and MW400 were associated with fertilizer; changes at Kaloko and 'Aimakapā Fishponds likely reflect greater nitrogen uptake by phytoplankton in December.

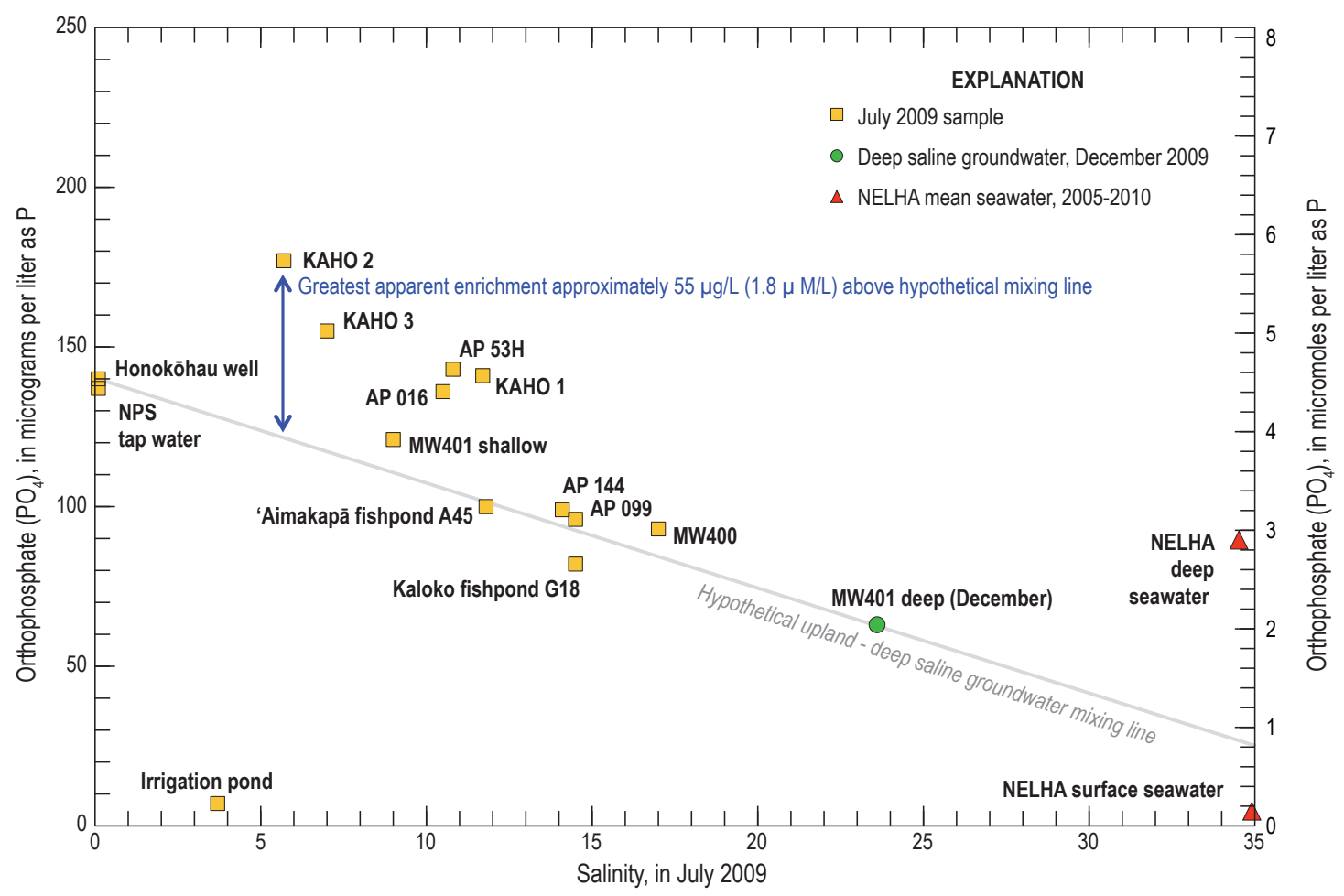

Figure 24. Graph showing orthophosphate versus salinity for July 2009 water samples at Kaloko-Honokōhau National Historical Park, Island of Hawai'i. Sites showing greatest enrichment (KAHO 1, KAHO 2, KAHO 3, AP 016, AP 53H) lie near and downslope from Kaloko Light Industrial Park and the KAHO visitor center. NELHA, Natural Energy Laboratory of Hawai'i Authority. 


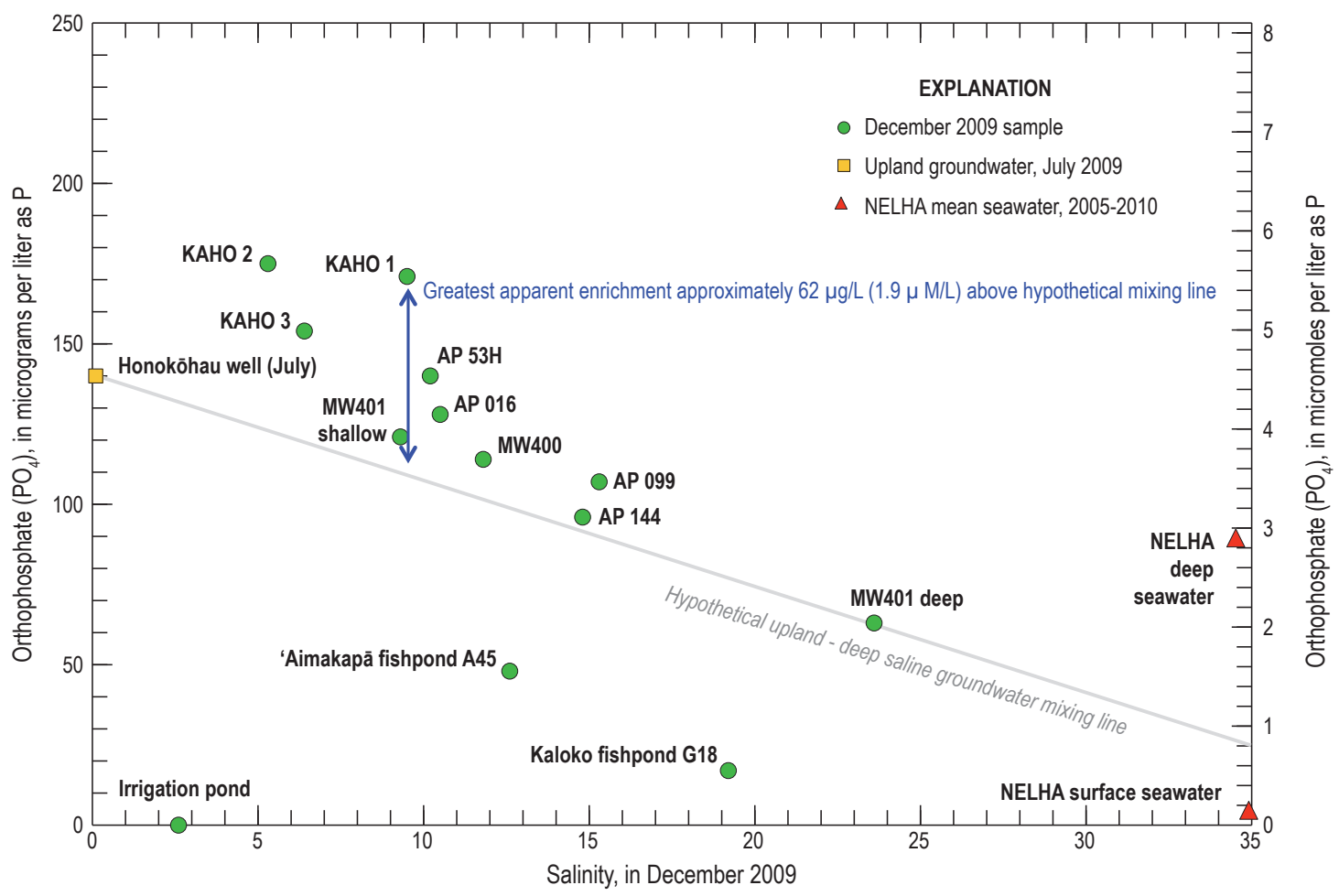

Figure 25. Graph showing orthophosphate versus salinity for December 2009 water samples at Kaloko-Honokōhau National Historical Park, Island of Hawai'i. Sites showing greatest enrichment (KAHO 1, KAHO 2, KAHO 3, AP 016, AP 53H) lie near and downslope from Kaloko Light Industrial Park and the KAHO visitor center. NELHA, Natural Energy Laboratory of Hawai'i Authority.

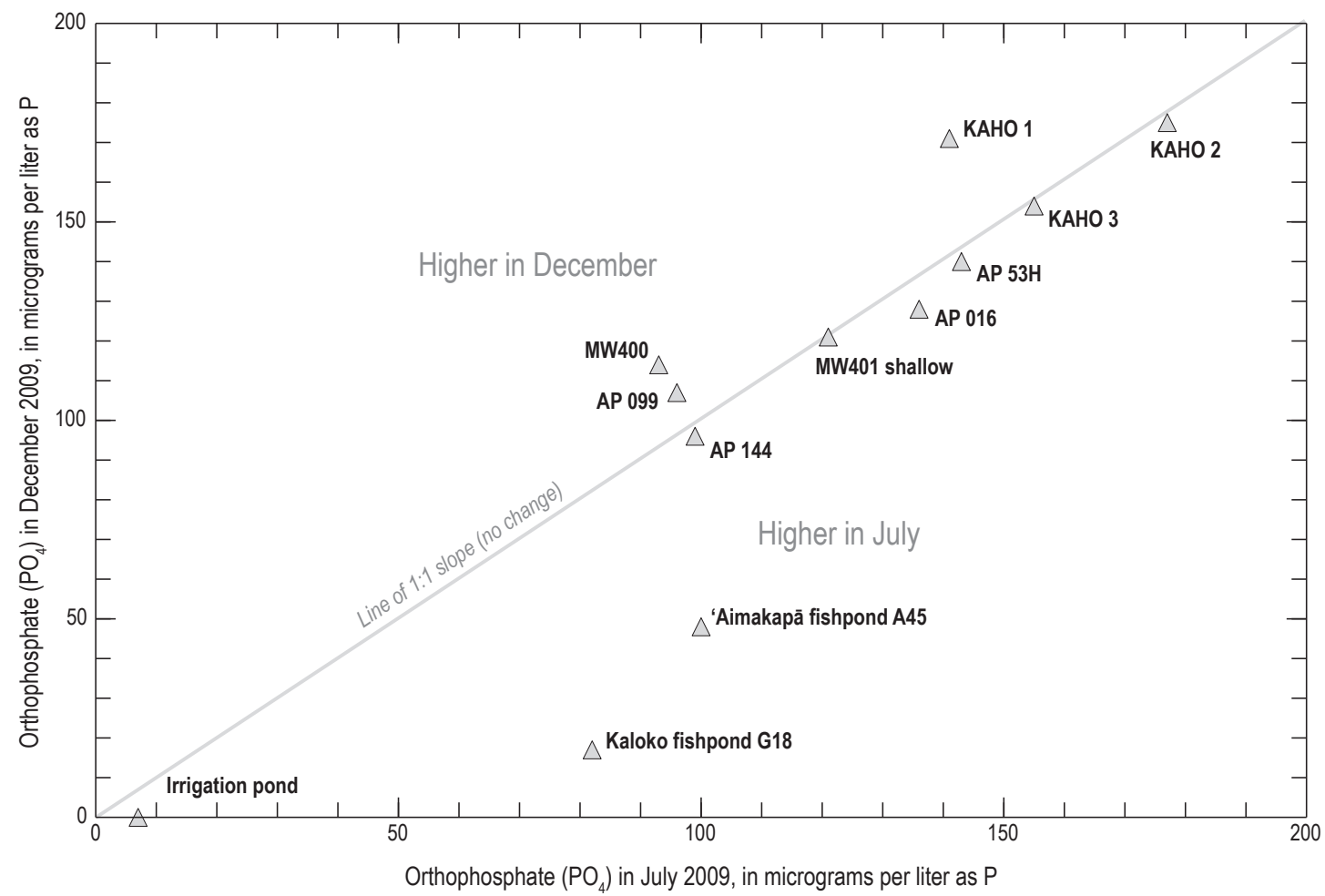

Figure 26. Graph showing change in orthophosphate from July to December 2009 at KalokoHonokōhau National Historical Park, Island of Hawai'i. Concentrations in Kaloko and 'Aimakapā Fishponds were higher in July; lower December concentrations may reflect greater phosphorus uptake by phytoplankton. 
yields an estimate of $16^{\circ} \mathrm{C}$ for fully saline groundwater. Temperatures this cold require that the saline groundwater contain a large fraction of cold subthermocline seawater, which is known to be much higher in nutrients than surface seawater. Average nutrient concentrations for NELHA surface seawater are $12 \mu \mathrm{g} / \mathrm{L} \mathrm{DIN} \mathrm{and} 4.2 \mu \mathrm{g} / \mathrm{L} \mathrm{PO}_{4}$ whereas corresponding averages for NELHA deep seawater are $590 \mu \mathrm{g} / \mathrm{L}$ DIN and $91 \mu \mathrm{g} / \mathrm{L} \mathrm{PO}_{4}$ (means of 56 measurements from 2005-10; Olson, 2010). The lower values illustrate the "nutrient-poor" character of surface seawater in the upper mixed layer of the ocean around Hawaiii, where nutrients are assimilated by phytoplankton (Bienfang and Szyper, 1981). In contrast, the higher values for NELHA deep seawater illustrate that subthermocline seawater is much more enriched in nutrients than surface seawater.

For nitrogen, extension of the mixing line in figure 21 to the right axis (salinity $=35$ ) results in a y-intercept of about $400 \mu \mathrm{g} / \mathrm{L}$ DIN, less than the DIN in NELHA deep seawater $(590 \mu \mathrm{g} / \mathrm{L})$ but 33 times greater than the DIN in NELHA surface seawater $(12 \mu \mathrm{g} / \mathrm{L})$. Similarly for phosphorus, extension of the mixing line in figure 24 results in a y-intercept of about $25 \mu \mathrm{g} / \mathrm{L} \mathrm{PO}_{4}$, roughly one-quarter of the $\mathrm{PO}_{4}$ in NELHA deep seawater $(91 \mu \mathrm{g} / \mathrm{L})$ but still 6 times the $\mathrm{PO}_{4}$ in NELHA surface seawater $(4.2 \mu \mathrm{g} / \mathrm{L})$.

These comparisons illustrate that ecologic interpretations in the brackish-water environment at KAHO (and similar areas are where cold saline groundwater exists) require awareness of the higher nutrient content of the colder seawater. This runs counter to general experience with shallow freshwatersaltwater mixing environments in Hawai'i, where one can usually assume nutrient-poor surface seawater as a saltwater end-member having nutrient concentrations that are nearly negligible in comparison to much higher concentrations in terrestrial fresh groundwater. Additional sampling to better characterize the cold saline groundwater is warranted, for example, by testing groundwater samples from other deep wells on the Kona coast and from deeper in monitoring well MW401 than was able to be sampled.

\section{Stable Isotopes of Nitrate for Nitrate Source Identification}

Nitrate stable isotopes (tables 3, 4) did not compellingly implicate septic nitrogen in KAHO groundwater in the expected way: by water samples having nitrate $\delta^{15} \mathrm{~N}$ values on the order of +10 per mil or more that would exceed the range for natural soil nitrogen (fig. 9) and be more strongly diagnostic of waste nitrogen. In fact, the heaviest $\delta^{15} \mathrm{~N}$ values of about 6.6, 7.7, and 6.4 per mil were in Kaloko Fishpond, 'Aimakapā Fishpond, and Kohanaiki irrigation pond, respectively (table 4), where they corresponded with low nitrate concentrations. This pairing of low nitrate concentration and heavy nitrate isotopic composition is likely to have resulted from nitrate removal by biochemical cycling such as biotic uptake and denitrification. Most remaining water samples had nitrate $\delta^{15} \mathrm{~N}$ values from
+3 to +5 per mil, heavier than the value of +2 per mil in the upland Honokōhau well, but still plotting in an area on figure 9 where natural soil nitrogen and waste nitrogen fields overlap and the two nitrogen sources cannot be distinguished.

Prior studies of septic-system and municipal wastewaters provide points of comparison for judging possible wastewater presence in KAHO water samples (table 6). Aravena and others (1993) sampled leachate from a single household septic system and found $\delta^{15} \mathrm{~N}=+10$ per mil and a nitrogen concentration of $30,000 \mu \mathrm{g} / \mathrm{L}$ as N. Municipal wastewater treatment plants tend to drive the already heavy isotopic composition of raw sewage even heavier by microbial action during treatment, especially if the plant incorporates advanced nitrogen removal using anoxic, denitrifying lagoons. If these treated effluents are disposed by injection wells, further denitrification tends to take place in the aquifer, driving isotopic compositions heavier still and making nitrogen isotopes very good tracers of municipal wastewater in the environment. Three examples from Hawai' $i$ wastewater treatment plants bear this out (table 6): Kealakehe, Kona $\left(\delta^{15} \mathrm{~N}=+12\right.$ per mil in treated wastewater, +20 per mil in the aquifer); Kīhei, Maui $\left(\delta^{15} \mathrm{~N}=+15\right.$ per mil in treated wastewater, +23 per mil in the aquifer); and Lahaina, Maui $\left(\delta^{15} \mathrm{~N}=+23\right.$ per mil in treated wastewater, +40 per mil in the aquifer). In contrast, groundwater from wells uphill of the wastewater injection plumes had lighter $\delta^{15} \mathrm{~N}$ values, ranging from +1 to +5 per mil that lie within the range for natural soil nitrogen (fig. 9).

Nitrate stable isotope compositions are shown graphically in figure 27 for July 2009 water samples at KAHO. Samples plotting up or to the right of other samples may reflect addition of isotopically heavier nitrate or may reflect evolution to heavier isotopic values through processes that deplete nitrate, like denitrification and biotic uptake. The isotopically lightest samples were NPS office tap water and the Honokōhau well, the upland background end member with $\delta^{15} \mathrm{~N}=+2$ per mil and $\delta^{18} \mathrm{O}=+0.4$ per mil. Most other samples cluster in the bottom half of the graph with $\delta^{15} \mathrm{~N}$ ranging between +3 and +5 per mil and $\delta^{18} \mathrm{O}$ ranging between 0 and +4 per mil. The slightly heavier isotopic compositions of these samples in comparison to the Honokōhau well sample may reflect addition of isotopically heavier nitrate as groundwater flowed from the uplands to these locations. This is plausible because many of these samples plot above the upland-deep saline groundwater mixing line in figure 21, indicating some addition of nitrogen over and above the DIN concentration in freshwater from the Honokōhau well. The sample with the heaviest $\delta^{15} \mathrm{~N}$ in July was 'Aimakapā Fishpond with $\delta^{15} \mathrm{~N}=+6.16$ per mil.

Also shown in figure 27 are two sets of parallel lines, with slope 1:2 (gray) representing possible denitrification trends and slope 1:1 (blue) representing possible uptake or assimilation of nitrate by phytoplankton. Samples plotting along trend up and to the right of another sample could conceivably have evolved from the other sample's composition by denitrification or biotic uptake, but only if (1) the map location of the samples makes one water a plausible parent for the other; (2) nitrate concentration is lower in the evolved sample 
Table 6. Nitrate stable-isotope compositions of wastewater sources for comparison to results of this study.

[TDN, total dissolved nitrogen, including both organic and inorganic forms; DIN, dissolved inorganic nitrogen; TDP, total dissolved phosphorus, including both organic and inorganic forms; $\mathrm{PO}_{4}$, orthophosphate, the predominant form of dissolved inorganic phosphorus; per mil, parts per thousand; $\mu \mathrm{g} / \mathrm{L}$, micrograms per liter; -, not applicable]

\begin{tabular}{|c|c|c|c|c|c|}
\hline $\begin{array}{l}\text { Location and type of water } \\
\text { sample }\end{array}$ & $\begin{array}{c}\delta^{15} \mathrm{~N} \text { of } \\
\text { nitrate } \\
\text { (per mil) }\end{array}$ & $\begin{array}{c}\delta^{18} \mathrm{O} \text { of } \\
\text { nitrate } \\
\text { (per mil) }\end{array}$ & $\begin{array}{l}\text { TDNa or } \\
\text { DIN }^{b} \\
(\mu \mathrm{g} / \mathrm{L})\end{array}$ & $\begin{array}{c}\text { TDPa }^{a} \text { or } \\
\mathrm{PO}_{4}^{\mathrm{b}} \\
(\mu \mathrm{g} / \mathrm{L})\end{array}$ & Remarks \\
\hline Household septic system effluent $^{1}$ & 10 & 3.4 & $30,000^{\mathrm{b}}$ & - & - \\
\hline Honokōhau upland background well ${ }^{2}$ & 2 & 0 & $1,160^{\mathrm{b}}$ & $140^{\mathrm{b}}$ & Uplands are mostly forest and grassland \\
\hline Kealakehe, treated wastewater ${ }^{3}$ & 12 & 0 & $3,750^{\mathrm{a}}$ & $5,080^{\mathrm{a}}$ & Secondary-treated wastewater \\
\hline Kealakehe, well in wastewater plume ${ }^{3}$ & 20 & 4 & $1,490^{\mathrm{a}}$ & $3,100^{\mathrm{a}}$ & Monitoring well \\
\hline Kīhei, upland background well ${ }^{4}$ & 5 & 1 & $1,170^{\mathrm{a}}$ & $67^{\mathrm{a}}$ & $\begin{array}{l}\text { Uplands are mostly scrub forest with some } \\
\text { ranch pasture }\end{array}$ \\
\hline Kīhei, treated wastewater ${ }^{4}$ & 15 & 8 & $7,330^{\mathrm{a}}$ & $1,720^{\mathrm{a}}$ & Tertiary-treated wastewater \\
\hline Kīhei, well in wastewater plume ${ }^{4}$ & 23 & 11 & $3,490^{\mathrm{a}}$ & $191^{\mathrm{a}}$ & Household irrigation well \\
\hline Lahaina, upland background well ${ }^{5}$ & 1 & 3 & $3,560^{\mathrm{b}}$ & $240^{\mathrm{b}}$ & High DIN from former sugarcane cultivation \\
\hline Lahaina, treated wastewater ${ }^{5}$ & 23 & 8 & $6,120^{\mathrm{a}}$ & $189^{\mathrm{a}}$ & Tertiary-treated wastewater \\
\hline Lahaina, spring in wastewater plume ${ }^{5}$ & 40 & 19 & $870^{\mathrm{b}}$ & $130^{\mathrm{b}}$ & Coastal submarine spring \\
\hline
\end{tabular}

${ }^{1}$ Aravena and others (1993), Cambridge, Ontario, Canada.

${ }^{2}$ Honokōhau well, Kona, island of Hawai'i, present (2009) study.

${ }^{3}$ Hunt (2008), Kealakehe, Kona, island of Hawai'i.

${ }^{4}$ Hunt (2007), Kīhei, island of Maui, Hawai'i

${ }^{5}$ Hunt and Rosa (2009), Lahaina, island of Maui, Hawai`i.

than in the parent water; and (3) nitrate concentration in the evolved sample is commensurately lower. "Commensurately" means that the observed reduction in nitrate concentration is proportionate with the observed amount of isotopic enrichment toward the heavier isotopes, as governed by Rayleigh equations with accepted enrichment factors from the scientific literature (for example, Kendall and McDonnell, 1998). An in-depth analysis using Rayleigh calculations is beyond the scope of this project and would be best carried out by an isotope specialist. A few trial calculations for presumed pairs of parent-daughter waters yielded enrichment factors outside the range of published values. Furthermore, several processes may have been active and cannot readily be distinguished by simple calculations that assume a single process. Therefore, only conditions (1) and (2) will be noted from here on.

An example of a possible denitrified sample is 'Aimakapā Fishpond in July, which plots roughly along a denitrification trend from KAHO 1 in figure 27. Groundwater at KAHO 1 is a plausible parent water because KAHO 1 lies just uphill from 'Aimakapā Fishpond (fig. 3) and groundwater in that vicinity is expected to discharge to the pond. DIN is lower in 'Aimakapā Fishpond than in KAHO 1 and by some cause other than dilution, because the "Aimakapā Fishpond sample does not lie along the upland-deep saline groundwater mixing line in figure 21 for the July samples. Instead, the 'Aimakapā sample has nearly the same salinity as KAHO 1, but has less nitrate and plots below the mixing line.

The sample with heaviest $\delta^{18} \mathrm{O}$ in nitrate was monitoring well MW401, plotted near the top of figure 27 with $\delta^{18} \mathrm{O}$ $=+5.50$ per mil. Recall from the nitrate source classification in figure 9 that nitrate fertilizer has heavier $\delta^{18} \mathrm{O}$ than most other nitrate sources, and that MW401 had a high concentration of likely fertilizer-derived nitrogen in July (fig. 21). Also lying in the direction of MW401 on figure 27 are the AP 144 and Kaloko Fishpond G18 samples, suggesting that they also contain some fraction of fertilizer nitrate. This is plausible because they are close to and downgradient from MW401. It is unknown why the $\delta^{18} \mathrm{O}$ value of +5.50 per mil at MW401 is not closer to the value of +20 per mil in figure 9 , although several possible reasons can be proposed. Foremost is that roughly one third of the nitrate in the MW401 sample is likely to be upland background nitrate, expected in all groundwater samples and having a $\delta^{18} \mathrm{O}$ composition close to zero, judging by the near-zero $\delta^{18} \mathrm{O}$ value at the Honokōhau well. Secondly, it's possible that not all the fertilizer applied was nitrate mineral fertilizer. Manure or urea fertilizers may also have been applied and contributed to a $\delta^{18} \mathrm{O}$ composition lighter than +20 per mil.

Interpretation is aided further by plotting nitrate concentration against $\delta^{15} \mathrm{~N}$ of nitrate for July samples in figure 28 . 


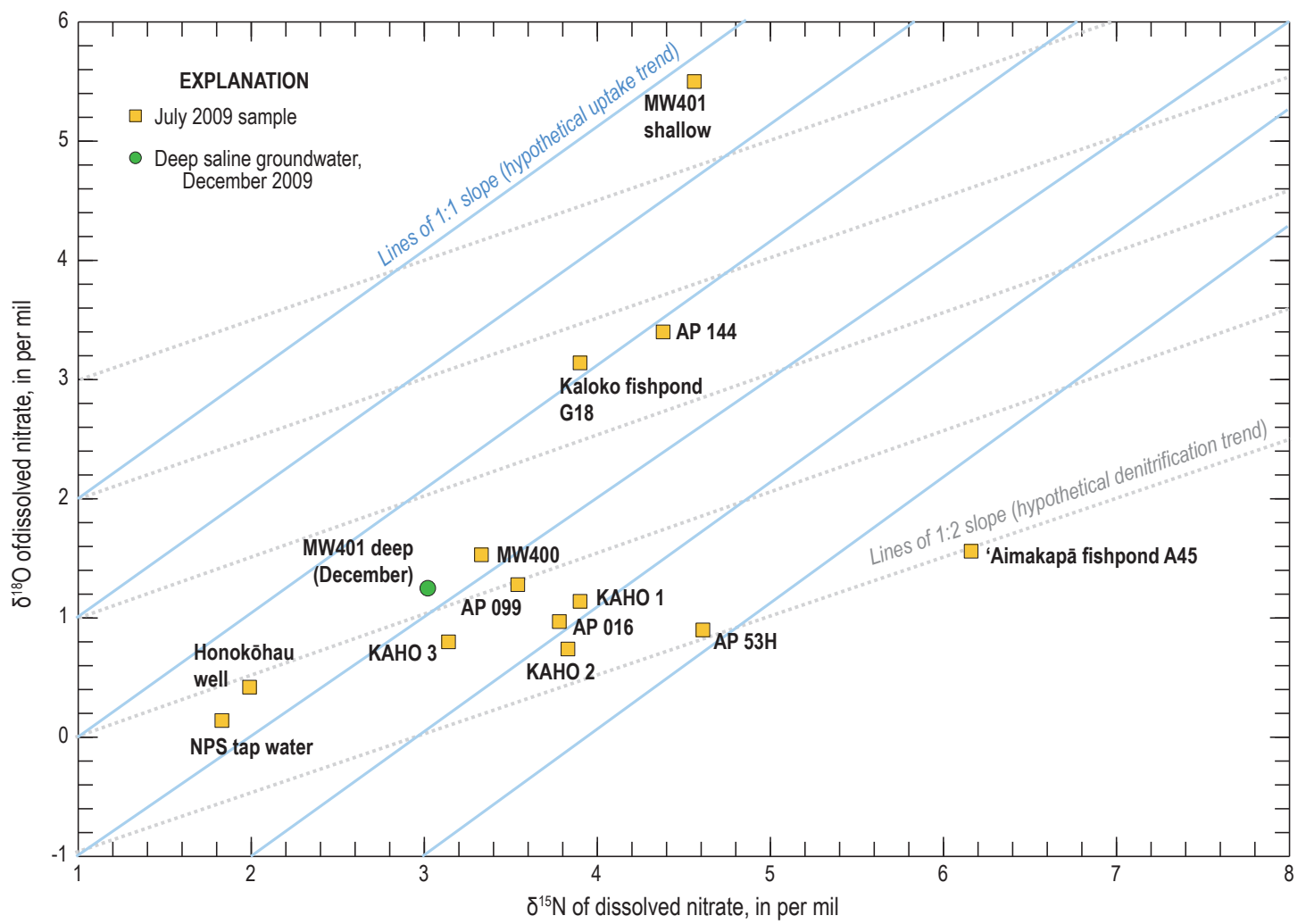

Figure 27. Graph showing $\delta^{18} \mathrm{O}$ versus $\delta^{15} \mathrm{~N}$ of nitrate for July 2009 water samples at KalokoHonokōhau National Historical Park, Island of Hawai'i. Samples plotting up or to the right of other samples may reflect addition of isotopically heavier nitrate, or may reflect denitrification or biotic uptake from other samples if they plot roughly in the direction of the parallel lines and if their nitrate concentration is commensurately less than proposed parent waters (see text).

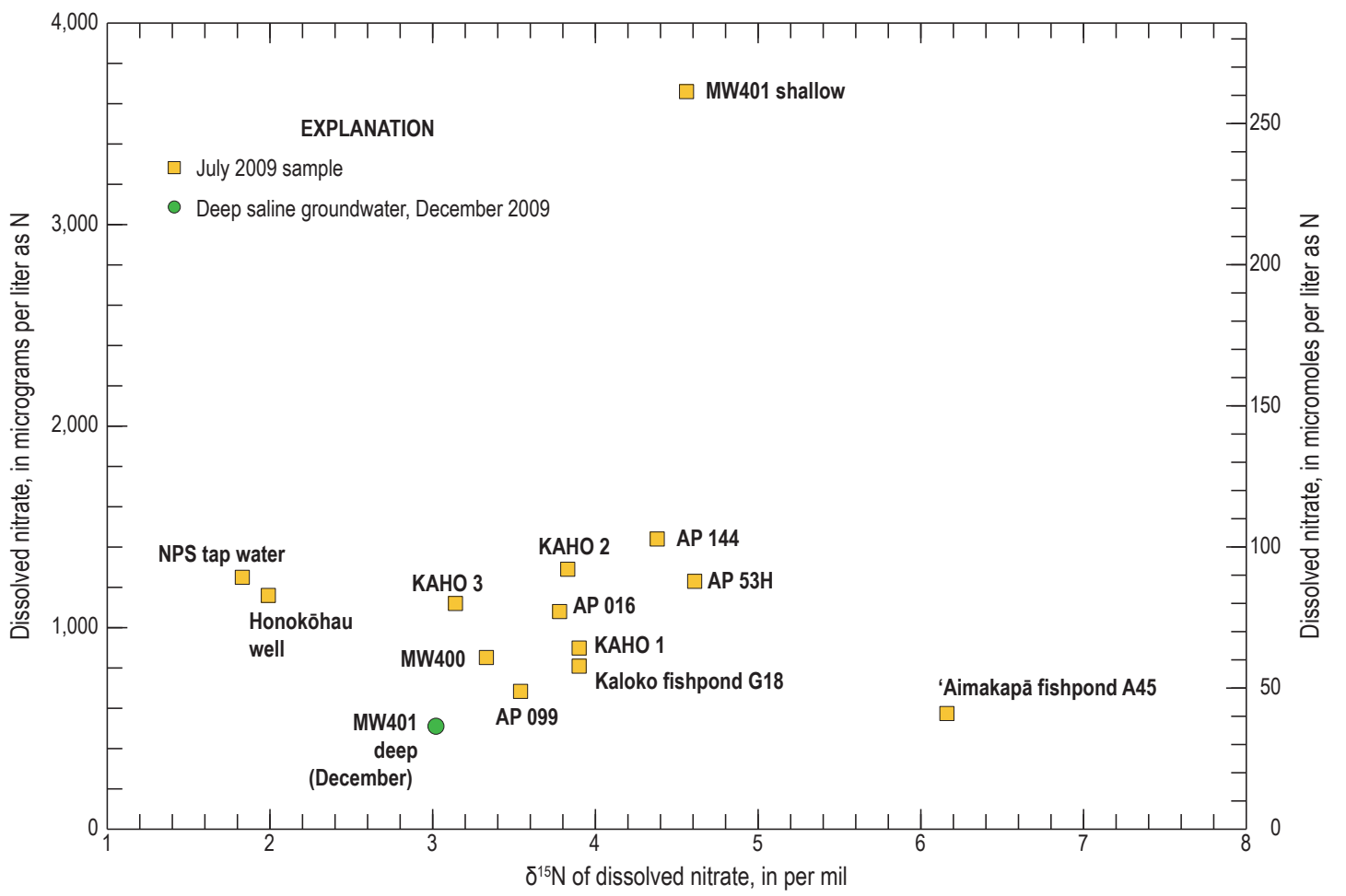

Figure 28. Graph showing nitrate versus $\delta^{15} \mathrm{~N}$ of nitrate for July 2009 water samples at Kaloko-Honokōhau National Historical Park, Island of Hawai'i. The highest $\delta^{15} \mathrm{~N}$ value at 'Aimakapā Fishpond corresponds with a fairly low nitrate concentration, suggesting it evolved at least partly by denitrification rather than addition of isotopically heavier nitrogen. 
Here, one can see that the highest $\delta^{15} \mathrm{~N}$ value at 'Aimakapā Fishpond corresponds with a low nitrate concentration, supporting a hypothesis that the heavy $\delta^{15} \mathrm{~N}$ composition there has evolved at least partly by nitrate removal processes such as denitrification and biotic uptake. The fishponds are bottomed with mud in which decomposition of organic matter favors denitrification under suboxic, chemically reducing conditions.

The rest of the samples have $\delta^{15} \mathrm{~N}$ values less than 5 per mil, and none of the samples have high enough $\delta^{15} \mathrm{~N}$ values to implicate septic waste nitrate as distinguishable from soil nitrate. However this does not mean that some fraction of septic nitrate is not present. All other samples have heavier $\delta^{15} \mathrm{~N}$ values than the Honokōhau well, and although many samples appear to have comparable or lower nitrate than the Honokōhau well, this plot does not incorporate the salinity mixing line that is required to compare samples of different salinities. Where that was done (figs. 21, 22), recall that many samples were actually enriched in DIN relative to the uplandsaline groundwater mixing line, indicating addition of nitrogen over and above the concentration in background freshwater from the Honokōhau well. In order to both enrich samples in DIN as in figure 21 and to displace samples plotting to the right of the Honokōhau well as in figure 28, nitrogen that is isotopically heavier than that at the Honokōhau well would need to be added to upland background water.

December samples displayed roughly similar isotopic relations as in July, with a few exceptions (fig. 29). Kaloko and 'Aimakapā Fishpond samples have shifted to the far upper right of the plot, being heavier in both $\delta^{15} \mathrm{~N}$ and $\delta^{18} \mathrm{O}$ in December than in July. Also, the MW401 shallow sample has migrated from its former plotted location at the extreme top of the graph to a position within the cluster of samples having more intermediate compositions. Furthermore, plotting at upper right is Kohanaiki irrigation pond, sampled at the shore of the open pond. Kohanaiki pond did not appear on the July isotope plots because the July sample did not have enough nitrate for isotope analysis. The small amount of nitrate it did have in December appears to be governed by similar biochemical cycling as in the fishponds, judging from its similar plotting position. Phytoplankton and macroalgae were visible in the irrigation pond.

The most likely explanation for the December plotting positions of the fishpond samples in figure 29 is uptake of nitrate by phytoplankton, although denitrification may also play a role. Both fishpond samples lie roughly along uptake trends from plausible parent waters (KAHO 1 as a parent for 'Aimakapā Fishpond; MW400, MW401, and AP 144 as possible parents for Kaloko Fishpond), and fishpond nitrate concentrations are much lower than any of these waters (fig. 30, table 4). The more moderate plotting position of the MW401 shallow sample in figure 29 likely resulted from the decline in DIN concentration from 3,660 to $2,010 \mu \mathrm{g} / \mathrm{L}$ since July, so that in December its isotopic composition was more reflective of nitrate in natural groundwater and less reflective of the fertilizer nitrate that was prominent there in July.

These arguments are strengthened by figure 30 , which plots nitrate concentration against $\delta^{15} \mathrm{~N}$ of nitrate for
December. The heaviest $\delta^{15} \mathrm{~N}$ values at 'Aimakapā and Kaloko Fishponds clearly corresponded with low nitrate concentrations. Because the fishponds are largely supplied by groundwater having a composition like that of the nearby anchialine pools and monitoring wells, strong nitrogen removal processes such as biotic uptake and denitrification are necessary to have depleted the fishpond waters of nitrogen to the extent seen in figure 30. Kohanaiki irrigation water nitrate concentration was expected to be low because the water has undergone reverse osmosis desalination, which removes much of the nitrate as well as salts. The MW401 shallow sample plots close to MW400 in figure 30, reflecting both a December nitrate concentration and $\delta^{15} \mathrm{~N}$ composition at MW401 that probably are more in line with local groundwater and less affected by the July fertilizer contamination.

Change plots (figs. 31, 32) show that isotope compositions of nitrate were relatively stable at most monitoring wells and anchialine pools from July to December. The most conspicuous changes were in the two fishponds, where both $\delta^{15} \mathrm{~N}$ and $\delta^{18} \mathrm{O}$ were heavier in the December samples than in the July samples. There was a slightly different emphasis in isotope changes in each pond. Kaloko Fishpond showed the greater increase in $\delta^{15} \mathrm{~N}$ from July to December (fig. 31), whereas 'Aimakapā Fishpond showed the greater increase in $\delta^{18} \mathrm{O}$ (fig. 32). The plot for monitoring well MW401 also stands out at the far right of figure 32 , reflecting the much heavier $\delta^{18} \mathrm{O}$ composition of nitrate there in July as a result of fertilizer contamination.

In summary, nitrate stable isotopes showed systematic relations within the dataset, with strong evidence that isotopic compositions are modified by biochemical cycling in the fishponds. The heaviest $\delta^{15} \mathrm{~N}$ values corresponded to low nitrate concentrations in the fishponds and likely resulted from nitrogen removal by biotic uptake and denitrification. Heavy $\delta^{18} \mathrm{O}$ at MW401 in July is consistent with a fertilizer source of nitrate and the high July DIN concentration there.

Remaining samples had $\delta^{15} \mathrm{~N}$ values that lie within the range of natural soil nitrogen and do not compellingly implicate septic nitrogen solely by their magnitude. However, many of these samples were enriched in DIN and $\mathrm{PO}_{4}$ (plotting above their respective background mixing lines) and had $\delta^{15} \mathrm{~N}$ values of +3 to +5 per mil that were slightly heavier than the +2 per mil at the upland Honokōhau well. These facts may indicate that many of the samples contain some fraction of septic effluent.

Alternately, at least for nitrogen, the addition of isotopically heavier nitrate could originate from other sources lower on the volcano flank than the Honokohau well, possibly as a result of elevation gradients in rainfall and vegetation. In arid parts of Hawai'i such as at low elevations in the Kona area, nitrogen-fixing dryland scrub trees Prosopis pallida (kiawe or mesquite) and Leucaena leucocephala (koa haole or lead tree) are prolific and contribute nitrate to groundwater (Kay and others, 1977; Brock and others, 1987). Wheeler and others (2007) measured soil nitrogen $\delta^{15} \mathrm{~N}$ values of +5.4 to +6.4 per mil beneath Prosopis velutina stands in Arizona, notably heavier than the +2 per mil at the Honokōhau well. 


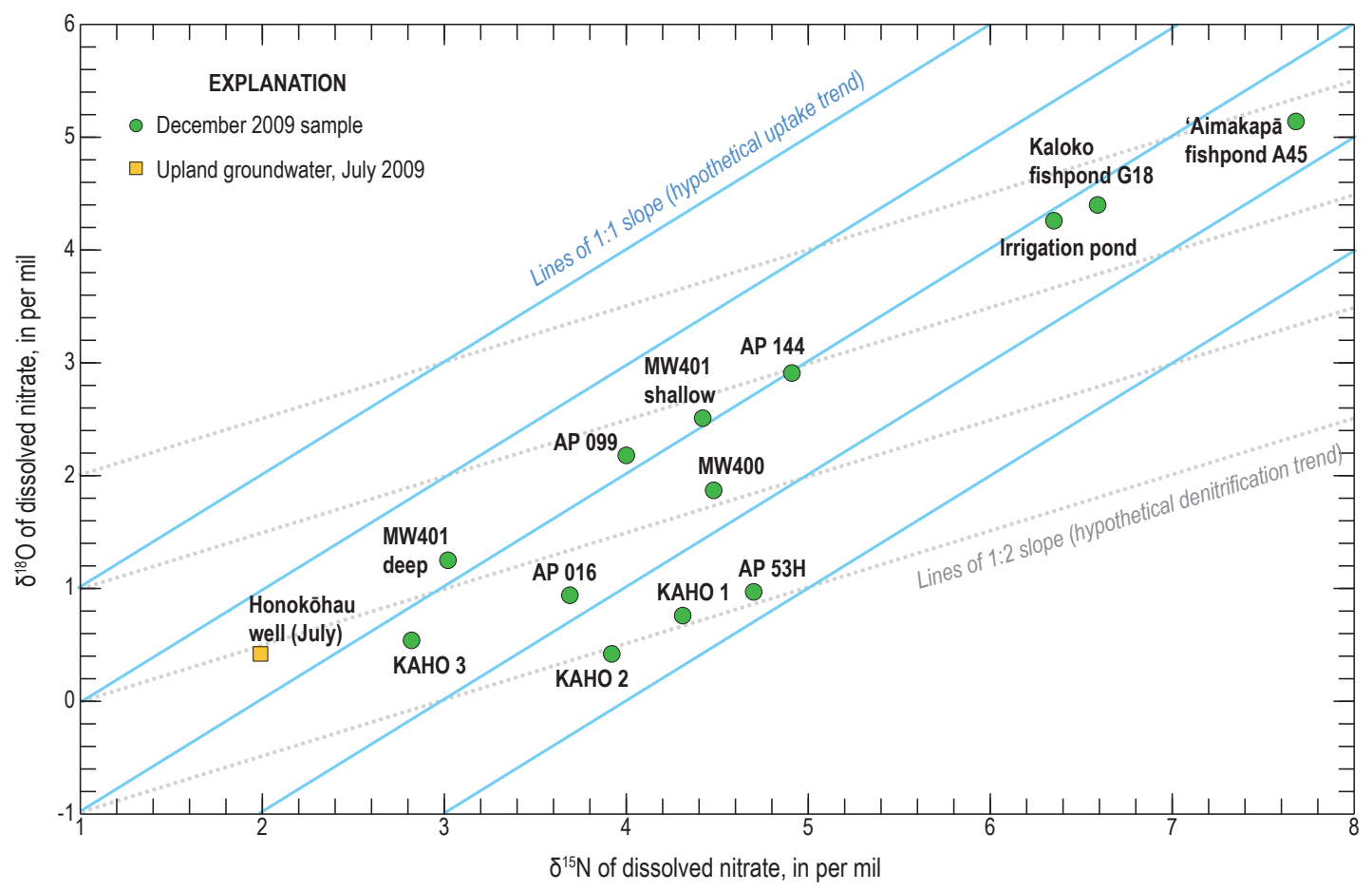

Figure 29. Graph showing $\delta^{18} \mathrm{O}$ versus $\delta^{15} \mathrm{~N}$ of nitrate for December 2009 water samples at Kaloko-Honokōhau National Historical Park, Island of Hawai'i. Kaloko and 'Aimakapā Fishponds plots have shifted far to the upper right from their July plotting positions, likely as a result of biotic uptake of nitrogen and denitrification.

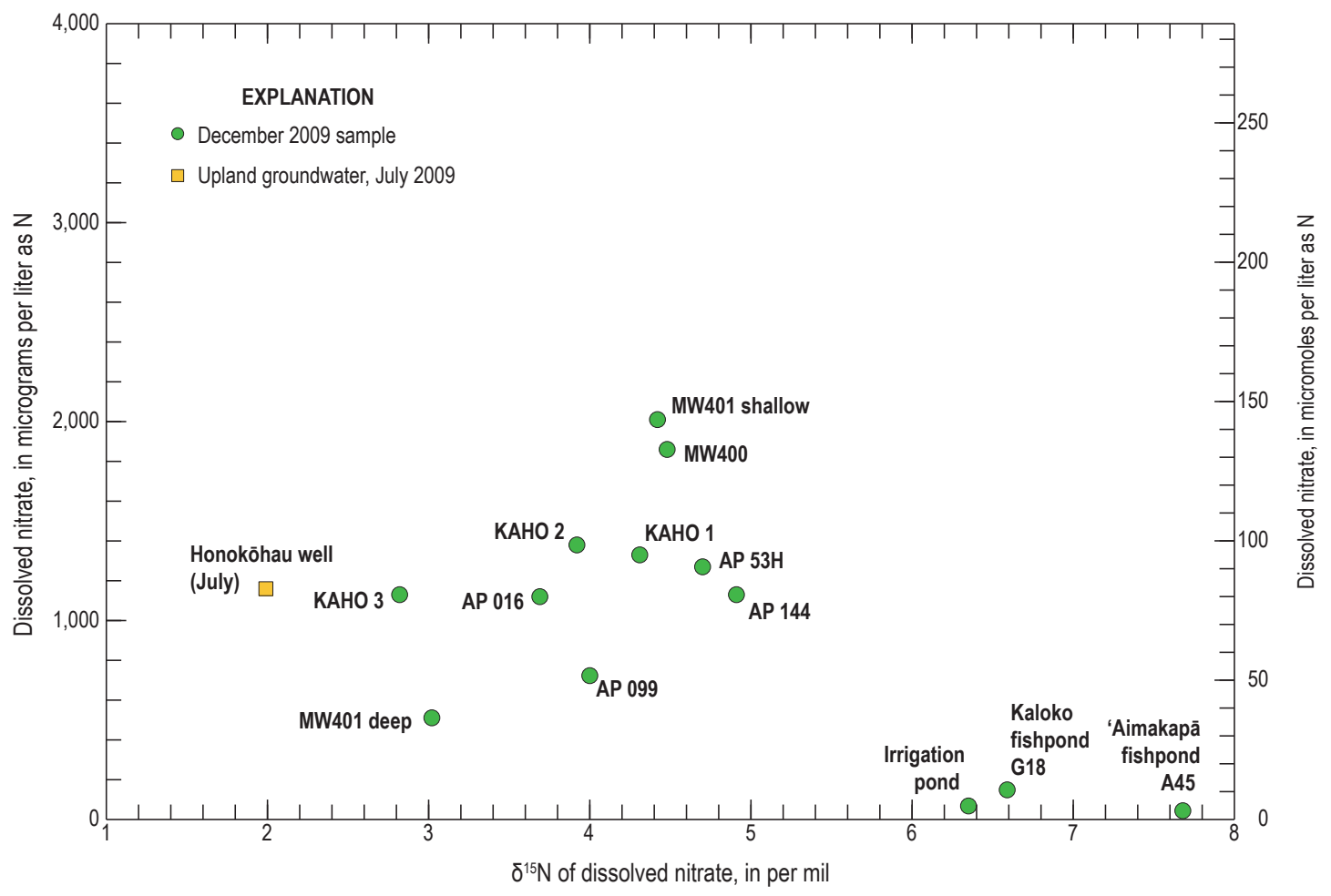

Figure 30. Graph showing nitrate versus $\delta^{15} \mathrm{~N}$ of nitrate for December 2009 water samples at Kaloko-Honokōhau National Historical Park, Island of Hawai'i. Heaviest $\delta^{15} \mathrm{~N}$ values in Kaloko and 'Aimakapā Fishponds correspond to low nitrate concentrations, suggesting they evolved by biotic uptake of nitrogen and denitrification. 


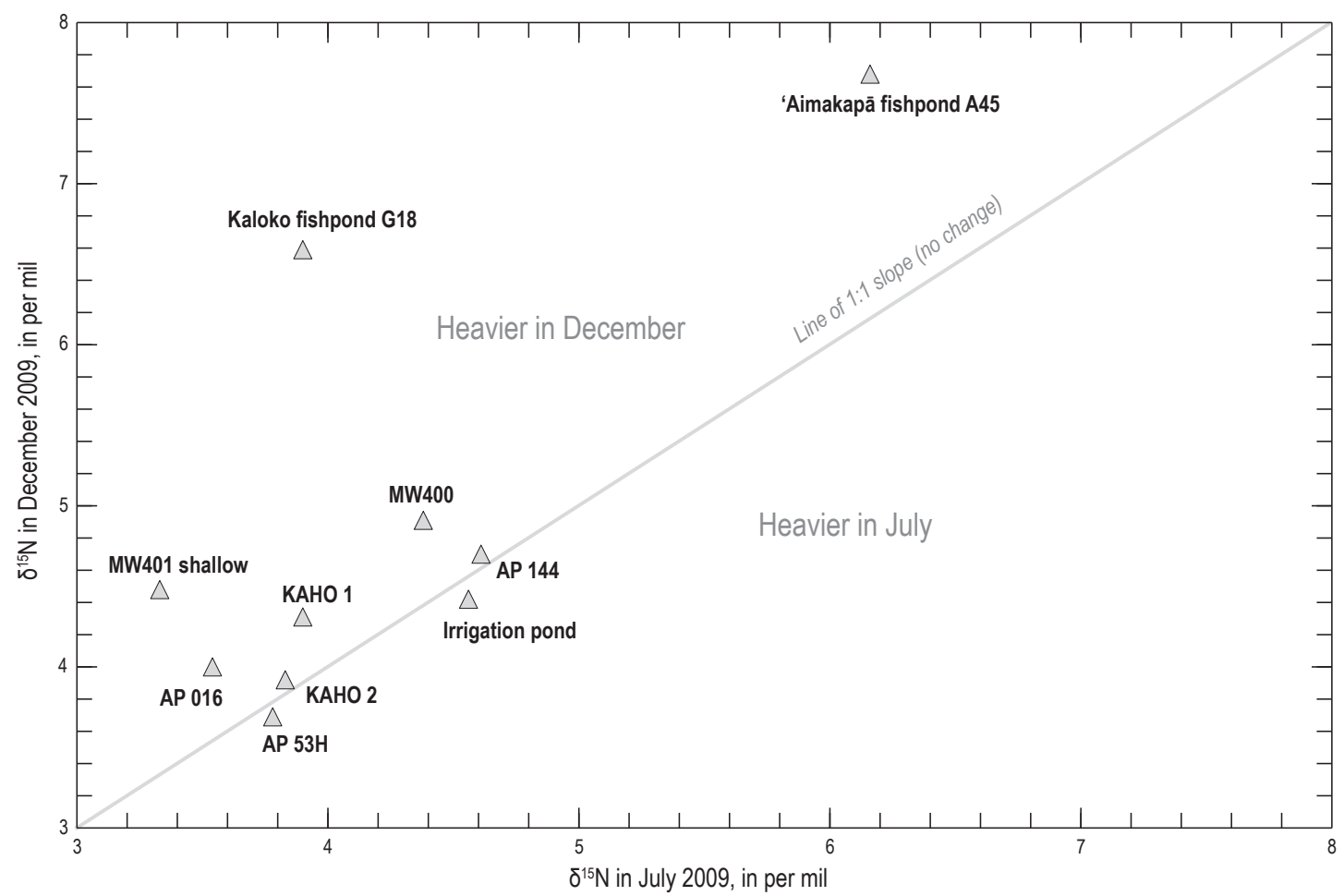

Figure 31. Graph showing change in $\delta^{15} \mathrm{~N}$ of nitrate from July to December 2009 at Kaloko-Honokōhau National Historical Park, Island of Hawai'i. Kaloko and 'Aimakapā Fishpond $\delta^{15} \mathrm{~N}$ values were much heavier in December, likely as a result of biotic uptake of nitrogen and denitrification.

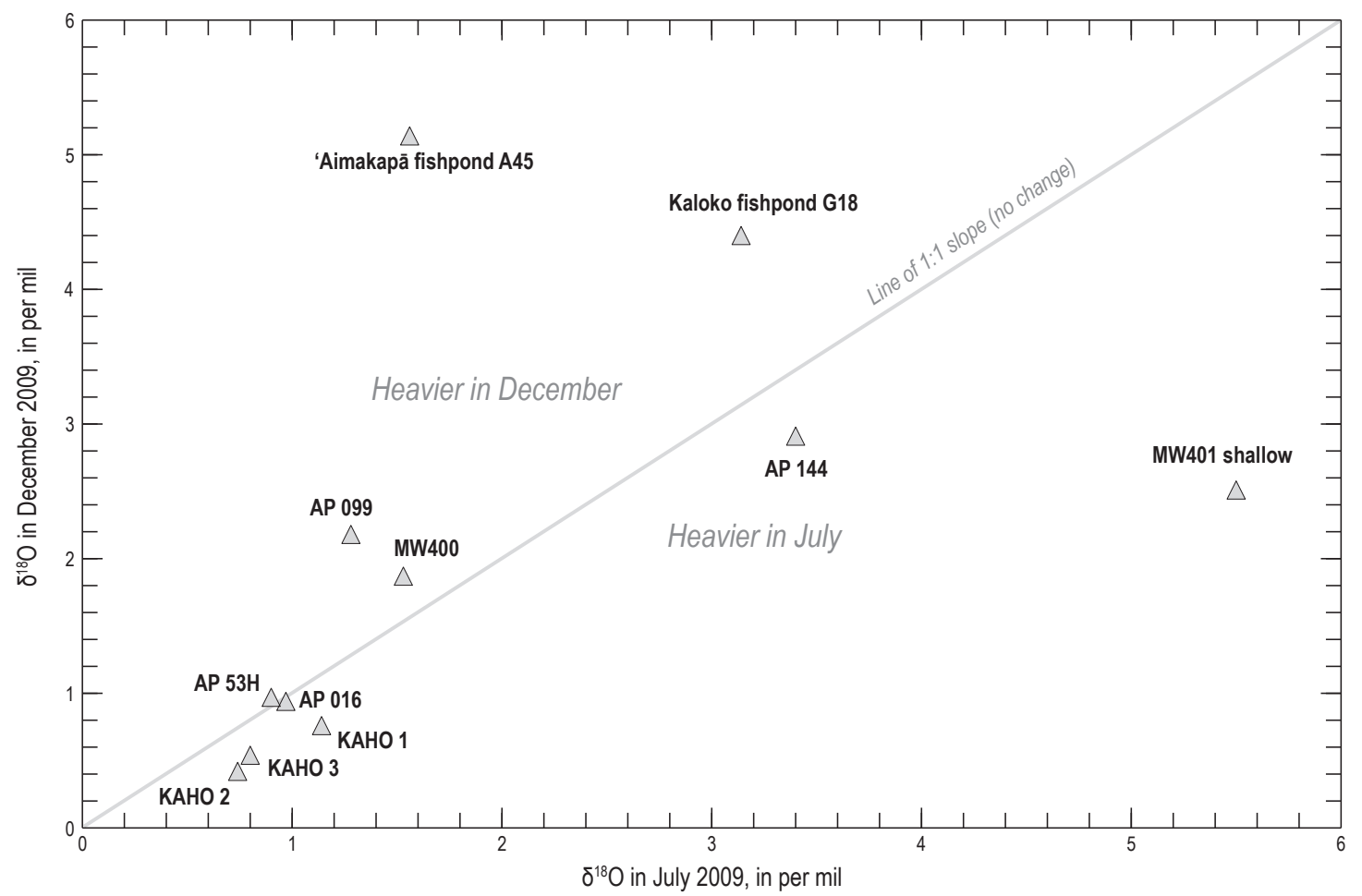

Figure 32. Graph showing change in $\delta^{18} \mathrm{O}$ of nitrate from July to December 2009 at Kaloko-Honokōhau National Historical Park, Island of Hawai'i. Kaloko and 'Aimakapā Fishpond $\delta^{18} \mathrm{O}$ values were higher in December, likely as a result of biotic uptake of nitrogen and denitrification. MW401 had much heavier $\delta^{18} \mathrm{O}$ in July, reflecting the composition of nitrate fertilizer contamination there at the time. 
Another possible source of isotopically heavier nitrogen is direct atmospheric deposition of vehicular exhaust from traffic, which has been shown to impart heavier $\delta^{15} \mathrm{~N}$ values to vegetation and water near roadways, as compared to natural or non-impacted conditions (Redling and others, 2013). For example, Pearson and others (2000) found that mosses collected near highways or busy urban roads had $\delta^{15} \mathrm{~N}$ values ranging from -1 to +6 per mil, whereas those collected in rural areas with little traffic had values ranging from -12 to -2 per mil. Using pine needles, Ammann and others (1999) measured $\delta^{15} \mathrm{~N}$ values about +2 per mil heavier near roadways than away from roads, and Kenkel and others (2013) measured a smaller offset of +1 per mil close to roads.

The Kona area has a dense network of roads in the various residential commercial developments and two main highways running parallel to the coast, one in the lowlands (Queen Ka'ahumanu Highway) that borders the inland edge of the Park. Further research and a greater number of mid-slope groundwater samples would be required to evaluate the effects of nitrogen-fixing vegetation and vehicular emissions on groundwater nitrogen and nitrate isotopic compositions in the vicinity of the Park.

\section{Stable Isotopes of Boron}

Boron isotopes did not work well as a wastewater tracer at KAHO. Only a few water samples were analyzed for boron isotopes at KAHO because it was anticipated that the brackish salinity of most waters would simply result in a seawater isotopic signature. This proved to be true for three groundwater samples from within the Park that were analyzed (KAHO 1, KAHO 2, and KAHO 3; table 3), all of which had $\delta^{11} \mathrm{~B}$ compositions very close to a seawater $\delta^{11} \mathrm{~B}$ composition of about +39.5 to +40 per mil (Widory and others, 2005; Thomas D. Bullen, USGS Boron Isotope Lab, oral commun., 2005).

Wastewater commonly has a light boron isotope composition imparted by laundry detergents that contain sodium perborate, a fabric whitening agent having a $\delta^{11} \mathrm{~B}$ composition of about 0 per mil (Vengosh and others, 1994; Thomas D. Bullen, USGS Boron Isotope Lab, oral commun., 2005). At Kīhei, Maui, a wastewater boron signature was detected successfully, being isotopically lighter than ambient groundwater (Hunt, 2007). Municipal wastewater at Kīhei had $\delta^{11} \mathrm{~B}=$ +32 per mil, presumably from detergent boron with $\delta^{11} \mathrm{~B}=0$ having been added to household tap water with $\delta^{11} \mathrm{~B}=+48$ per mil in the course of doing laundry. The intermediate $\delta^{11} \mathrm{~B}$ value of +32 per mil in wastewater contrasted strongly with the local groundwater $\delta^{11} \mathrm{~B}$ of +49 per mil, thereby making boron isotopes a good wastewater tracer at Kīhei. Indeed, a water sample from a lowland well within the injected wastewater plume had a $\delta^{11} \mathrm{~B}$ value of +30 per mil, confirming the presence of wastewater in the aquifer (along with other confirmatory constituents). However, in terms of concentration, Kīhei wastewater contained only $195 \mu \mathrm{g} / \mathrm{L}$ of boron, whereas seawater contains roughly 4,400 $\mu \mathrm{g} / \mathrm{kg}$ of boron (QuinbyHunt and Turekian, 1983), or 4,300 $\mu \mathrm{g} / \mathrm{L}$ due to the density difference of seawater versus freshwater (1.025 versus 1.000). In a coastal aquifer, groundwater containing more than about 15-20 percent saltwater will have a boron content dominated by seawater boron, which will greatly mask lesser boron contributions from other sources and force the isotopic signature to very near the seawater value of $\delta^{11} \mathrm{~B}=+39$ to +40 per mil.

This situation appears to be true at KAHO. Boron-isotope values at KAHO 1, KAHO 2, and KAHO 3 were all very close to +40 per mil and the samples ranged from 16 to 33 percent seawater (table 3 ). Nearly all of the other pond and anchialine pool samples were saltier than 20 percent seawater, and so $\delta^{11} \mathrm{~B}$ will not likely be a useful wastewater tracer at KAHO because seawater boron will dominate the isotopic signature of most park waters.

In addition to the $\delta^{11} \mathrm{~B}$ values from well samples at $\mathrm{KAHO} 1$, KAHO 2, and KAHO 3, the $\delta^{11} \mathrm{~B}$ values from the Honokōhau well and NPS office tap water were considered. These two freshwater sites sampled had $\delta^{11} \mathrm{~B}$ values of about +24 per mil, already lighter than the Kinhei wastewater composition and not much different from the +26 value of Kealakehe wastewater (Hunt, 2008). Therefore, if these samples are generally representative of upland groundwater in the area, one will not be able to distinguish a wastewater component from the regional fresh groundwater as was apparent at Kỉhei, where upland groundwater was isotopically heavier than wastewater $\left(\delta^{11} \mathrm{~B}=+49\right.$ versus +32 per mil). That is, even if light or intermediate compositions well under the seawater value of +40 per mil were to be detected, it would be impossible to distinguish whether the light composition was signifying wastewater or simply isotopically light upland groundwater. A wider-ranging survey of upland groundwater will be necessary if use of boron isotopes is to be attempted as a wastewater tracer in the Kailua-Kona area. Even then, application near the coast will be difficult because of the overwhelming effect of salinity in greatly masking lighter freshwater $\delta^{11} \mathrm{~B}$ signatures to the seawater value.

\section{Apparent Chlorofluorocarbon Age at the Honokōhau Well}

A chlorofluorocarbon (CFC) groundwater age was determined on a single groundwater sample from the Honokōhau well (table 3). Analysis yielded an apparent groundwater age of 48-52 years from the 2009 sampling date, or an apparent recharge date of 1955-61. The apparent age or date corresponds to the time of last contact with atmospheric air before the water became sequestered below the water table. More specifically, "last contact" will be with air in pore spaces of the unsaturated zone (just above the water table in the aquifer) and not air at the land surface, so infiltration time from land surface to the water table is not part of the CFC apparent age.

Chlorofluorocarbons are anthropogenic compounds that have been released to the atmosphere over decades as a result of their use as refrigerants, propellants, solvents, and foamblowing agents. Three CFC compounds (CFC-11, CFC-12, 
CFC-113) are used for dating water samples by comparing concentrations in the sample with atmospheric concentration histories that have been established for each compound (Plummer and Busenberg, 1999).

The Honokōhau well was the only suitable site on which to attempt CFC dating because the well is solid-cased to $14 \mathrm{ft}$ below the water table, preventing water pumped from below the water table from contacting the modern atmosphere or air in the unsaturated zone. In contrast, anchialine pools and the fishponds are directly exposed to the modern atmosphere, and the KAHO monitoring wells have screens or openings that extend above the water table. This exposes well water to modern air in the shallow unsaturated zone, and this is exacerbated by tidal fluctuations of the water table that entrain modern air from the capillary fringe into shallow groundwater on every tidal cycle.

The significance of the five-decade old CFC groundwater age at the Honokōhau well is not immediately clear. One might expect water from this well to be younger, given its location in the high-recharge band on the mountain flank where young recharge should be arriving at the water table continually. But the long open interval of the well (130 ft long, from 14-144 ft below the water table) may allow a substantial amount of old water to be drawn from deep in the well, blending in and resulting in a fairly old apparent age. The well may also draw some amount of old water flowing laterally from higher elevations, water that has been in the aquifer a long time during its journey downslope.

\section{Pharmaceuticals, Wastewater Compounds, and Volatile Organic Compounds}

Pharmaceuticals and wastewater compounds at KAHO were mostly non-detectable or at low, "trace-level" concentrations below laboratory reporting levels and did not yield strong indications of wastewater presence. If wastewater or septic leachate is present throughout the study area, it is at no more than trace levels, at least as expressed by pharmaceuticals and wastewater compounds analyses on the water samples that were collected. Furthermore, no solvents, gasoline compounds, or other VOCs were detected that could be attributed to commercial and industrial activities at the industrial park or roadside dry wells just upslope from the Park.

All KAHO samples were analyzed for pharmaceuticals and wastewater compounds (tables 3,4 ) because there are known septic systems and cesspools upslope from the Park and because of the proven usefulness of these compounds for indicating wastewater presence in the environment. Research and sampling surveys for these compounds have been conducted internationally and in the United States (for example, Kolpin and others, 2002; Glassmeyer and others, 2005; Focazio and others, 2008), as well as locally on Maui (Hunt, 2007; Hunt and Rosa, 2009) and south of KAHO at Kealakehe (Hunt, 2008). Volatile organic compounds are another class of chemicals that were analyzed for selected sites at KAHO. These chemicals include solvents and gasoline hydrocarbons that are generally thought of as urban contaminants, for which possible sources might include Kaloko Light Industrial Park and roadside dry wells immediately upslope from the Park (fig. 3; Izuka and others, 2009).

\section{Results for July}

In July, wastewater compound analysis detected bromoform $(3.6 \mu \mathrm{g} / \mathrm{L})$ in NPS office tap water, bromoform $(0.283 \mu \mathrm{g} / \mathrm{L})$ and methyl salicylate $(0.1 \mu \mathrm{g} / \mathrm{L})$ at anchialine pool AP 099, and cholesterol $(1 \mu \mathrm{g} / \mathrm{L})$ at Kohanaiki irrigation pond (table 3$)$. At AP 099, VOC analysis also detected bromoform at $0.52 \mu \mathrm{g} / \mathrm{L}$, providing some support to the bromoform detection on the wastewater compounds analysis (the difference in concentrations is not of great concern and may arise from different instrument sensitivities and differing degrees of compound recovery between the two methods). Neither bromoform nor methyl salicylate were detected at AP 099 in December (table 4), despite being resampled for both the wastewater compounds and VOC analyses.

Bromoform is most commonly known as a disinfection byproduct of water chlorination. Methyl salicylate is listed as being used in liniment, food, beverages, and UV-absorbing products such as sunscreens. Cholesterol is a naturally occurring plant and animal sterol; its detection at Kohanaiki irrigation pond may have resulted from plant or animal biota having become established in the lined but open pond.

Detection of bromoform in the tap water sample is unsurprising because the tap water is drinking water that has been chlorinated, and chlorination is a known means of bromoform creation. Bromoform was not detected in the Honokohau well sample, and this is explainable because the sample was drawn at the wellhead, prior to tank storage and chlorination for distribution through the water-delivery pipeline system. These results support a conclusion that bromoform is not present in upland groundwater but is instead a chlorination by-product introduced in the chlorinated water supply distributed to the tap.

Bromoform at anchialine pool AP 099 might originate by natural processes or from chlorinated water. Bromoform is produced naturally by macroalgae (Nightingale and others, 1995) and so its presence may be a natural product of algae in the anchialine pool itself or in nearby seawater. Chorinated water could migrate to AP 099 as groundwater flow from the east or by tidal incursion of harbor seawater into the peninsula aquifer from north and south. Anchialine pool AP 099 lies within a narrow peninsula (fig. 3), with Honokōhau Harbor adjacent to its south side and the 'Ai'ōpio Fishtrap and beaches to the north. Potential sources of chlorinated water in the vicinity include wash-down hoses at boat slips, several "wash rack" areas east of the peninsula for boats pulled from the water, and several septic systems at harbor restrooms and restaurants. Also, the harbor is thought to intercept the treated and chlorinated wastewater effluent plume from Kealakehe 
WWTP, as evidenced by high phosphorus concentrations in harbor seawater (Johnson and others, 2008) and tracing of the pharmaceutical compounds carbamazepine and sulfamethoxazole in the aquifer from the point of effluent disposal to groundwater springs at the back wall of the harbor (Hunt, 2008). Other potential sources of chlorine include the use of bleach and cleaning products in washing down boats, both at individual boat slips in the harbor and at on-land wash racks. Methyl salicylate at AP 099 may reflect a sunscreen or liniment origin, either from direct contact from visitors to the Park, or by tidal incursion of ocean water into the peninsula aquifer.

Remaining laboratory detections are of low confidence. Caffeine was detected at low concentrations below the LT-MDL in a number of samples in both the pharmaceuticals and wastewater compounds analyses; however, it was also detected in the field blank on the pharmaceuticals method and in both the field and laboratory blanks on the wastewater compounds method (table 3). Because of the blank detections, the laboratory initially raised the laboratory reporting level (LRL) for this data set from the usual $0.06 \mu \mathrm{g} / \mathrm{L}$ to $0.2 \mu \mathrm{g} / \mathrm{L}$ and reported all samples as non-detections for caffeine at $<0.2 \mu \mathrm{g} / \mathrm{L}$. This effectively "hard-censored" the caffeine results at $0.2 \mu \mathrm{g} / \mathrm{L}$, with no further reporting of values below that. Because one will look for concurrence between two methods for a compound that is in both analyses, it became important to equalize the reporting style for both analytical schedules (pharmaceuticals and wastewater compounds) and, in fact, the laboratory had detected low caffeine concentrations in many samples below the LT-MDL prior to hard-censoring at $0.2 \mu \mathrm{g} / \mathrm{L}$ on the wastewater compounds analysis. These raw values were obtained from the lab to better evaluate potential concurrence or non-concurrence of results from the two methods. Now having both sets of low-level results available for comparison, there was co-detection between the two methods for 6 of 16 samples (including the field blanks), 5 samples where the two methods agreed on non-detection, and 3 samples where caffeine was detected on one analysis but not the other.

Recognizing that caffeine concentrations reported for the environmental samples are very low (below the LT-MDL) and that they are accompanied by detections in blanks, the caffeine results should be considered inconclusive. The data may contain some true environmental detections originating from septic sources upslope or perhaps even a field contamination artifact via pervasive atmospheric deposition from coffee roasting facilities (there is at least one roaster in the commercial zone along the main highway between Honokōhau Harbor and the landfill; fig. 3). However, this last possibility cannot be meaningfully distinguished from the possibility of laboratory contamination at such low concentrations.

Other than caffeine, a few other compounds were reported below the LT-MDL in July (table 3). Many of the detections were in the sample from Kohanaiki irrigation pond, which is open to contamination from the environment and from workers on the property. The irrigation pond has an artificial membrane liner that may explain detections of compounds such as plasticizers. Toluene was detected above the laboratory reporting level in the VOC field blank but not in any environmental samples.

\section{Results for December}

There were only two detections above the LT-MDL in December (table 4): caffeine in the wastewater compounds analysis at both Kaloko Fishpond and Kohanaiki irrigation pond. Possible sources include recreational swimmers at Kaloko Fishpond, dumping of soft drinks or coffee at both sites, and possible atmospheric deposition from coffee roasters in nearby commercial zones, as was previously mentioned. Caffeine was also detected in field and laboratory blanks, but at concentrations roughly one and two orders of magnitude lower (lab blank and field blank, respectively) than the environmental concentrations.

At monitoring well KAHO 2, closest to Kaloko Light Industrial Park, trace-level concentrations (below the LT-MDL) were detected on the pharmaceuticals method for carbamazepine $(0.001 \mu \mathrm{g} / \mathrm{L})$, sulfamethoxazole $(0.003 \mu \mathrm{g} / \mathrm{L})$, and thiabendazole $(0.016 \mu \mathrm{g} / \mathrm{L})$. Carbamazepine was also detected at $0.001 \mu \mathrm{g} / \mathrm{L}$ in anchialine pool AP 099. The three compounds were not detected in laboratory blanks, and a field blank was not run for pharmaceuticals because only three samples were being analyzed in December.

Carbamazepine is an anticonvulsant, sulfamethoxazole is an antibiotic, and thiabendazole is a fungicide and worming agent. Carbamazepine and sulfamethoxazole are very persistent once released to the environment (Drewes and others, 2003; Barber and others, 2008) and are commonly the only pharmaceuticals detected in some water samples. Carbamazepine and sulfamethoxazole were detected in treated municipal wastewater and in wells and coastal springs within injected wastewater plumes on Maui, although at concentrations one to two orders of magnitude greater than the concentrations at KAHO 2 and AP 099 (Hunt, 2007; Hunt and Rosa, 2009). Both compounds were detected south of KAHO by Hunt (2008), who sampled Kealakehe treated wastewater, two coastal springs at Honokōhau Harbor, and two monitoring wells between the harbor and the Kealakehe wastewater disposal pit. Carbamazepine was detected in all samples and sulfamethoxazole was detected in all samples except one of the two harbor springs. Concentrations decreased progressively from the disposal pit to the harbor, with concentrations reaching one to two orders of magnitude greater than the concentrations at KAHO 2 and AP 099.

The very low concentrations of carbamazepine, sulfamethoxazole, and thiabendazole reported for the KAHO 2 sample may represent trace-level detections of septic leachate from Kaloko Light Industrial Park and suburban developments farther upslope. Carbamazepine at AP 099 could be a tracelevel indication of incursion of harbor seawater, containing a slight wastewater fraction into the peninsula aquifer. 


\section{Optical Brightener Fluorescence}

A screening test for laundry fabric brighteners (optical brighteners) gave positive results for many samples (table 5). Samples testing positive either in July or December were

- Monitoring wells KAHO 1, KAHO 2, KAHO 3, MW401 shallow;

- 'Aimakapā Fishpond and Kohanaiki irrigation pond; and

- Anchialine pools AP 016, AP 53H, AP 144.

Samples testing negative were

- Monitoring wells MW400 and MW401 deep;

- Kaloko Fishpond; and

- Anchialine pool AP 099.

All blanks and controls tested negative, and a replicate sample at monitoring well KAHO 1 in December tested positive in the same fashion as the primary sample for KAHO 1.

Samples were screened for optical brighteners using UV-fluorescence methods. Meter readings were in arbitrary fluorescence units and strictly comparable only within the dataset and in relation to control samples of deionized water and tap water. Some environmental readings were below zero, but not as strongly negative as the control samples, indicating "more fluorescence" than the controls (the instrument was not reset to a zero value corresponding to the control samples but was instead simply left at the factory calibration setting).

Taken at face value, these results would be thought to indicate the presence of optical brighteners - presumably from laundry graywater - at nearly all sites. While this may be the case, it is important to remember that this is simply a screening method using fluorescence, which is subject to potential interferences such as dissolved organic matter (DOM). A more rigorous test for optical brighteners would be a gas-chromatograph test for the brightener compounds themselves. To infer the presence of wastewater and (or) graywater with confidence, one would also hope to detect pharmaceutical or wastewater compounds as supporting evidence.

Fluorescence readings can be equivocal because of interference from naturally occurring DOM such as humic and fulvic compounds, whose fluorescence spectrum overlaps the optical brightener emission band (Chen and others, 2003; Turner Designs, 2007b). A familiar example of high-DOM water is transparent but highly colored swamp water that resembles brownish tea.

Also of potential significance are the relatively low initial readings for the KAHO samples in table 5 (the highest reading corresponding to a positive result was 4.5 units on the meter). This was the same meter used by Hunt (2008) that produced readings of 31 for Kealakehe treated wastewater effluent and readings of 20 and 23 at two monitoring wells in the presumed aquifer wastewater plume between the Kealakehe wastewater disposal pit and Honokōhau Harbor. If the much lower readings in table 5 are reliable indicators of brightener presence, they indicate a much more dilute graywater and (or) wastewater fraction than that in the Kealakehe effluent and aquifer plume. This is expected, considering that cesspool and (or) septic sources of laundry graywater upslope from KAHO are widespread and not concentrated in one localized area like the Kealakehe wastewater plume. A final factor is that the 5and 10-minute UV illumination steps were not applied to the Kealakehe samples, and there is no way to know how much of the UV fluorescence readings for those samples was contributed by dissolved organic matter, which could be quite high in the municipal effluent.

\section{Summary and Conclusions}

Baseline water-quality sampling was conducted for dissolved nutrients, and chemical and stable-isotope tracers at Kaloko-Honokōhau National Historical Park on the Island of Hawai' $i$ in July and December 2009. Sites in and near the Park included four anchialine pools, two large fishponds, five monitoring wells, an upland production well, tap water, and a holding pond for golf-course irrigation water. There were no significant rainstorms during the sampling period, so both samplings were fair-weather snapshots of water quality; although intended, it was not possible to obtain a wet-weather or storm sample because of the unusual dryness in 2009. Wetweather results could differ from those reported here.

Water samples within the coastal park were brackish, ranging in salinity from 15 to 67 percent seawater. The freshest water sampled was from outside of the Park, a reference sample of background fresh groundwater from the upland Honokōhau production well at an elevation of $1,675 \mathrm{ft}$ above sea level. The saltiest water was two-thirds that of seawater salinity and was obtained from $45 \mathrm{ft}$ below the water table in monitoring well MW401. Temperature and salinity profiles measured in that well by NPS indicate that the coastal brackish groundwater lens is underlain by cold saline water much different from the warm surface seawater nearby and originating from deep within the oceanic thermocline offshore. The cold saline groundwater is much higher in nitrogen and phosphorus than surface seawater, and it is important to take this into account in water-quality studies at the Park.

Samples were analyzed for dissolved inorganic nutrients (nitrogen and phosphorus), stable isotopes (nitrogen and oxygen in dissolved nitrate; hydrogen and oxygen in the water molecule; dissolved boron), pharmaceuticals, wastewater compounds, and volatile organic compounds. Samples were also screened for the presence of laundry fabric brighteners using UV-fluorescence tests.

Highly elevated nitrogen concentrations were detected at three sites on the Park's north boundary and can be attributed to fertilizer contamination. Maximum nitrogen concentrations at monitoring wells MW401 and MW400, and anchialine pool site AP 144 were 280, 111, and 75 percent above expected background concentrations along a freshwater-saltwater 
mixing line defined for the area, respectively. These highly elevated concentrations likely resulted from fertilizer application during the turf grow-in period of the newly constructed golf course at The Shores at Kohanaiki resort. The fertilizer influence appears to have been temporary, with the highest nitrogen concentration in July falling substantially by December, although not fully back to the expected background level for that vicinity.

Aside from this localized fertilizer influence, remaining samples had lesser enrichments of nitrogen and phosphorus above expected background concentrations (40 percent or less above background for nitrogen and 57 percent or less above background for phosphorus). The nitrogen and phosphorus enrichments at KAHO reflect gains in nutrient concentrations across the intervening landscape between the upland Honokōhau well and the coastal lowlands. Potential sources for the nutrient enrichment include rock weathering; nitrogen fixation and decomposition of natural vegetation on the mountain flank; fertilizers used on suburban, commercial, and agricultural lands; septic leachate from suburban and commercial developments; and atmospheric deposition including vehicular emissions.

Stable isotopes of nitrate did not implicate septic or waste nitrate in the usual way; that is, by conspicuously heavy $\delta^{15} \mathrm{~N}$ values of +10 per mil or greater that would tend to exclude a natural soil nitrogen source. Most water samples had nitrate $\delta^{15} \mathrm{~N}$ values ranging +3 to +5 per mil, heavier than the value of +2 in upland background water from the Honokōhau well, but still within the range for natural soil nitrate, and therefore not strongly indicative of waste nitrogen. Samples with heaviest nitrate $\delta^{15} \mathrm{~N}$ values (ranging from +6.2 to +7.7 per mil) were from the fishponds, where plants, animals, and microbes drive biotic cycling such as phytoplankton uptake of nutrients, transformations within the food chain, and denitrification in pond-bottom sediments. Despite the lack of a conspicuous waste nitrogen isotopic signature, groundwater samples with $\delta^{15} \mathrm{~N}$ values of +3 to +5 per mil were still isotopically heavier than the +2 per mil in upland groundwater at the Honokōhau well. This isotopic enrichment could reflect a fraction of septic nitrate in the samples or some other unknown variation in nitrate isotopic composition on the mountain flank, for example spatial variation of nitrogen-fixing plants such as Prosopis pallida (kiawe or mesquite) and Leucaena leucocephala (koa haole or lead tree). Vehicular emissions could also be a source of isotopically heavier nitrogen across the watershed, as studies have shown heavier $\delta^{15} \mathrm{~N}$ values in plants and soil next to busy roadways than at control sites farther from roads.

Some fraction of septic leachate is expected in KAHO groundwater given the extensive residential and commercial developments upslope that are on septic systems and cesspools. Evidence for detection of septic leachate was greatest at monitoring wells KAHO 1 and KAHO 2 (closest to Kaloko Light Industrial Park) and included enrichment of nitrogen and phosphorus above expected background concentrations, heavier $\delta^{15} \mathrm{~N}$ values than background, detection of hydrogen sulfide by smell (KAHO 1), and detection of the pharmaceuticals carbamazepine, sulfamethoxazole, and thiobendazole (KAHO 2) at trace-level, parts-per-trillion concentrations.

If septic contamination is present generally in park waters, it appears to be at a subtle level that is not conspicuous in most samples. Pharmaceuticals, wastewater compounds, and volatile organic compounds did not indicate strong septic or other contamination in park waters; only a few compounds were detected and most of these at trace-level concentrations. A screening-level test for laundry fabric brighteners indicated positive detection at most sites. However, initial readings were quite low compared to prior experience with municipal wastewater plumes, and the method is subject to interference from natural humic and fulvic compounds. If laundry graywater is present in most of the samples that tested positive, it may be a small, dilute fraction.

One possible explanation for the apparent lack of strong wastewater and graywater indicators is that cesspool and septic sources are widespread and leach at low individual rates, approximating a diffuse nonpoint source or a widespread distribution of small point sources. This is a very different setting than the concentrated municipal wastewater injection plumes previously studied, where chemical and isotopic evidence of wastewater presence in wells and springs was apparent on Maui (Hunt, 2007; Hunt and Rosa, 2009) and south of the Park at Kealakehe (Hunt, 2008).

No solvents, gasoline compounds, or other VOCs were detected that could be attributed to commercial and industrial activities at Kaloko Light Industrial Park or to roadside dry wells in and uphill from the Park. Bromoform and methyl salicylate were detected at anchialine pool AP 099, possibly indicating the presence of chlorinated water (bromoform) and liniment or sunscreen (methyl salicylate). These detections may have originated directly, from human activity at the anchialine pool; or possibly indirectly, by incursion of surface seawater into the narrow peninsula from Honokōhau Harbor to the south or from the 'Ai'oppio Fishtrap, its adjacent beach to the north.

\section{Study Limitations and Opportunities for Future Research}

Results of this study provide a reasonable baseline of nutrients and wastewater tracers for future comparison. A serious limitation to the study is that a wet-weather or storm sampling was not obtainable because the study period was unusually dry. Another limitation is that - in order to make best use of available funding - not all sites were sampled twice, and some of the more expensive laboratory analyses were not applied at all sites, but only at sites where it was presumed they were more likely to yield definitive results.

Repeat monitoring would need to employ some of the same methods for comparability, but it may be sensible to drop 
some methods or shift financial resources to other methods that may prove more productive. Simple dissolved species of inorganic nutrients were analyzed and were sufficient to document a general nutrient enrichment above background in many samples, and acute but temporary effects of fertilizer leaching at sites along the north boundary of the Park. Nutrient results also appear to reflect the influence of biotic cycling in the larger fishponds; however, organic and particulate nutrient forms would need to be analyzed for further understanding of biotic nutrient cycling within park waters. Similarly, organic nutrient species and dissolved organic carbon could be useful constituents to measure for more complete monitoring of septic influences.

Stable isotopes of nitrate did not give strong indications of septic nitrogen directly, but did reflect a general pattern of heavier isotopic values in the lowlands as well as the likely influence of biotic nitrogen cycling in the larger fishponds where $\delta^{15} \mathrm{~N}$ values were heaviest. All groundwater samples were isotopically heavier than upland groundwater at the Honokōhau well; this reflects some addition of heavier nitrate in the samples, either from septic sources, from nitrogenfixing vegetation, or from atmospheric deposition of vehicular exhaust. This topic could be pursued by an experienced isotope geochemist who might also apply additional measurements such as stable isotopes of phosphorus, carbon, and sulfur. A critical need would be samples from some "midslope" wells; that is, between the coastal lowlands and park environs and Māmalahoa Highway where the Honokōhau well is located.

VOCs were analyzed mainly as an initial screening tool for sites closest to Kaloko Light Industrial Park. Given the general lack of detections on that method, one might drop it in future sampling in favor of more widespread sampling for pharmaceuticals and wastewater compounds. Alternately, VOCs might be retained but only for a few sentry sites such as KAHO 1 and KAHO 2 that are closest to Kaloko Light Industrial Park.

Even in the pharmaceutical and wastewater compound analyses there were few detections, and one might question the cost-effectiveness of continuing to monitor for these compounds. However, that perspective doesn't address the possibility of contaminants from roadside dry wells and cesspools in Kaloko Light Industrial Park and elsewhere being flushed into groundwater by runoff and infiltration during intense rainstorms. Storm-sampling strategies considered during this study included an initial sampling within a week or so of a storm that might reflect direct vertical infiltration, followed by a subsequent sampling a month or more later that would allow time for lateral groundwater transport of contaminants from upslope to reach monitoring wells and anchialine pools within the Park. Groundwater modeling could be used to estimate lateral groundwater travel times to guide the choice of sampling delay time.

The screening test for laundry fabric brighteners is a very approximate, reconnaissance-level method using a hand-held fluorometer. More definitive testing might be attempted using laboratory-grade fluorescence spectroscopy, and this would best be done by an expert in the methodology with experience in wastewaters and fabric brightener fluorescence in particular.

\section{References Cited}

Ammann, M., Siegwolf, R., Pichlmayer, F., Suter, M., Saurer, M., and Brunold, C., 1999, Estimating the uptake of trafficderived $\mathrm{NO}_{2}$ from ${ }^{15} \mathrm{~N}$ abundance in Norway spruce needles: Oecologia, v. 118, p. 124-131.

Apple, R.A., and Macdonald, G.A., 1966. The rise of sea level in contemporary times at Honaunau, Kona, Hawaii: Pacific Science, v. 20, no. 1, p. 125-136.

Aravena, R., Evans, M.L., and Cherry, J.A., 1993, Stable isotopes of oxygen and nitrogen in source identification of nitrate from septic systems: Ground Water, v. 31, no. 2, p. 180-186.

Barber, L.B., Meyer, M.T., LeBlanc, D.R., Kolpin, D.W., Bradley, P.M., Chapelle, F.H., and Rubio, F., 2008, Subsurface fate and transport of sulfamethoxazole, 4-nonylphenol, and 17beta-estradiol, in Trefry, M.G., ed., Groundwater quality 2007-Securing groundwater quality in urban and industrial environments: International Association of Hydrological Sciences IAHS Redbook, no. 324, p. 133-139.

Bear, J., 1979, Hydraulics of groundwater: New York, McGraw Hill, Inc., 569 p.

Beavers, S., and Hunt, C.D., Jr., 2008, Using stable isotope tracers to determine anthropogenic inputs to water quality at Kaloko-Honokōhau National Historical Park: Joint project proposal by National Park Service and U.S. Geological Survey, $15 \mathrm{p}$.

Bienfang, P., 1980, Water quality characteristics of Honokohau Harbor-A subtropical embayment affected by groundwater intrusion: Pacific Science, v. 34, no. 3, p. 279-291.

Bienfang, P., 2007, Assess nutrient sources, fluxes, and water quality of ponds within the Kaloko-Honokōhau National Historical Park: Report to Hawaii-Pacific Islands Cooperative Ecosystem Studies Unit, National Park Service, 38 p. and appendices.

Bienfang, P., 2008, Assess nutrient sources, fluxes, and water quality of ponds within the Kaloko-Honokōhau National Historical Park - Addendum to February 2007 report: Report to Hawaii-Pacific Islands Cooperative Ecosystem Studies Unit, National Park Service, 57 p. and appendices.

Bienfang, P., and Johnson, W., 1980, Planktonic properties of Honokohau Harbor-A nutrient-enriched subtropical embayment: Pacific Science, v. 34, no. 3, p. 293-300.

Bienfang, P.K., and Szyper, J.P., 1981, Phytoplankton dynamics in the subtropical Pacific Ocean off Hawaii: Deep Sea Research, Part A. Oceanographic Research Papers, v. 28, no. 9, p. 981-1000. 
Bowles, S.P., 2007, Evidence and implications of saline cold ground-water, Honokohau, Hawaii: Report by Waimea Water Services, Inc., appendix G-2 in Kona Kai Ola environmental impact statement, $7 \mathrm{p}$.

Bowles, S.P., Mink, J., and Yuen, G., 2006, Geology and ground-water hydrology in the vicinity of Honokohau Harbor: Report by Waimea Water Services, Inc., assisted by Mink and Yuen, Inc., appendix G-1 in Kona Kai Ola environmental impact statement, $16 \mathrm{p}$.

Brock, R.E., 2010, Water quality monitoring report for the development of The Shores at Kohanaiki, North Kona, during construction period - 13 July, 1 September, and 10 November 2009 dry period surveys: Prepared for Kohanaiki Golf And Ocean Club, Kailua-Kona, Hawaii, 123 p.

Brock, R.E., and Kam, A.K.H., 1997, Biological and water quality characteristics of anchialine resources in KalokoHonokōhau National Historical Park, with recommendations for their management: Honolulu, Department of Botany, University of Hawaii, Cooperative National Park Resources Study Unit, Technical Report no. 112, 115 p.

Brock, R.E., Norris, J.E., Ziemann, D.A., and Lee, M.T., 1987, Characteristics of water quality in anchialine ponds of the Kona, Hawaii, coast: Pacific Science, v. 41, p. 200-208.

Campbell, J.F., and Erlandson, D., 1979, OTEC-1 Anchor Site Survey, Final Report: Honolulu, University of Hawaii, Hawaii Institute of Geophysics Technical Report HIG-79-6, $60 \mathrm{p}$.

Cao, Y., Griffith, J.F., and Weisberg, S.B., 2009, Evaluation of optical brightener photodecay characteristics for detection of human fecal contamination: Water Research, v. 43, p. 2273-2279.

Chen, W., Westerhoff, P., Leenheer, J.A., and Booksh, K., 2003, Fluorescence excitation-emission matrix regional integration to quantify spectra for dissolved organic matter: Environmental Science and Technology, v. 37, no. 24, p. 5701-5710.

Childress, C.J., Foreman, W.T., Connor, B.F., and Maloney, T.J., 1999, New reporting procedures based on long-term method detection levels and some considerations for interpretations of water-quality data provided by the U.S. Geological Survey National Water Quality Laboratory: U.S. Geological Survey Open-File Report 99-193, 19 p.
Connor, B.F., Rose, D.L., Noriega, M.C., Murtagh, L.K., and Abney, S.R., 1998, Methods of analysis by the U.S. Geological Survey National Water Quality Laboratory-Determination of 86 volatile organic compounds in water by gas chromatography/mass spectrometry, including detections less than reporting limits: U.S. Geological Survey OpenFile Report 97-829, 78 p.

DeVerse, K., 2006, Appendix A - Kaloko-Honokōhau National Historical Park resource overview, in HaySmith, L., Klasner, F.L., Stephens, S.H., and Dicus, G.H., Pacific Island Network vital signs monitoring plan: Natural Resource Report NPS/PACN/NRR_-2006/003, National Park Service, Fort Collins, Colo., 156 p.

Dollar, S.J., and Atkinson, M.J., 1992, Effects of nutrient subsidies from groundwater to nearshore marine ecosystems off the island of Hawaii: Estuarine, Coastal and Shelf Science, v. 35 , p. $409-424$.

Drewes, J.E., Heberer, T., Rauch, T., and Reddersen, K., 2003, Fate of pharmaceuticals during ground water recharge: Groundwater Monitoring and Remediation, v. 23, no. 3, p. 64-72.

Engott, J.A., 2011, A water-budget model and assessment of groundwater recharge for the Island of Hawaii: U.S. Geological Survey Scientific Investigations Report 2011-5078, $53 \mathrm{p}$.

Fishman, M.J., ed., 1993, Methods of analysis by the U.S. Geological Survey National Water Quality LaboratoryDetermination of inorganic and organic constituents in water and fluvial sediments: U.S. Geological Survey OpenFile Report 93-125, 217 p.

Focazio, M.J., Kolpin, D.W., Barnes, K.K., Furlong, E.T., Meyer, M.T., Zaugg, S.D., Barber, L.B., and Thurman, E.M., 2008, A national reconnaissance for pharmaceuticals and other organic wastewater contaminants in the United States - II. Untreated drinking water sources: Science of the Total Environment, v. 402, p. 201-216.

Foote, D., 2005, Inventory of anchialine pools in Hawaii's National Parks: U.S. Geological Survey Fact Sheet 2005-3129, 2 p.

Furlong, E.T., Werner, S.L., Anderson, B.D., and Cahill, J.D., 2008, Methods of analysis by the U.S. Geological Survey National Water Quality Laboratory-Determination of human-health pharmaceuticals in filtered water by chemically modified styrene-divinylbenzene resin-based solidphase extraction and high-performance liquid chromatography/mass spectrometry: U.S. Geological Survey Techniques and Methods, book 5, chap. B5, 56 p. 
Giambelluca, T.W., Nullet, M.A., and Schroeder, T.A., 1986, Rainfall atlas of Hawaii: Hawai'i Department of Land and Natural Resources, Division of Water and Land Development Report R76, 267 p. [Also available at http://files. hawaii.gov/dlnr/cwrm/publishedreports/R76_Rainfall.pdf.]

Gibbs, A.E., Cochran, S.A., Logan, J.B., and Grossman, E.E., 2007, Benthic habitats and offshore geological resources of Kaloko-Honokōhau National Historical Park, Hawai' $i$ : U.S. Geological Survey Scientific Investigations Report 2006-5256, 62 p.

Glassmeyer, S.T., Furlong, E.T., Kolpin, D.W., Cahill, J.D., Zaugg, S.D., Werner, S.L., Meyer, M.T., and Kryak, D.D., 2005, Transport of chemical and microbial compounds from known wastewater discharges-Potential for use as indicators of human fecal contamination: Environmental Science and Technology, v. 39, no. 14, p. 5157-5169.

Granger, J., Sigman, D.M., Needoba, J.A., and Harrison, P.J., 2004, Coupled nitrogen and oxygen isotope fractionation of nitrate during assimilation by cultures of marine phytoplankton: Limnology and Oceanography, v. 49, no. 5, p. 1763-1773.

Grossman, E.E., Logan, J.B., Presto, M.K., and Storlazzi, C.D., 2010, Submarine groundwater discharge and fate along the coast of Kaloko-Honokōhau National Historical Park, Island of Hawai' $i$, Part 3, Spatial and temporal patterns in nearshore waters and coastal groundwater plumes, December 2003-April 2006: U.S. Geological Survey Scientific Investigations Report 2010-5081, 76 p.

Hagedorn, C., Saluta, M., Hassall, A., and Dickerson, J., 2005, Fluorometric detection of optical brighteners as an indicator of human sources of water pollution-Development as a source tracking methodology: Environmental Detection News (Virginia Tech University), v. 2, nos. 3-4, p. 1-13.

Hartel, P.G., Hagedorn, C., McDonald, J.L., Fisher, J.A., Saluta, M.A., Dickerson, J.W., Jr., Gentit, L.C., Smith, S.L., Mantripragada, N.S., Ritter, K.J., and Belcher, C.N., 2007, Exposing water samples to ultraviolet light improves fluorometry for detecting human fecal contamination: Water Research, v. 41, p. 3629-3642.

Hawaii State Department of Health, 2006, State of Hawaii water quality monitoring and assessment report: Hawaii State Department of Health Web page, accessed May 19, 2014, at http://health.hawaii.gov/cwb/files/2013/05/ Integrated_2006_StateOfHawaii.pdf.

Hawaii State Department of Health, 2013, Hawaii Administrative Rules Title 11 Department of Health Chapter 54 Water Quality Standards: Hawaii State Department of Health Web page, accessed May 19, 2014, at http://health.hawaii. gov/cwb/files/2013/04/Clean_Water_Branch_20131210_ HAR11_54.pdf.
Hawaii State Office of Planning, 2008, Hawaii Statewide GIS Program: Hawaii State Office of Planning Web page, accessed May 19, 2014 at http://planning.hawaii.gov/gis/.

HaySmith, L., Klasner, F.L., Stephens, S.H., and Dicus, G.H., 2005, Pacific Island Network vital signs monitoring plan: Natural Resource Report NPS/PACN/NRR—2006/003, National Park Service, Fort Collins, Colo., 156 p.

Hem, J.D., 1985, Study and interpretation of the chemical characteristics of natural water ( $3^{\mathrm{d}}$ ed.): U.S. Geological Survey Water-Supply Paper 2254, 263 p.

Holthuis, L.B., 1973, Caridean shrimps found in land-locked saltwater pools at four Indo-West Pacific localities (Sinai Peninsula, Funafuti Atoll, Maui and Hawaii Islands), with a description of one new genus and four new species: Zoologische Verhandelingen, v. 128, p. 1-48.

Hoover, D.J., and Gold, C., 2005, Assessment of coastal water resources and watershed conditions in Kaloko-Honokōhau National Historical Park, Hawai ${ }^{\top}$ i: National Park Service Technical Report NPS/NRWRD/NRTR-2005/344, 139 p.

Hunt, C.D., Jr., 2004, Ground-water quality and its relation to land use on Oahu, Hawaii, 2000-01: U.S. Geological Survey Water-Resources Investigations Report 03-4305, 76 p.

Hunt, C.D., Jr., 2007, Ground-water nutrient flux to coastal waters and numerical simulation of wastewater injection at Kihei, Maui, Hawaii: U.S. Geological Survey Scientific Investigations Report 2006-5283, 69 p.

Hunt, C.D., Jr., 2008, Results of sampling for wastewater tracers at and near Kealakehe WWTP, Kona, Hawaii: U.S. Geological Survey briefing presentation on wastewater and nutrient source tracking, accessed May 19, 2014, at http:// hi.water.usgs.gov/studies/beachmonitoring/pdf/USGS DOH_Kealakehe_Kona_slides.pdf.

Hunt, C.D., Jr., and Rosa, S.N., 2009, A multitracer approach to detecting wastewater plumes from municipal injection wells in nearshore marine waters at Kihei and Lahaina, Maui, Hawaii: U.S. Geological Survey Scientific Investigations Report 2009-5253, 166 p.

Izuka, S.K., Perreault, J.A., Jones, T., and Kozar, K., 2011, Protocol for long term groundwater-hydrology monitoring in American Memorial Park, Commonwealth of the Northern Mariana Islands, and Kaloko-Honokōhau National Historical Park, Hawai' $\mathrm{i}$ - Version 1.0: Fort Collins, Colo., National Park Service Natural Resource Report NPS/PACN/ NRR—2011/472.

Izuka, S.K., Senter, C.A., and Johnson, A.G., 2009, Reconnaissance assessment of the potential for roadside dry wells to affect water quality on the Island of Hawai' $i$ : U.S. Geological Survey Scientific Investigations Report 2009-5249, $55 \mathrm{p}$. 
Jensen, Chelsea, 2013, Kealakehe WWTP needs upgrade, sludge removal: West Hawaii Today, January 3, 2013. [Also available at http://westhawaiitoday.com/sections/news/ local-news/kealakehe-wwtp-needs-upgrade-sludge-removal. html.]

Johnson, A.G., Glenn, C.R., Burnett, W.C., Peterson, R.N., and Lucey, P.G., 2008, Aerial infrared imaging reveals large nutrient-rich groundwater inputs to the ocean: Geophysical Research Letters, v. 35, p. 5606-5612.

Kauahikaua, J., 1993, A west Mauna Loa structure revealed by static groundwater levels and geophysical evidence, Hawaii [abs.]: Eos, American Geophysical Union Transactions, supplement October 26, 1993.

Kauahikaua, J., Duarte, K., and Foster, J., 1998, A preliminary gravity survey of the Kailua-Kona area, Hawaii, for delineation of a hydrologic boundary: U.S. Geological Survey Open-File Report 98-110, 21 p.

Kay, E.A., Lau, L.S., Stroup, E.D., Dollar, S.J., Fellows, D.P., and Young, R.H.F., 1977, Hydrologic and ecologic inventories of the coastal waters of west Hawaii: Honolulu, Hawaii, University of Hawaii at Manoa, Water Resources Center Technical Report No. 105, 94 p.

Kendall, C., and McDonnell, J.J., eds., 1998, Isotope tracers in catchment hydrology: Amsterdam, Elsevier Science, 839 p.

Kenkel, J.A., Sisk, T., Hultine, K., Sesnie, S., Bowker, M., and Johnson, N.C., 2013, Cars and canyons - Understanding roadside impacts of automobile pollution in Grand Canyon National Park: Park Science, v. 30, no. 2, p. 52-57, accessed May 19, 2014, at http://www.nature.nps.gov/ParkScience/ archive/PDF/Article_PDFs/ParkScience30(2)Fall2013_5257_Kenkel_et_al_3667.pdf.

Knee, K.L., Street, J.H., Grossman, E.E., Boehm, A.B., and Paytan, A., 2010, Nutrient inputs to the coastal ocean from submarine groundwater discharge in a groundwaterdominated system; relation to land use (Kona coast, Hawaii, U.S.A.): Limnology and Oceanography, v. 55, no. 3, p. 1105-1122.

Knee, K.L., Street, J.H., Grossman, E.E., and Paytan, A., 2008, Submarine ground water discharge and fate along the coast of Kaloko-Honokōhau National Historical Park, Hawai' i-Part 2, Spatial and temporal variations in salinity, radium-isotope activity, and nutrient concentrations in coastal waters, December 2003-April 2006: U.S. Geological Survey Scientific Investigations Report 2008-5128, $31 \mathrm{p}$.

Kolpin, D.W., Furlong, E.T., Meyer, M.T., Thurman, E.M., Zaugg, S.D., Barber, L.B., and Buxton, H.T., 2002, Pharmaceuticals, hormones, and other organic wastewater contaminants in U.S. streams, 1999-2000-A national reconnaissance: Environmental Science and Technology, v. 36, no. 6, p. $1202-1211$.
National Park Service, 2000, Baseline water quality data inventory and analysis, Kaloko-Honokōhau National Historical Park: Technical Report NPS/NRWRD/NRTR99/247, United States Department of the Interior, National Park Service, Water Resources Division.

National Park Service, 2014a, Frequently Asked Questions: Kaloko-Honokōhau National Historical Park Web page, accessed May 19, 2014, at http://www.nps.gov/kaho/ faqs.htm.

National Park Service, 2014b, NPSpecies Search, Information on species in National Parks: National Parks Web page, accessed May 19, 2014, at https://irma.nps.gov/NPSpecies/ Search/SpeciesList/KAHO.

National Oceanic and Atmospheric Administration, 2010, Historic tide data, Kawaihae, Hawaii, Station ID 1617433: National Oceanic and Atmospheric Administration Web page, accessed May 19, 2014, at http://tidesandcurrents. noaa.gov/data menu.shtml?stn $=1617433 \% 20$ Kawaihae,\%20HI\&type $=$ Historic + Tide+Data.

National Oceanic and Atmospheric Administration [2014], NOAA tide predictions - Hawaii: National Oceanic and Atmospheric Administration Web page, accessed May 19, 2014, at http://tidesandcurrents.noaa.gov/tide_predictions. html?gid=353.

Nightingale, P.D., Malin, G, and Liss, P.S., 1995, Production of chloroform and other low-molecular-weight halocarbons by some species of macroalgae: Limnology and Oceanography, v. 40 , p. 680-689.

Oki, D.S., 1999, Geohydrology and numerical simulation of the ground-water flow system of Kona, Island of Hawaii: U.S. Geological Survey Water-Resources Investigations Report 99-4073, 70 p.

Oki, D.S., Tribble, G.W., Souza, W.R., and Bolke, E.L., 1999, Ground-water resources in Kaloko-Honokōhau National Historical Park, Island of Hawaii, and numerical simulation of the effects of ground-water withdrawals: U.S. Geological Survey Water-Resources Investigations Report 99-4070, $49 \mathrm{p}$.

Olson, K., 2010, Annual report for the comprehensive environmental monitoring program covering the period July 1, 2009 through June 30, 2010: Kailua Kona, Hawaii, Natural Energy Laboratory of Hawaii Authority, $40 \mathrm{p}$. and appendixes.

Pearson, J., Wells, D.M., Seller, K.J., Bennett, A., Soares, A., Woodall, J., and Ingrouille, M.J., 2000, Traffic exposure increases natural ${ }^{15} \mathrm{~N}$ and heavy metal concentrations in mosses: New Phytologist, v. 147, p. 317-326.

Plummer, L.N., and Busenberg, E., 1999, Chlorofluorocarbons, chap. 15 of Cook, P., and Herczeg, A.L., eds., Environmental tracers in subsurface hydrology: Boston, Mass., Kluwer Academic Publishers, p. 441-478. 
Presto, M.K., Storlazzi, C.D., Logan, J.B., and Grossman, E.E., 2007, Submarine ground water discharge and fate along the coast of Kaloko-Honokōhau National Historical Park, Hawaii-Part 1, Time-series measurements of currents, waves, salinity and temperature, November 2005-July 2006: U.S. Geological Survey Open-File Report 2007-1310, 39 p.

Quinby-Hunt, M.S., and Turekian, K.K., 1983, Distribution of elements in sea water: Eos, Transactions American Geophysical Union, v. 64, no. 14, p. 130-132.

Redling, K., Elliott, E., Bain, D., and Sherwell, J., 2013, Highway contributions to reactive nitrogen deposition-Tracing the fate of vehicular $\mathrm{NO}_{\mathrm{x}}$ using stable isotopes and plant biomonitors: Biogeochemistry, v. 116, no. 1-3, p. 261-274.

Révész, K., and Casciotti, K., 2007a, Determination of the $\delta(15 \mathrm{~N} / 14 \mathrm{~N})$ of nitrate in water-RSIL Lab Code 2899 of Révész, K., and Coplen, T.B., eds., Methods of the Reston Stable Isotope Laboratory: U.S. Geological Survey Techniques and Methods, book 10, section C, chap. 16, 24 p.

Révész, K., and Casciotti, K., 2007b, Determination of the $\delta\left({ }^{15} \mathrm{~N} /{ }^{14} \mathrm{~N}\right)$ and $\delta\left({ }^{18} \mathrm{O} /{ }^{16} \mathrm{O}\right)$ of nitrate in water-RSIL Lab Code 2900 of Révész, K., and Coplen, T.B., eds., Methods of the Reston Stable Isotope Laboratory: U.S. Geological Survey Techniques and Methods, book 10, section C, chap. 17, 24 p.

Révész, K., and Coplen, T.B., 2008a, Determination of the $\delta\left({ }^{2} \mathrm{H} /{ }^{1} \mathrm{H}\right)$ of water: RSIL lab code 1574 , of Révész, K., and Coplen, T.B., eds., Methods of the Reston Stable Isotope Laboratory: U.S. Geological Survey Techniques and Methods, book 10, section C, chap. 1, 27 p.

Révész, K., and Coplen, T.B., 2008b, Determination of the $\delta\left({ }^{18} \mathrm{O} /{ }^{16} \mathrm{O}\right)$ of water: RSIL lab code 489 , of Révész, K., and Coplen, T.B., eds., Methods of the Reston Stable Isotope Laboratory: U.S. Geological Survey Techniques and Methods, book 10, section C, chap. 2, 28 p.

Richmond, B.M., Gibbs, A.E., and Cochran, S.A., 2008, Geologic resource evaluation of Kaloko-Honokōhau National Historical Park, Hawaii; Geology and coastal landforms: U.S. Geological Survey Open-File Report 2008-1191, 28 p.

Rotzoll, K., 2010, Effects of groundwater withdrawal on borehole flow and salinity measured in deep monitor wells in Hawai ${ }^{i}$ - Implications for groundwater management: U.S. Geological Survey Scientific Investigations Report 2010-5058, 42 p.

Scholl, M.A., Ingebritsen, S.E., Janik, C.J., and Kauahikaua, J.P., 1995, An isotope hydrology study of the Kilauea Volcano area, Hawaii: U.S. Geological Survey Water Resources Investigations Report 95-4213, 44 p.

Scholl, M.A., Gingerich, S.B., and Tribble, G.W., 2002, The influence of microclimates and fog on stable isotope signatures used in interpretation of regional hydrology-East Maui, Hawaii: Journal of Hydrology, v. 264, p. 170-184.
Schwarzenbach, R.P., Gschwend, P.M., and Imboden, D.M., 2002, Environmental organic chemistry (2d ed.): New York, Wiley, 1,328 p.

Sherrod, D.R., Sinton, J.M., Watkins, S.E., and Brunt, K.M., 2007, Geologic map of the State of Hawaii: U.S. Geological Survey Open-File Report 2007-1089, 83 p., 8 plates, scales 1:100,000 and 1:250,000, with GIS database.

Soicher, A.J., and Peterson, F.L., 1997, Terrestrial nutrient and sediment fluxes to the coastal waters of west Maui, Hawaii: Pacific Science, v. 51, no. 3, p. 221-232.

Storlazzi, C.D., and Presto, M.K., 2005, Coastal circulation and water column properties along Kaloko-Honokōhau National Historical Park, Hawaii- Part 1, Measurements of waves, currents, temperature, salinity and turbidity, April-October 2004: U.S. Geological Survey Open-File Report 2005-1161, 30 p.

Stearns, H.T., and Macdonald, G.A., 1946, Geology and ground-water resources of the island of Hawaii: Hawaii Division of Hydrography Bulletin 9, 363 p.

Street, J.H., Knee, K.L., Grossman, E.E., and Paytan, A., 2008, Submarine groundwater discharge and nutrient addition to the coastal zone and coral reefs of leeward Hawaii: Marine Chemistry, v. 109, p. 355-376.

Thomas, D.M., Paillet, F.L., and Conrad, M.E., 1996, Hydrogeology of the Hawaii Scientific Drilling Project borehole KP-1; 2-Groundwater geochemistry and regional flow patterns: Journal of Geophysical Research, v. 101, no. B5, p. 11, 683-11, 694 .

Tillman, F.D., Oki, D.S., Johnson, A.G., 2014, Waterchemistry data collected in and near Kaloko-Honokōhau National Historical Park, Hawai' i, 2012-2014: U.S. Geological Survey Open-File Report 2014-1173, 14 p.

Tom Nance Water Resource Engineering, 2013, Assessment of the potential impact of the proposed Kaloko Makai project on water resources (appendix C), in Second Draft Environmental Impact for Kaloko Makai, Kaloko and Kohanaiki, North Kona, Island of Hawaii: prepared by Wilson Okamoto Corporation and Ho'okuleana LLC, August 2013, v. 2,23 p.

Turner Designs, 2004, Aquafluor handheld fluorometer and turbidimeter; User's manual: Sunnyvale, Calif., 36 p., accessed May 19, 2014, at http://www.turnerdesigns.com/ t2/instruments/aquafluor.html.

Turner Designs, 2007a, Optical brighteners-Application note S-0080: Turner Designs Web page, accessed May 19, 2014, at http://www.turnerdesigns.com/t2/doc/ appnotes/S-0080.pdf.

Turner Designs, 2007b, CDOM instrumentation and optical kit ordering information-Application note S-0022: Turner Designs Web page, accessed May 19, 2014, at http://www. turnerdesigns.com/t2/doc/appnotes/S-0022.pdf. 
U.S. Geological Survey, 2008, DOTABLES Dissolved-oxygen solubility tables - online calculator, version 2.0: U.S. Geological Survey Water Resources Web page, at http://water. usgs.gov/software/DOTABLES/.

U.S. Geological Survey, variously dated, National field manual for the collection of water-quality data: U.S. Geological Survey Techniques of Water-Resources Investigations, book 9, chap. A1-A9, accessed May 19, 2014, at http://water. usgs.gov/owq/FieldManual/.

Van Dyke, P., 2001, Growing makaloa (Cyperus laevigatus L.) in constructed wetlands for weaving and treating wastewater: Final report for U.S. Geological Survey grant No. 99CRGR0003, Bishop Museum, 15 p., accessed May 19, 2014 at http://www.bishopmuseum.org/research/pdfs/ makaloa.pdf.

Vengosh, A., Heumann, K.G., Juraske, S., and Kasher, R., 1994, Boron isotope application for tracing sources of contamination in groundwater: Environmental Science and Technology, v. 28, no. 11, p. 1968-1974.

Visher, F.N., and Mink, J.F., 1964, Ground-water resources in southern Oahu, Hawaii: U.S. Geological Survey WaterSupply Paper 1778, 133 p.

Wagner, R.J., Boulger, R.W., Jr., Oblinger, C.J., and Smith, B.A., 2006, Guidelines and standard procedures for continuous water-quality monitors; Station operation, record computation, and data reporting: U.S. Geological Survey Techniques and Methods book 1, section D, chap. 3, 51 p. plus attachments, accessed May 19, 2014, at http://pubs. usgs.gov/tm/2006/tm1D3/.
Weiss, R.F., 1970, The solubility of nitrogen, oxygen, and argon in water and seawater: Deep Sea Research, v. 17, no. 4 , p. $721-735$

Western Regional Climate Center, 2010a, Kaloko-Honokōhau RAWS remote automated weather station: Western Regional Climate Center Web page, accessed May 19, 2014, at http:// www.wrcc.dri.edu/cgi-bin/rawMAIN.pl?hiHKAL.

Western Regional Climate Center, 2010b, Historical climate data for Honokohau weather station: Western Regional Climate Center Web page, accessed May 19, 2014, at http:// www.wrcc.dri.edu/cgi-bin/cliMAIN.pl?hi1880.

Wheeler, C.W., Archer, S.R., Asner, G.P., and McMurtry, C.R., 2007, Climatic/edaphic controls on soil carbon/nitrogen response to shrub encroachment in desert grassland: Ecological Applications, v. 17, no. 7, p. 1911-1928.

Widory, D., Petelet-Giraud, E., Negrel, P., and Ladouche, B., 2005, Tracking the sources of nitrate in groundwater using coupled nitrogen and boron isotopes-A synthesis: Environmental Science and Technology, v. 39, p. 539-548.

Wolfe, E.W., and Morris, J., 1996, Geologic map of the Island of Hawaii: U.S. Geological Survey Miscellaneous Investigations Series I-2524-A, scale 1:100,000.

Zaugg, S.D., Smith, S.G., Schroeder, M.P., Barber, L.B., and Burkhardt, M.R., 2006, Methods of analysis by the U.S. Geological Survey National Water Quality LaboratoryDetermination of wastewater compounds by polystyrenedivinylbenzene solid-phase extraction and capillary-column gas chromatography/mass spectrometry: U.S. Geological Survey Water-Resources Investigations Report 01-4186, $37 \mathrm{p}$. 
Menlo Park Publishing Service Center, California

Manuscript approved for publication August 15, 2014

Edited by Larry Slack and Kate Jacques

Design and layout by James E. Banton 


\section{$\frac{\mathbb{2}}{\mathrm{C}}$}

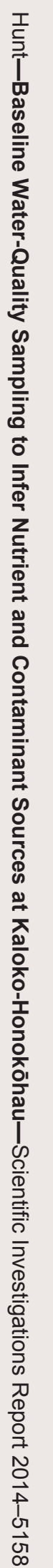

ISSN 2328-0328 (online) 